\title{
Hydropower and Livelihoods in the Mekong Basin: Reservoir Operation for Farming and Fishing Livelihoods, Optimal Livelihood Strategies, and Simultaneous Optimization of Hydropower and Livelihood Goals
}

\author{
A Dissertation \\ Presented to \\ the Faculty of the School of Engineering and Applied Sciences \\ University of Virginia
}

In Partial Fulfillment

of the Requirements for the Degree

Doctor of Philosophy

in

Civil and Environmental Engineering

by

Julia Reis

December 2013 


\section{APPROVAL SHEET}

This dissertation is submitted in partial fulfillment of the requirements for the degree of Doctor of Philosophy in Civil Engineering

\section{Julia Reis}

(Author)

This dissertation has been read and approved by the examining committee:

Teresa B. Culver, Ph.D. (Advisor)

James A. Smith, Ph.D. (Chairman)

Paolo D’Odorico, Ph.D.

Garrick E. Louis, Ph.D.

Joanna C. Curran, Ph.D.

Accepted for the School of Engineering and Applied Science

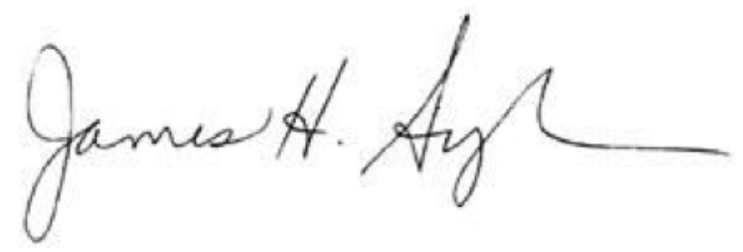

Dean, School of Engineering and Applied Science 


\begin{abstract}
Hydropower construction, with the promise of providing sustainable energy, government revenue, and economic development, is surging throughout many regions of the world, especially in Asia. The hydropower dams, however, damage natural fisheries and submerge fields. As dam construction dislodges rural communities, rural development experts struggle with how to help the displaced make their livelihoods in new lacustrine environments. One question is whether the dam infrastructure can directly benefit those who remain within the vicinity of the reservoir. Integrated water resources management (IWRM), the preeminent management paradigm for multi-objective reservoir management, seeks to consider hydrological, socio-economical, and ecological factors concurrently, yet water managers lack options to include livelihoods in their analyses. Managing land and water resources as an integrated system has become a goal of natural resource management during the past few decades. Despite the interest in integration, the tools for managing water resources and land use remain independent. As a result, water resource engineers and land use planners cannot easily work together on problems that involve multiple systems.
\end{abstract}

This dissertation analyzes reservoir operation and land use in one resettlement community adjacent to a new hydropower dam, located in the center of Lao People's Democratic Republic. The overall objective is to develop tools and plans for coordinating hydropower reservoir operation and management of rural livelihoods. The first study investigates, through simulation, how dam and reservoir management may accommodate fishers and farmers in the resettlement village. The needs identified are for vegetable 
farming on the banks of the reservoir and diversified habitat for fish. The interventions investigated are 1) a lower water level during the cultivation period in order to expose the shoreline gardens and 2) constructed wetlands adjacent and connected to the reservoir to enhance fisheries. The recession agriculture measure lowered the average annual hydropower production by $8.1 \%$, mainly during the months April-June. The constructed wetlands would have no impact on the operation of the hydropower system, and our calculations show that the wetlands are more likely to function as independent ponds separate from the reservoir as opposed to seasonally submerged marshes, potentially serving as a source of livelihoods for fishers.

The second study in this dissertation analyzes farming and fishing livelihoods by developing an optimization model to allocate resources, allowing economically productive and sustainable livelihoods for impacted communities to be identified and analyzed. This model maximizes net gains over five years to identify profitable livelihood strategies, including traditional activities (upland rice, shoreline gardens, extensive livestock, fishing) and a pilot program for irrigated vegetable gardens, given limited labor, land, and capital resources. For our case study, during a wet year when the area for shoreline gardening is restricted, the net gain is reduced only by $1 \%$ for the 5 years optimized. Achieving such a small reduction was accomplished by allocating $2 \%$ more labor to fishing. Other key findings were that diversification of labor would not be practiced in some scenarios given only a short-term outlook; a longer-term perspective is needed to survive the variability of the agricultural and fishing economy. We found that the communities that value food security over income sacrifice a maximum of $9 \%$ in net gain. A pilot program for dry-season vegetables, which may be introduced with an 
irrigation source of small conservation wetlands being constructed upstream, would generate $25 \%$ more net gain. Lastly, we found that sharing resources, enabling lower costs and labor requirements, generates $36 \%$ more net gain.

The third study links reservoir simulation with livelihoods optimization through a penalty-based optimization model. The model uses a gradient-based search tool to find optimal reservoir operation given multiple goals for farm benefits and hydropower. The goals for this study are hydropower generation and access to shoreline gardens to improve the livelihoods of displaced farmers. The optimization minimizes penalties relating to these goals, and the results can be compared to the baseline, considered to be the releases modeled in the baseline case in Chapter 2. When all goals are equally weighted, the optimal reservoir management policy resulted in $31 \%$ lower penalties compared to the baseline, which translates to a $3.2 \%$ increase in average energy generation and a 15\% longer growing season in the reservoir drawdown area. Applying exclusively the agriculture penalty reduced the energy generation by $9.4 \%$. Because of the high cost to reservoir operation, dam plant managers may choose to address livelihood goals in other ways including compensating farmers for their losses. 


\section{Table of Contents}

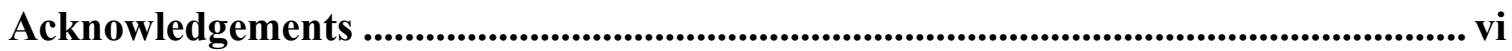

Published Works and Presentations by Julia Reis ........................................................ viii

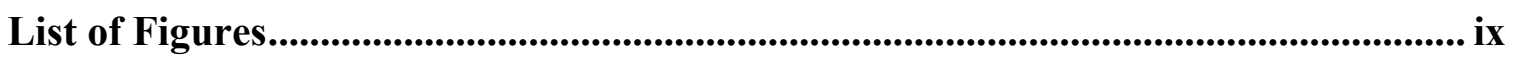

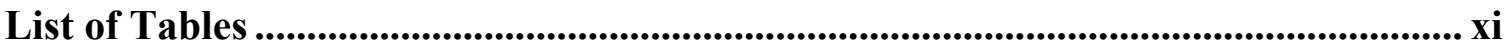

Chapter 1: Introduction ........................................................................................... 1

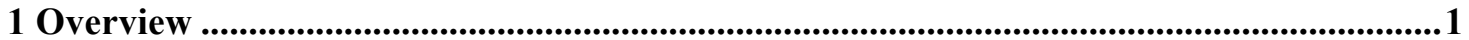

1.1 Water resources case study in the Lower Mekong Basin ..............................................

1.2 Objectives...........................................................................................................................................8

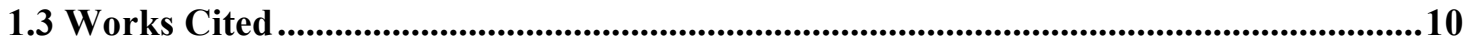

Chapter 2: Reservoir Operation for Farming and Fishing Livelihoods ................... 14

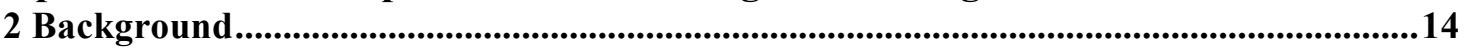

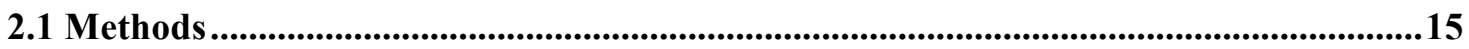

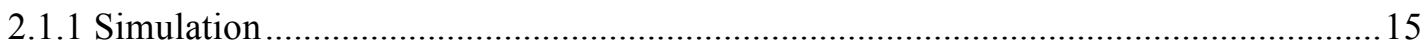

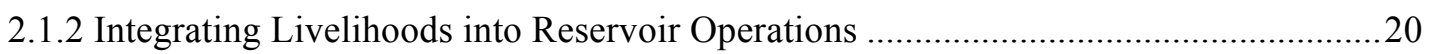

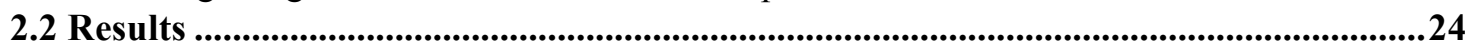

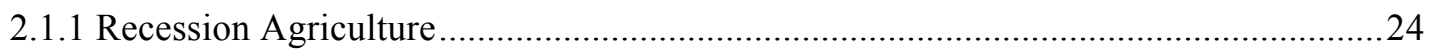

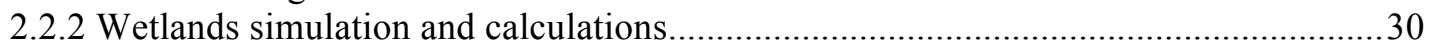

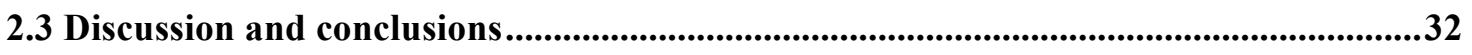

2.4 Works Cited ...........................................................................................................................................34

Chapter 3: Optimizing and evaluating water- and land-based livelihoods ................ 36

3 Introduction ...................................................................................................................................36

3.1 Methods ..............................................................................................................................................38

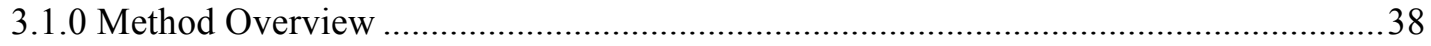

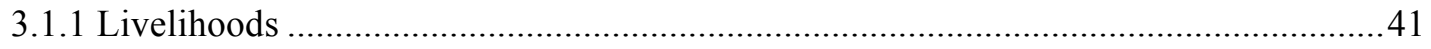

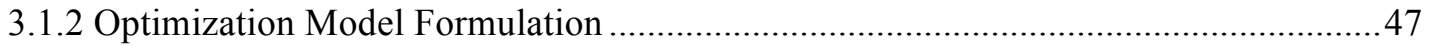

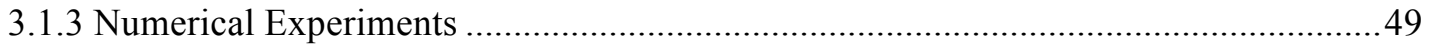

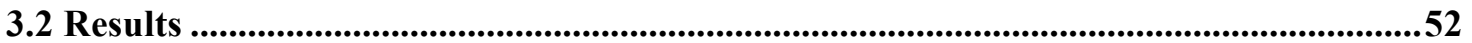

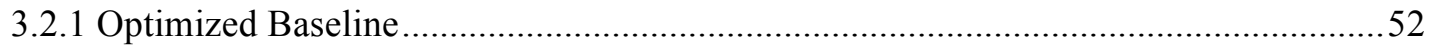

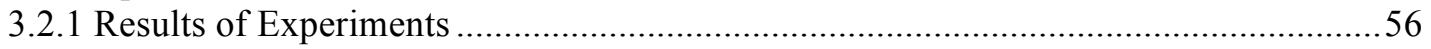

3.3 Conclusions and Discussion................................................................................................60

3.4 Works Cited ...........................................................................................................................................65

Chapter 4: Reservoir optimization for hydropower and shoreline gardening goals 67

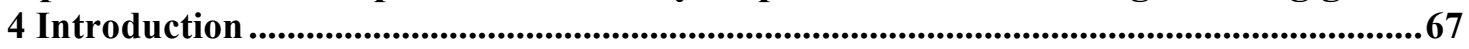

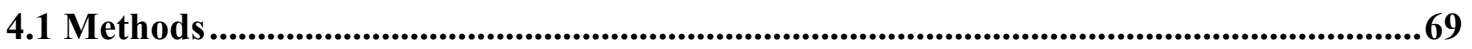

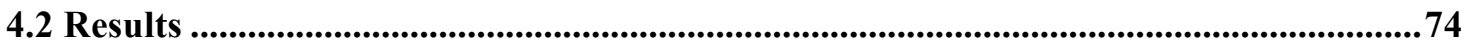

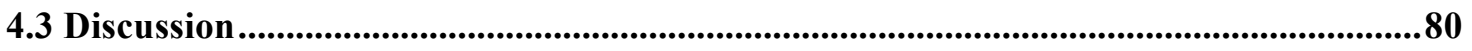




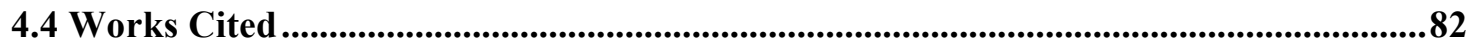

Chapter 5: Conclusions and Discussion .............................................................................. 84

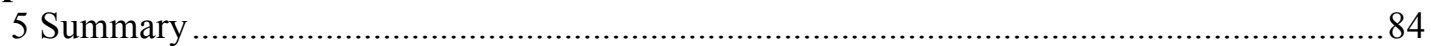

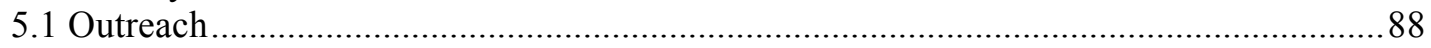

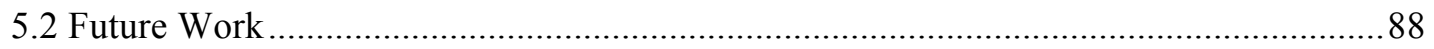

Appendix A: Time series used in Chapter 2 2.................................................................... 90

Appendix B. Survey of livelihoods data in Keosengkham ............................................... 90

Appendix C: Standard labor, revenues, and costs used in Chapter 3 ........................ 92

Appendix D: Report on workshop for farm-livelihoods analysis game in

Keosenkham, Laos ..................................................................................................................... 94

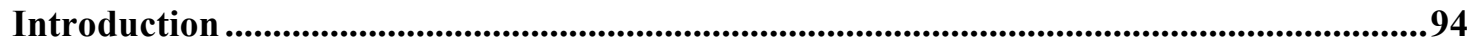

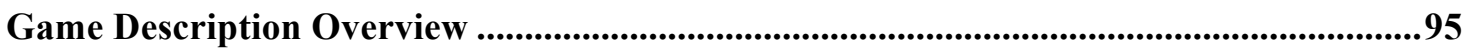

Description of Methods.......................................................................................................................95

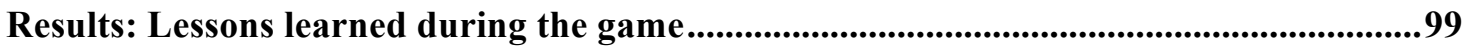

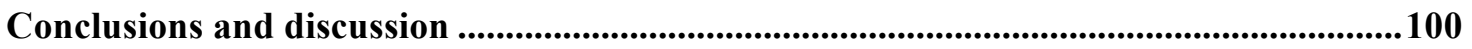

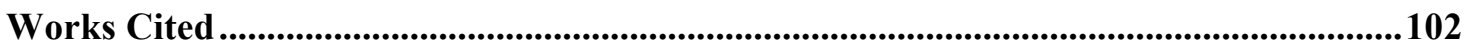




\section{Acknowledgements}

The National Science Foundation provided funds for this research through a Doctoral Dissertation Enhancement Program award. The Explorer's Club Washington Group also provided assistance. I am grateful to the Theun Hinboun Power Company for sharing data and their vision of the dam operation. The Mekong River Commission contributed data for this project. The research in chapters two and three were proposed as part of the Challenge Program for Water and Food Mekong 1 (MK1) project, led by the International Water Management Institute. The MK1 project investigates initiatives to enhance livelihoods in the resettlement communities. Drs. Ed Hall and Katherine Holcomb of the University of Virginia Alliance for Computational Science and Engineering supported this research technically.

Researchers and staff at the International Water Management have been the bedrock of my research while in Lao People's Democratic Republic (PDR). My gratitude goes to Sonali Senaratna Sellamuttu, the project leader for the MK1, Guillaume Lacombe, my local advisor and co-investigator regarding the Nam Gnouang hydrology and reservoir operation, Chu Thai Hoanh, my local advisor for optimizing livelihood strategies, Anousith Keophaxay, Somphasith Douangsavanh, Suan Pheng Kam, Olivier Joffre, Matthew McCartney, Sengkham Xayalath, and many others. I have a huge debt to the residents of Keosenkham, who while settling into their brand-new village and lifestyle, graciously hosted me and answered many questions. The friends I made in Lao PDR over three visits and seven months have shared the warmth of their country.

Most importantly, this research would not have been possible without the support, mentorship, and careful editing from my dissertation advisor Dr. Teresa Culver. I thank 
my committee members, Jim Smith, Joanna Curran, Garrick Louis, and Paolo D'Odorico. I have many friends to thank for incredible support, good cheer, and occasionally, technical help. I am grateful for my fellow graduate students, especially Lydia Abebe and Noah Goodall, my parents Mary Ruth and Richard Reis, my sister Rose Weeks, my fiancé's mother and extraordinary baby whisperer Carylon Pavlacka, and my fiancé Chris Pavlacka. This thesis is dedicated to our daughter Gisele. 


\section{Published Works and Presentations by Julia Reis}

\section{Journal Article:}

Reis, J., Culver, T. B., McCartney, M., Lautze, J., Kibret, S., 2011, Water resources implications of integrating malaria control into the operation of an Ethiopian dam, Water Resources Research, 47.

Reis, J., Culver, T. B., Lacombe, G. and Sellamuttu, S. S., 2013, Reservoir Operation for Farming and Fishing Livelihoods in the Mekong Basin, Article in preparation for submission to the Journal of Water Resources Planning and Management.

\section{Conference Paper:}

McCartney, M., J. Reis, S. Kibret, J. Lautze, and T. Culver, Manipulating dam operation for malaria control: an investigation of the Koka dam, Ethiopia, Hydro 2011 - Practical Solutions for a Sustainable Future, Prague, Czech Republic, October 2011.

\section{Oral Presentations:}

Reis, J., Culver, T. B., McCartney, M., and Block, P., 2013, Exploring the impact and uncertainty of reservoir management with malaria control as climate changes, Oral presentation, World Environmental \& Water Resources Congress, Cincinnati, Ohio, May 19-23, 2013.

Reis, J., Culver, T. B., Lacombe, G. and Sellamuttu, S. S., 2013, Integrating interventions for shoreline farming and fishing into dam operation, Lao PDR, Oral presentations, World Environmental \& Water Resources Congress, Cincinnati, Ohio, May 19-23, 2013.

2009 Climate Change and Health Symposium, Architecture, UVA.

Botchwey, N., Boissevain, J. R., Cunningham, T., Louis, G., Learmonth, G., Firehock, K., Terni, C., Swap, R., Spreen, C. A., Samie, A., Reis, J., Netshandama, V., Dillingham, R., 2009, Water and health in Limpopo Province, South Africa: A community-centered collaborative initiative of the University of Venda and the University of Virginia, Oral presentation at the American Public Health Association.

\section{Poster Presentations:}

Reis, J., Lacombe, G., Hoanh, C. T., McCartney, M., Douangsavanh, S., Metzger, L., Teoh, S. J., Culver, T. B., Kam, S. P., Sellamuttu, S. S., 2011, Adjusting hydropower dam operation to complement livelihood strategies in the Lower Mekong Basin, Poster, The $3^{\text {rd }}$ International Forum on Water and Food, Student Scholarship, Tshwane, South Africa;

Reis, J., T. Culver, G. Lacombe, C.T. Hoanh, A. Keophaxay, S. Douangsavanh, S.J. Teoh, S. P. Kam, and S.S. Sellamuttu, Adjusting hydropower dam operation to complement livelihood strategies in the Lower Mekong Basin, Poster, $4{ }^{\text {th }}$ Mekong Forum on Water Food and Energy, Hanoi, Vietnam, Nov. 19-21, 2013

Reis, J., Culver, T. B., McCartney, M., 2011, Stretching the Reservoir Budget: Managing Malaria with Climate Change and Irrigation Expansion, Poster, World Environmental and Water Resources Congress, Palm Springs, California, May 22-26, 2011. 
Reis, J., Culver, T. B., McCarthy, M., Lautze, J., Kibret, S., 2009, Integrating Public Health Concerns into Reservoir Management: Koka Reservoir, Ethiopia, Poster for Unite for Sight Global Health Conference, Yale University, New Haven, Connecticut.

\section{List of Figures}

Figure 1.1. The Nam Gnouang catchment in Lao PDR, with gauging stations (circles), dams (triangles), and other relevant features. Surrounding LMB countries shown in insert.

Figure 1.2. Timeline of completed dam construction projects and resettlement, creating Keosenkham Village. NG and THXP dams were built concurrently.

Figure 2.1. The median time series of the flow to Nam Gnouang Dam measured and calculated using the flow duration curve method.

Figure 2.2. Simulated water level (m) of NG Reservoir.

Figure 2.3. The median releases, combined flow from Nam Theun (NT) and Nam Gnouang (NG), and water level from the NG Dam for the baseline model.

Figure 2.4. Diagram of crops that could be grown on the shores of the reservoir. The blue line represents the minimum legal water level in the NG Reservoir. The numbers along the y-axis represent the lowest elevation of the gardens at each of the four former villages ( $1=$ Phonkeo, $2=$ Saensi, $3=$ Thambing, $4=$ Sopchat $)$. $\mathrm{P}=$ planting; $\mathrm{H}=$ harvesting.

Figure 2.5. The median elevation of the water level of the NG Reservoir in the Baseline and recession agriculture models $\mathrm{A} 1$ and $\mathrm{A} 2$.

Figure 2.6. The percent exceedence curves for the baseline and measures A1 and A2 for the annual and dry months April-June.

Figure 2.7. The median and lower power production quartile of the hourly baseline meet the weekday demand. The lower quartile garden measure A2 falls short of this goal.

Figure 2.8. The weekend demand (dashed line) is not fully met for $10 \%$ of days. The production is nearly zero for the minimum of days simulated for both baseline and garden scenarios.

Figure 2.9. Large flows out of the NG reservoir are more common with the gardening measure A2.

Fig. 3.1. The resettlement village Keosenkham (starred), the location of the former subvillages, and the land use zones allocated by THPC. 
Fig. 3.2. The cost distance zones identified through spatial analysis (analysis and figures by Kam 2013), superimposed over the land use zones shown in Fig. 3.1. The red zone is closest to the village, and the purple zones are furthest away. Left plot: Case D, accounting for travel by the road (shown in Fig. 3.1) or by the NG Reservoir, as applied for the sub-villages Phonkeo, Saensi, and Thambing. Right plot: Case E, accounting for travel only by the road, as applied for the sub-village Sopchat.

Fig. 3.3. The shoreline gardening areas shown in dark green (Kam 2013).

Fig. 3.4. The labor distribution for the survey data compared to the baseline. The fishing component increased significantly, reflecting the model's use of all available labor.

Fig. 3.7. The average net gain for all sub-villages each year, for each activity, and in total for the baseline.

Fig. 3.6. The average net gain for all sub-villages each year, for each activity, and in total for the Steady Fish Response.

Fig. 3.7. The average net gain for the villages Phonkeo and Sopchat remain higher than that of Sopchat and Thambing, except during year 5 with the decline of fish.

Fig. 3.8. The percent change in the labor distribution from the pilot program of dryseason gardening compared to the model without the pilot, over the 5 years optimized.

Fig. 3.9. The optimized labor distribution for years 1, 2, and 5, including the dry season vegetable pilot in both options, compared to the community-level results. Average annual net gain is shown in USD.

Fig. 4.1. The baseline and PenEq-optimized values for release $\left(\mathrm{Mm}^{3}\right)$ and water level (m) in the Nam Gnouang Reservoir.

Fig. 4.2. The PenEq-optimized and baseline median water level (m) in the Nam Gnouang Reservoir.

Fig. 4.3. The average energy median water level above the minimum operating reservoir level (WL- $420 \mathrm{~m}$ ), and percent garden exposure during the growing season for the baseline, 2xAg and OnlyAg models are shown as a fraction of the baseline metrics. The values of the baseline metrics are shown for reference, as a scale for the axes.

Fig. 4.4. The percent distribution of the water level for the baseline, 2xAg, and OnlyAg.

Fig. 4.5. The percent distribution of the energy for the baseline, 2xEn, and OnlyEn.

Fig. 4.6. Results for all simulations and optimizations in terms of percent garden exposure during the growing season (Apr-Jul) and mean energy generation $\left(\mathrm{GWh} \bullet \mathrm{mo}^{-1}\right)$. The approximate Pareto Optimal Frontier is sketched. 
Fig. 4.7. The percent garden exposure during the growing season for the simulated and optimized OnlyAg models, initializing with the Baseline, A1, and A2 reservoir releases modeled in Chapter 2.

\section{List of Tables}

Table 2.1. Gauging stations and dams (NG, THXP, and NT2) with their catchment areas.

Table 2.3. The pond identity number given by THPC, elevation, max and averaged depth, and percentile not inundated by or separate from the NG Reservoir each year.

Table 2.2. The net inflow $\left(\mathrm{Mm}^{3}\right)$ to Pond 4 for median, dry $(10 \%)$, and wet $(90 \%)$ months.

Table 3.1. The percent distribution of labor $(\gamma)$ for upland rice and shoreline vegetable cultivation. Sub-villages and their population are also shown.

Table 3.2. The available land area (ha) for upland rice for Phonkeo, Saensi, and Thambing (Case D) and Sopchat (Case E). The available land area (ha) for shoreline gardening.

Table 3.3. The coefficients for fishing revenue ( $\left.10^{4} \mathrm{LAK}\right)$.

Table 3.4. The fraction of the fishing revenue assumed over five years.

Table 3.5. The number of fishers with and without (household) commercial licenses in each sub-village.

Table 3.6. The coefficient ratios, $\frac{R_{i}}{L_{i}}$ and $\frac{C_{i}}{L_{i}}$ in Eq. 3.8 and 3.9, for calculating revenue and costs (USD). The cost values, except for upland rice, are slightly higher for Thambing and Sopchat to account for the greater travel costs. The difference is small and does not show up at the scale displayed in this table. The revenue for fishing is given in Eq. 3.3, with the coefficients shown in Table 3.3.

Table 3.7. The values used in equation 3.12.

Table 3.8. The land area (ha) available during the baseline (above $425 \mathrm{~m}$ ), repeated for comparison, and High Water (above $430 \mathrm{~m}$ ), and MaxWL (above $435 \mathrm{~m}$ ).

Table 4.1. Energy produced and corresponding penalties $\left(p_{t e}\right)$ and water level deficit $(D)$ and corresponding penalties $\left(p_{t a}\right)$. Penalties are linearly interpolated for values between those indicated below. 


\section{Chapter 1: Introduction}

\section{Overview}

As of 2010, the World Bank Group had reserved over \$2 billion for future dam construction, having approved 67 hydropower projects since FY2003 (Goodland 2010). Hydropower is increasingly a torrent on the path to economic development throughout low- and middle-income countries (Foster and Briceño-Garmendia 2010; Vaidyanathan 2011; WB-ADB 2006; Ziv et al. 2012). Worldwide, water reservoirs have displaced 4080 million people, causing many of the displaced to lose their livelihoods (Goodland 2010). Fields have been flooded, moving farming plots to areas that are often less fertile and steeper. Newly created lakes have the potential to cause geographical isolation and to flood sacred places, leading to economic and cultural losses that may prompt migration out of traditionally settled areas (Egré and Senécal 1990; Richter et al. 2010). Typically, affected people are not offered benefits from the hydropower development (Cernea 2008; Mokorosi and van der Zaag 2007). As hydropower and storage reservoirs are constructed enthusiastically in Africa and Asia, strategies need to be developed that mitigate losses to local economies without conceding regional or national benefits.

While the resettlement population of any given project may be small, especially in upland areas, agricultural strategies of smallholder farmers should be considered. Small farms are seen as key to improving livelihoods and transforming national economies, because an overwhelming majority, over $85 \%$, of farmers in low- and middle-income countries grow food on fewer than 2 hectares (Bank 2008). For example, in Africa and India, respectively $80 \%$ and $78 \%$ of farms are small, and in Brazil $85 \%$ of farmers occupy just $30 \%$ of cultivated land (Altieri 2008). 
The livelihoods of displaced smallholders, despite their importance in the resettlement process, have largely been ignored in hydropower development projects. Livelihoods have been defined as five interacting sets of capital: natural, financial, physical (e.g. housing structures), human (knowledge and capacity), and social (relationships and leadership) (Campbell et al. 2005). Since the 1970s, social scientists have made policy recommendations to address lost livelihoods. These recommendations include: accounting for or replacing commonly held land in addition to private plots; considering the fertility of newly allocated plots, particularly in the context of swidden, or "slash and burn", which may need larger tracts of land; providing a full title to allocated land; and to plan for simple as opposed to complex schemes for replacing livelihoods (Laissally-Jacob 1996). More recently, engineering solutions, including those that address water resources, are being proposed in addition to social programs to address disruption of livelihoods (Merrey et al. 2005; Molle et al. 2009; Pearse-smith 2012). For example, providing small volumes of water for irrigation can increase the yearly farm yield and in turn the income of small farmers (IWMI and ADB 2004; Lipton 2007; Lipton et al. 2003).

Integrated water resources management (IWRM) gained prominence in the 1990s following the recognition that water resources had been developed for national and international benefit, but on the local level only the costs of these developments are experienced, not the rewards (Molle 2009). Historically, a key attribute of IWRM is its emphasis on ecological non-consumptive uses of water. Contemporary IWRM research aims to include systems that have been neglected in the past, notably including land resources and rural livelihoods into the planning process. This new focus arose because 
water managers, particularly hydropower planners, have neglected the livelihoods of rural people, including fisheries, riverbank agriculture, and cultural preferences (Dooge 2003;

\section{LARS2 2003).}

Although some have argued that livelihoods are the next factor to be integrated with water reservoirs in an IWRM perspective (Merrey et al. 2005), the concept of planning water resources with livelihood goals such as farming and fishing has not been developed into operable measures or decision support systems (DSS). One master's study considered livelihoods in reservoir operation, using dynamic programming to optimize the ideal water level for fish catch and irrigation storage in a reservoir in Vietnam (Tran et al. 2011). No work was found that developed operable reservoir measures for livelihoods, optimized livelihoods that intersect with a water reservoir, or integrated simulation and optimization methods for linking goals for reservoir operation and livelihoods.

\subsection{Water resources case study in the Lower Mekong Basin}

The Mekong River, the longest river in Southeast Asia, and its tributaries support the agriculture, fishing, and forestry livelihoods of the 60 million people who live in the Mekong River Basin; 85\% of the basin residents live at a subsistence level (Bruhl and Waters 2009). According to the Mekong River Commission, overall, it is estimated that approximately 29.6 million people live within $15 \mathrm{~km}$ of the mainstream and within this corridor there are high levels of dependence on water resources for food and income (Hall and Bouapao 2010). Historically, the rivers in the Mekong Basin have been relatively unobstructed, but during the present decade the rivers are being dammed quickly (Grumbine and $\mathrm{Xu}$ 2011). This is happening throughout Southeast Asia, where 
China plans to increase hydropower by $90 \%$ by 2020 (Ran and Lu 2011). The current active storage capacity in reservoirs along the Mekong River is $9.35 \mathrm{~km}^{3}$. The planned storage is over $107 \mathrm{~km}^{3}$ (MRC 2011), capitalizing on 30,000 MW of potential in the Lower Mekong Basin (LMB) (Bird and Phonekeo 2010; Hall and Bouapao 2010), which is contained within Cambodia, Lao People's Democratic Republic (Lao PDR or Laos), Thailand, and Vietnam.

While water storage infrastructure can supply irrigation projects, in hilly or mountainous regions the newly submerged valley terrain may have been the most productive agricultural land. Further, dams disrupt fisheries by turning rivers into lakes and impeding fish migration upstream to spawn and downstream to feed (Dugan 2008; Ziv et al. 2012). Consequently, the national economic benefit of dam development exists in tension with the negative impact on fishing and farming in the Mekong Basin. Further, due to the growth in the hydropower sector in the LMB, especially in Laos, there are an increasing number of resettlement communities whose livelihoods have been disrupted.

The LMB is a major focus of modeling and decision-support analysis because of the hydroelectric potential in the Mekong River and the needs for improved agriculture and fisheries protection. Despite the institutional support for planning in the hydropower sector in the Mekong Basin, people displaced by hydropower have not been offered its observed benefits (Bakker 1999; Matthews 2012). Three-quarters of all livelihoods in the LMB are agricultural (Laborte et al. 2002). In the past 50 years there have been large investments for developing irrigation in the LMB from international donor agencies and national governments, particularly in Thailand (Molle et al., 2009). Despite early large gains in rice yield in some places (as high as $81 \%$ during the 1990s in Cambodia), crops 
fell far short of expectations, partly due to poor management, and waning investment (Molle et al., 2009). As of 2003 and for the preceding 20 years, the ratio of irrigated to arable land in the LMB has been just 26.8\% (compared to $45 \%$ in all of Asia) (Molle et al., 2009). Despite the gains from irrigating rice fields, much of the LMB will remain rain-fed, particularly in the upland regions where hydropower is prevalent.

The case study of this paper is the Nam Gnouang (NG) Dam, located in the Borikhamxay Province of eastern central Laos (Fig. 1.1). Dam operation is at the center of the Lao national strategy for development. This area, like most of Laos, has a tropical wet and dry climate, the Wet-Dry Tropical (AW) type in the Köppen classification (Peel et al. 2007). The monsoon rains are the heaviest between June and November. The Borikhamxay Province is located in the Annamite Mountains, which define the border between Laos and Vietnam, and its eastern alluvial slopes. The sedimentary and metamorphosed sedimentary rocks, especially porous limestone just southeast of the NG Dam, creates a complex regional groundwater hydrology (Norplan 2008). 


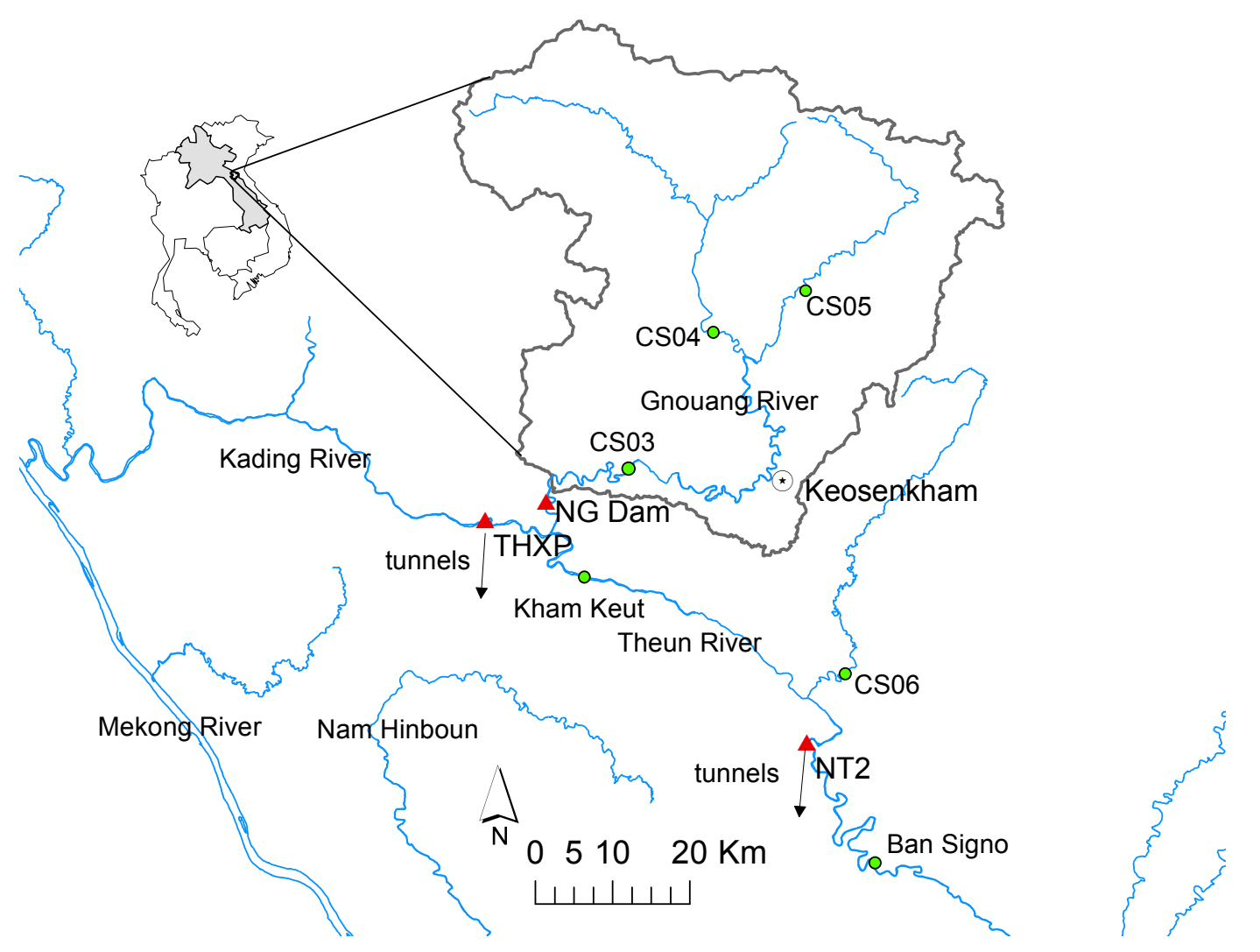

Fig. 1.1. The Nam Gnouang catchment in Lao PDR, with gauging stations (circles), dams (triangles), and other relevant features. Surrounding LMB countries shown in insert.

Figure 1.1 shows the resettlement village Keosenkham, the NG and TheunHinboun Expansion Project (THXP) dams (owned by the Theun Hinboun Power Company (THPC)) and all of the gauging stations and other features described in this paper. A timeline of the project's history is shown in Figure 1.2. The NG reservoir was constructed in part to supply flows lost due to another diversion project, the Nam Theun 2 (NT2) dam, which came online in 2010, whose spillway discharges into the Theun River. The NT2 turbines release through tunnels into the Se Bang Fai River (not shown in Fig. 1.1), which flows directly into the Mekong River. The NG Reservoir doubles the capacity 
of the downstream THXP dam reservoir and tunnel system. The tunnel system below THXP reservoir diverts water from the Theun to the Hinboun River.

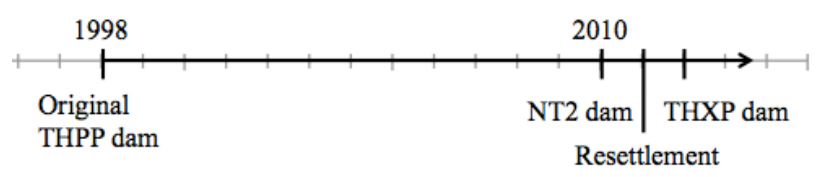

Fig. 1.2. Timeline of completed dam construction projects and resettlement, creating Keosenkham Village. NG and THXP dams were built concurrently.

In 2011, about one thousand people from four villages upstream of the dam were relocated to the Keosenkham village, sited on a ridge of the Nam Gnouang dam that the THPC cleared and outfitted with well water and electricity. The names of the former villages that populated Keosenkham are Phonkeo, Saensi, Thambing, and Sopchat. Rice production was compromised because all rice paddies were along the banks of the river, which have now been flooded, and for many families the land deeded by the THPC for upland rice is smaller, further away, or of lower quality than the upland plots farmers had prior to resettlement. Riverbank gardens located in the original villages are now submerged for part of the growing season. With the loss of rice paddies and insufficient upland rice acreage, vegetable cultivation in riverbank gardens could supplement the losses from rice farming. However, research is needed to determine whether the shoreline gardens can be exposed by the reservoir long enough to allow cultivated vegetables to be harvested. Prior to impoundment, fishing comprised 11-24\% of incomes (average 19\%) in upstream villages (THPC 2011a). In neighboring villages, 30\% of fish were caught in seasonal wetlands (THPC and NORPLAN 2008). Researchers have hypothesized that constructing wetlands along small tributaries into the NG reservoir would provide habitat for birds and fish for conservation, and support fisheries for livelihoods (Meynell 2012). 


\subsection{Objectives}

The objectives of this dissertation research are to develop a methodology for integrating hydropower management and farm-based livelihoods. The dissertation investigates the following research hypotheses:

1) Reservoir operation rules can be modified to incorporate livelihood management into the multi-objective reservoir operations.

a. Riverbank farming and fishing can be supported by dam operation.

b. Alterations to reservoir operation will not compromise hydropower production.

2) The livelihoods optimization model will allocate resources in an economically productive and sustainable way.

3) Linking this livelihoods optimization model to the reservoir simulation through an optimization routine will provide an effective methodology for IWRM.

The first hypothesis of this dissertation is investigated by developing and analyzing reservoir operation measures and modifications that are designed to improve livelihoods. In Chapter 2, a simulation model of the NG Reservoir is described. To allow cultivation of vegetables on the shorelines of the NG Lake, an operation measure draws down the water level below most garden plots during the growing season. The impact of the small wetland ponds is evaluated in terms of reservoir operation, and the morphology of the ponds, under wet and dry hydrologic conditions, is determined based on water mass balances to estimate the wetlands' potential benefit to fisheries and impact on livelihoods.

The second hypothesis of this dissertation is evaluated in Chapter 3 by developing an optimization model for planning farm-based livelihoods in the context of a hydropower reservoir. While others have employed land optimization models in previous 
works, they have not included reservoir-based livelihoods such as fishing, with the yield being highly variable in a newly dammed lake. This chapter optimizes the following farm-based livelihoods: rice farming on upland hills, shoreline vegetable gardening (nonirrigated), small and large livestock husbandry, and fishing. Through the spatially distributed optimization model, labor and land are allocated to households, given constraints of labor, land, capital, and preferences stated by residents of Keosenkham. The net gain from these activities is compared, for the wealthier and poorer parts of the village. Numerical experiments are performed in relation to fish response to the developing reservoir, the goals of food security versus income, and a potential pilot project for vegetable gardens irrigated with water from the wetland ponds. These experiments are developed for household and community levels to demonstrate the potential benefit from sharing resources.

The third hypothesis of this dissertation is investigated by leveraging the reservoir simulation and the livelihoods optimization models to develop an integrated model to optimize water-resource and livelihoods goals. Chapter 4 links the reservoir simulation and the livelihoods analysis by optimizing reservoir operation for goals of hydropower generation and shoreline gardening. The livelihood goal was identified as the main link between reservoir operation and livelihoods, and was supported by the profitability of shoreline gardening, demonstrated in Chapter 3. The model described here optimizes the reservoir releases to find the ideal operating rule curve for the objectives, variously weighted. This model also weighs the economic cost in terms of energy generation of the operation measure for shoreline gardening, and vice versa. 
By focusing on the operation of hydropower reservoir systems, the techniques developed in this study have the potential to be applied to support communities throughout the world that make their livelihoods in conjunction with hydropower reservoirs. While the models described here account for a single case study, the tools and methods could be applied to other communities undergoing resettlement or other changes to livelihoods. In creating integrated tools for reservoir operation and farming, this dissertation demonstrates an innovative method in integrated water resources management.

\subsection{Works Cited}

Altieri, M. A. (2008). Small Farms as a Planetary Ecological Asset: Five Key Reasons Why We Should Support the Revitalisation of Small Farms in the Global South. Penang, Malaysia.

Bakker, K. (1999). "The politics of hydropower: developing the Mekong." Political Geography, 18(2), 209-232.

Bank, T. W. (2008). World Development Report 2008: Agriculture for Development. The World Bank, Washington, D.C.

Bird, J., and Phonekeo, V. (2010). "Hydropower development in the context of integrated water resources management." $1-10$.

Bruhl, H., and Waters, M. (2009). "Transboundary Cooperation in Action for Integrated Water Resources Management and Development in the Lower Mekong Basin." Integrated Water Resources Management in Practices: Better water management for development, R. Lenton and M. Muller, eds., Earthscan Publications.

Campbell, B., Sayer, J. A., Frost, P., Vermeulen, S., Pérez, M. R., Cunningham, A., and Prabhu, R. (2005). "Assessing the performance of natural resource systems." Ecology And Society, 5(2).

Cernea, M. M. (2008). "Compensation and benefit sharing: Why resettlement policies and practices must be reformed." 1(1), 89-120.

Dooge, J. C. I. (Ed.). (2003). "Water and ethics: Preliminary version." Unesco and International Hydrological Programme, UNESCO, Paris. 
Dugan, P. (2008). Examining the Barrier Effect of Mainstream Dams to Fish Migration in the Mekong, with an Integrated Perspective to the Design of Mitigation Measures. Conclusions from an Independent Expert Group Meeting, Vientian, Laos.

Egré, D., and Senécal, P. (1990). "RESETTLEMENT STUDIES AND HUMAN ENVIRONMENT IMPACT ASSESSMENT OF WATER CONTROL PROJECTS: Similarities and Discrepancies." Impact Assessment, 8(3), 5-18.

Foster, V., and Briceño-Garmendia, C. (2010). Africa's Infrastructure: A Time for Transformation. Washington, D.C., 27.

Goodland, R. (2010). "Viewpoint --The World Bank Versus the World Commission on Dams." 3(2), 384-398.

Grumbine, R. E., and Xu, J. (2011). “Mekong Hydropower Development.” Science, 322.

Hall, D., and Bouapao, L. (2010). Social Impact Monitoring and Vulnerability Assessment Social Impact Monitoring and Vulnerability Assessment. Mekong River Commission. Vientiane, Lao PDR, 179.

IWMI, and ADB. (2004). "Pro-Poor Intervention Strategies in Irrigated Agriculture in Asia (IWMI-ADB Project)." International Water Management Institute (IWMI) and Asian Development Bank $(A D B),<$ http://www.iwmi.cgiar.org/propoor/index.asp $>$ (Mar. 7, 2013).

Laborte, A. G., Roetter, R. P., and Hoanh, C. T. (2002). The Land Use Planning and Analysis System of the Systems Research Network in Asia. Brisbane, Australia.

Laissally-Jacob, V. (1996). "Land-Based Strategies in Dam-Related Resettlement Programmes in Africa." Understanding Impoverishment: The Consequences of Development-Induced Poverty, C. McDowell, ed., Berghahn Books, Providence, RI.

LARS2. (2003). LARS 2 Statement- Fisheries issues in large rivers. Cambodia.

Lipton, M. (2007). "Farm water and rural poverty reduction in developing Asia." Irrigation and Drainage, 56(2-3), 127-146.

Lipton, M., Litchfield, J., and Faures, J.-M. (2003). "The effects of irrigation on poverty: a framework for analysis." Water Policy, 5.

Matthews, N. (2012). "Water Grabbing in the Mekong Basin: An Analysis of the Winners and Losers in Thailand's Hydropower Development in Lao PDR." Water Alternatives, 5(2), 392-411.

Merrey, D. J., Drechsel, P., Vries, F. W. T. P. de, and Sally, H. (2005). "Integrating 'livelihoods' into integrated water resources management: taking the integration 
paradigm to its logical next step for developing countries." Regional Environmental Change, 5(4), 197-204.

Meynell, P.-J. (2012). Creating wetlands within reservoirs: Concept note for CPWF $M K 3$.

Mokorosi, P. S., and Zaag, P. van der. (2007). "Can local people also gain from benefit sharing in water resources development? Experiences from dam development in the Orange-Senqu River Basin." Physics and Chemistry of the Earth, Parts $A / B / C$, 32(15-18), 1322-1329.

Molle, F. (2009). "River-basin planning and management: The social life of a concept." Geoforum, 40, 484-494.

Molle, F., Tira, F., and Kokonen, M. (Eds.). (2009). Contested waterscapes in the Mekong Region: Hydropower livelihoods and governance. Earthscan Publications, Washington, D.C.

MRC. (2011). Basin Development Plan Programme, Phase 2. Assessment of basin-wide development scenarios. Main Report. Phnom Penh, Vientiane.

Norplan. (2008). Theun Hinboun Expansion Project: Final EIA/EMMP. Environment.

Pearse-smith, S. W. D. (2012). "The Impact of Continued Mekong Basin Hydropower Development on Local Livelihoods." 7, 62-75.

Peel, M. C., Finlayson, B. L., and McMahon, T. A. (2007). "Updated world map of the Köppen-Geiger climate classification." Hydrology and Earth System Sciences Discussions, Copernicus Publications, 4(2), 1633-1644.

Ran, L., and Lu, X. X. (2011). "Cooperation is key to Asian hydropower." Nature, 473(7348), 452.

Richter, B. D., Postel, S., Revenga, C., Scudder, T., Lehner, B., Churchill, A., and Chow, M. (2010). "The Downstream Human Consequences of Dams." Water Alternatives, $3(2), 14-42$.

THPC. (2011). Social and Environmental Division (SED) Annual Monitoring 2010 Final Report.

THPC, and NORPLAN. (2008). RAP (Resettlement Action Plan).

Tran, L., Schilizzi, S., Chalak, M., and Kingwell, R. (2011). "Managing multiple-use resources : optimizing reservoir water use for irrigation and fisheries." 55th Annual AARES National Conference, Melbourne, Victoria. 
Vaidyanathan, G. (2011). "Dam controversy: Remaking the Mekong.” Nature, 478(7369), 305-7.

WB-ADB. (2006). Future directions for water resources management in the Mekong River Basin. WB/ADB joint working paper on Mekong Water Resources Assistance Strategy. Washington, D.C., 70.

Ziv, G., Baran, E., Nam, S., Rodríguez-Iturbe, I., and Levin, S. A. (2012). "Trading-off fish biodiversity, food security, and hydropower in the Mekong River Basin." Proceedings of the National Academy of Sciences of the United States of America, 109(15), 5609-14. 


\section{Chapter 2: Reservoir Operation for Farming and Fishing}

\section{Livelihoods}

\section{Background}

To overcome skepticism by hydropower managers to novel operation regimes, engineers and planners use simulation to evaluate the water resources implications of different operation policies. There is an art to effective simulation that typically involves multiple iterations, with analysis of each successive result. Multiple factors complicate reservoir simulation. For un-gauged basins, reservoir inflow must be estimated. Evaporation, leakage, and seepage within a reservoir system are rarely understood well and are difficult to measure (Kay and Davies 2008). With so much uncertainty, even carefully assembled data sets and patched time series may suffer large errors. Anomalies point to possible errors, and parameters such as leakage and seepage can be adjusted based on the range of reported estimates to match the modeled data to the historic record of time series such as water releases, energy generated, and reservoir water level. Typically a model can be considered valid when there is reasonable agreement between the historic data and modeled results. When little or no historical operation data exists, the baseline and alternative operation models can be compared to evaluate the alternative measure with respect to goals of water resources management.

Climate change complicates reservoir simulation that is done with the objective of evaluating future reservoir operation, because the probability of future precipitation and flow may vary from the past (Nemec and Schaake 1982; Rani and Moreira 2010; de Wit and Stankiewicz 2006). Climate driven changes in the Southeast Asia are unknown, however, with predictions ranging from small decreases in precipitation to intensified 
monsoon events (Cruz et al. 2007). In the Mekong Basin, Keskinen et al. (2010) argued that hydrological changes due climate change would be small relative to large changes in riverine flows due to hydropower development.

\subsection{Methods}

This work develops a simulation model to predict the water levels and releases from the NG reservoir and the power production at THXP, based on upstream flows and average releases from NT2 for the period from 1986 to 2011. A baseline model and results are developed based on historical reservoir operation rules. Alternative operating rules are also developed to support the livelihoods of riverbank gardening and fisheries. I then compare the results with the alternative rules for livelihood support to the baseline results. A key objective of these simulations is to find the impact of livelihood measures on hydropower production. Whether the impact on hydropower is negative or positive, I will have shown for the first time the implications of how operating a reservoir to augment livelihoods would impact a dam's hydropower generation. Furthermore, I will have demonstrated a methodology for integrating the management of water resources and livelihoods.

\subsubsection{Simulation}

This work developed a reservoir simulation model of the Theun Hinboun Expansion Project (THXP) reservoir system using ResSim (Klipsche and Hurst 2007). Table 2.1 shows the catchment areas of the gauging stations of the Theun and Gnouang Rivers (locations shown in Fig. 1.1 and a list of available time series is shown in Appendix A). River flow gauges in the NG catchment were installed only within the last decade, and the Theun River at Kham Keut was only gauged for 5 nonconsecutive years. 
Since the NG dam construction was completed in 2011, there is no historical flow record demonstrating the hydraulic impact of the NG dam that can be used to calibrate our simulation results.

Table 2.1. Gauging catchment stations (CS) and dams (NG, THXP, and NT2) with their catchment areas.

\begin{tabular}{lccccccccc}
\hline Location & NG & THXP & CS03 & CS04 & CS05 & CS06 & Kham Keut & NT2 & Ban Signo \\
\hline Area $\left(\boldsymbol{k m}^{2}\right)$ & 2830 & 8937 & 2595 & 1300 & 486 & 1190 & 5820 & 4013 & 3370 \\
\hline
\end{tabular}

Given the limitations of existing data, I considered several methods to calculate inflows to NG and THXP dams. I selected a flow duration curve (FDC) method (Hughes and Smakhtin 1996) to preserve the statistical variation in the NG flows. The gauged stream flow at the station Ban Signo, the longest gauged location in the region, was used to calculate the inflows to gauging station CS03 prior to 2001 when the NG catchment was not gauged. Next, I scaled the FDC-calculated and gauged time series of flows at CS03 (1986-2000 and 2001-2011, respectively) to the area of the entire NG catchment (catchment shown in Fig. 1.1). The FDC method was also performed to estimate the flows for the ungauged years at Kham Keut using the gauged streamflow at Ban Signo. Then, the calculated and observed time series at Kham Keut were scaled to the area of the catchment of the Theun River at the confluence with the Gnouang River, with the NT2 catchment area subtracted to account for the subtraction of flows in the Theun River due to the NT2 tunnel diversion (Fig. 2.1). This composite time series was added to the average spillway releases from the NT2 dam (Norplan 2008) to simulate the flow from the Theun River into the THXP. 


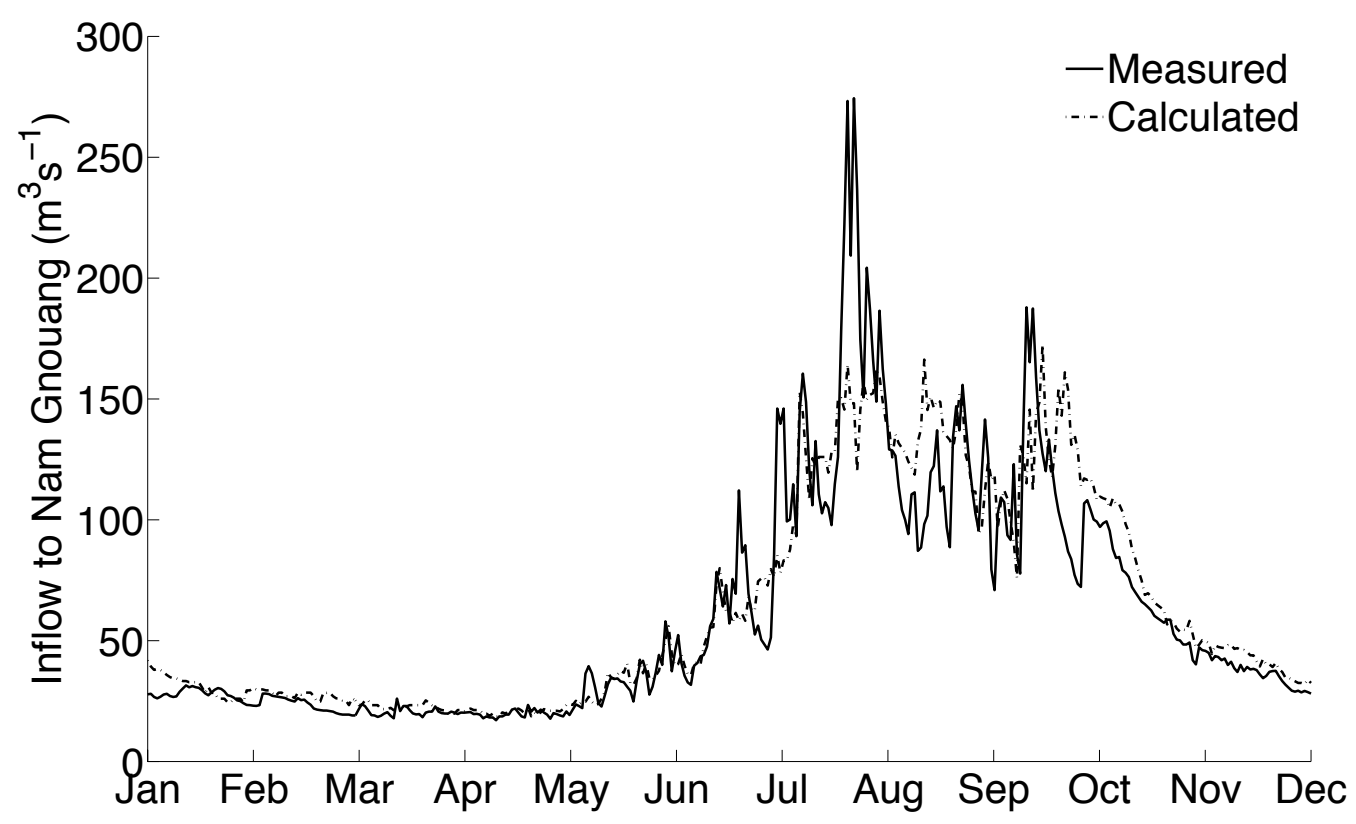

Fig. 2.1. The time series of the median flow to Nam Gnouang Dam over the years measured and calculated using the flow duration curve method.

Reservoir operational rules were developed in ResSim's jython interface (an implementation of Python designed to run in Java). Composed of several logical equations, these rules determined the release rates from the $N G$ reservoir $\left(Q_{N G}\right.$ in $\left.\mathrm{m}^{3} \mathrm{~s}^{-1}\right)$. The baseline rule, which simulates a typical operation scheme for hydropower management at NG reservoir, is defined by equations $2.1-2.3$, as follows:

$$
\begin{aligned}
& Q_{N G 1}=205 \mathrm{~m}^{3} \mathrm{~s}^{-1}-Q_{N T} \\
& Q_{N G 2}=\frac{S_{\max }-S_{\min }}{4 m o \times 30.4 d \times 24 h \times 3600 s}
\end{aligned}
$$

From July to November: $\mathrm{Q}_{\mathrm{NG}}=Q_{N G 1}$

From December to June: $\mathrm{Q}_{\mathrm{NG}}=\min \left(\mathrm{Q}_{\mathrm{NG} 1}, \mathrm{Q}_{\mathrm{NG} 2}\right)$

Equation 2.1 requires the confluence of the Theun (NT) and Gnouang Rivers to receive a specified flow of $205 \mathrm{~m}^{3} \mathrm{~s}^{-1}$ based upon the THPC respective demands for optimal hydropower generation in the THXP tunnels (which occurs at $200 \mathrm{~m}^{3} \mathrm{~s}^{-1}$ ) and a small 
environmental flow into the Kading River $\left(5 \mathrm{~m}^{3} \mathrm{~s}^{-1}\right)$. Equation 2.2 is used to simulate the release of a constant volume over the dry season (Dec-Jun), where $S_{\max }$ is the storage on October $31^{\text {st }}$ and $S_{\min }$ is the minimum storage of $420 \mathrm{~m}$. Equation 2.2 approximates the release profile that the THPC leaders described in meetings (Allen 2012). The release is determined by equation $2.3 \mathrm{a}$ during the wet season and equation $2.3 \mathrm{~b}$ during the dry season.

A further restriction is that the water level in the NG reservoir must be above levels set by the Thai power purchaser. This was simulated in ResSim by specifying no release below these proprietary water levels. The company has stated that the only criterion for dam operation is the hydropower production at the downstream tunnels of the THXP Reservoir, implying that flooding may not be a concern.

A series of figures characterizes the baseline operation of the NG dam and highlights hydrologically key areas for interventions and potential vulnerabilities for changing the operation to support livelihoods. Figure 2.2 shows the baseline elevation (m) of the NG Reservoir from 1986 to 2011 . The water level typically reaches the minimum of $420 \mathrm{~m}$, but reaches the full supply level of $455 \mathrm{~m}$ in just six out of 26 years. Figure 2.3 shows the daily medians for total flow out from the dam $\left(\mathrm{m}^{3} \mathrm{~s}^{-1}\right)$ and water level (m) in the baseline NG simulation. Note that the median outflows are less than the target release of $205 \mathrm{~m}^{3} \mathrm{~s}^{-1}$. As shown, there is a steep drop in the outflow toward the end of April when the elevation in the NG Reservoir approaches $420 \mathrm{~m}$. At $420 \mathrm{~m}$, outfalls simply match inflows as there is no storage to meet the requirements for Eq. 2.1-2.3. During the wet season, there are often no releases from NG dam because the flows from the Theun River are sufficient to meet the downstream power demand and the 
environmental flow release requirement into the Kading River, as the THPC dike stabilizes the tailwater level (Fig. 2.3). During the dry season, the interquartile range of releases is approximately $50 \mathrm{~m}^{3} \mathrm{~s}^{-1}$, while the variation during the wet season is much greater. Since the dam came on line in 2012, baseline simulations cannot be calibrated to historical operation data; nevertheless, the water level and release profiles qualitatively match those described by the dam company (Allen 2012). When the simulated combined flows in the Theun and Gnouang Rivers are insufficient and the storage in the THXP cannot supply the deficit demand, the baseline power production at THXP declines. The annual optimal capacity of $400 \mathrm{MW}$ is met more than half of all days, and $18 \mathrm{MW}$ is exceeded $99 \%$ of the days.

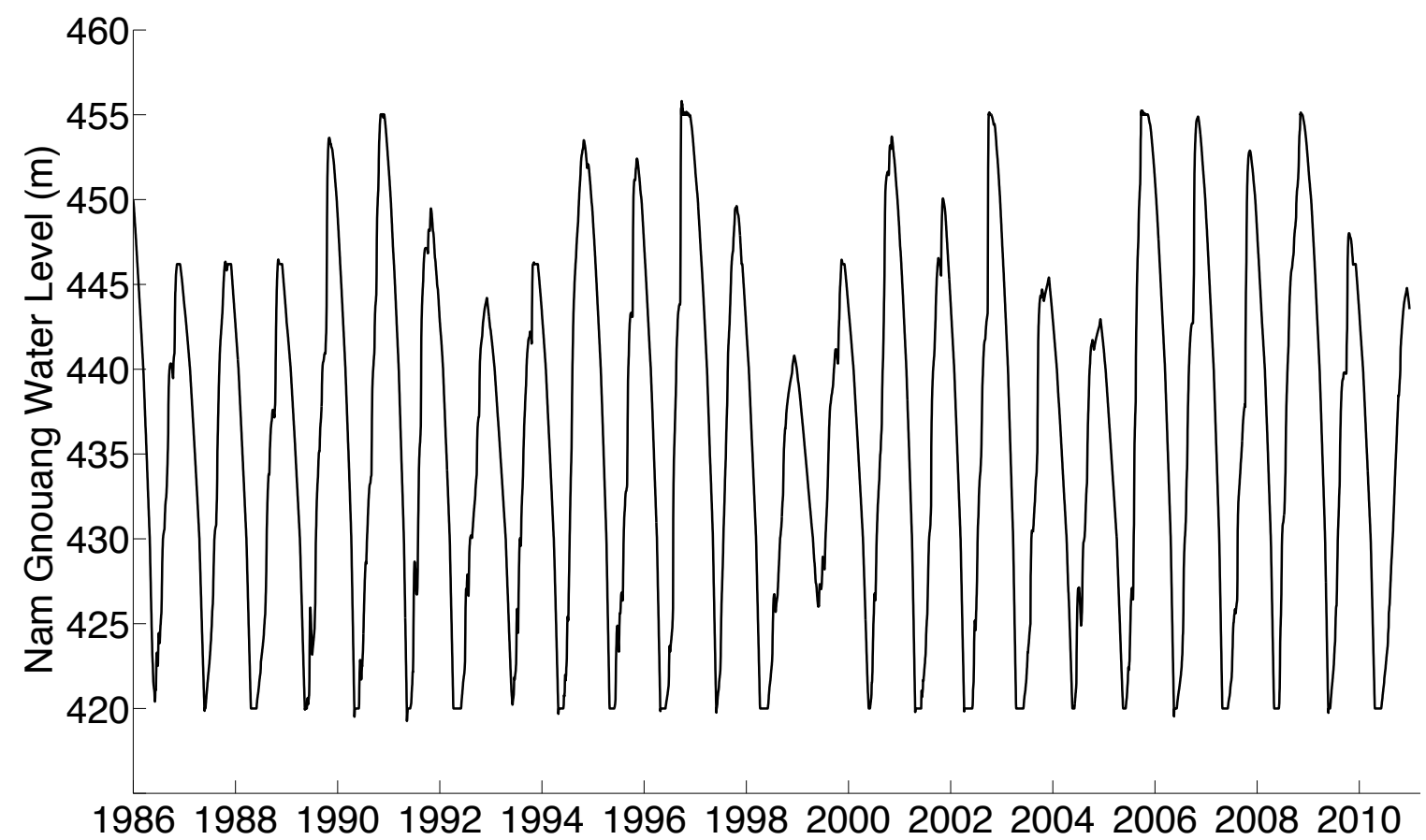

Fig. 2.2. Baseline water level (m) of NG Reservoir over the 26 years simulated. 


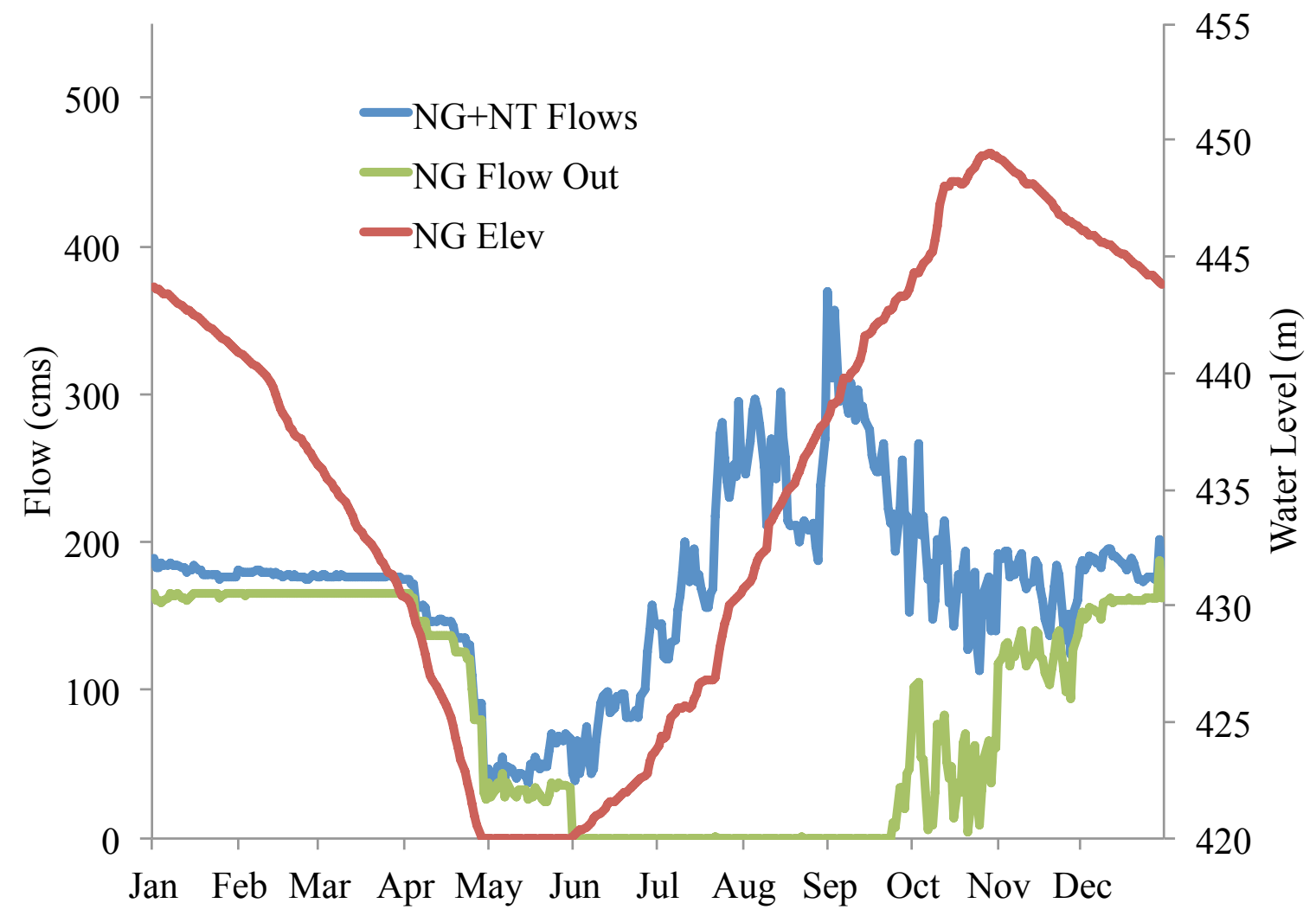

Fig. 2.3. The median releases, combined flow from Nam Theun (NT) and Nam Gnouang (NG), and water level from the NG Dam for the baseline model.

\subsubsection{Integrating Livelihoods into Reservoir Operations}

The reservoir operation and livelihoods parameters interact such that the land and water resources may be managed together. For example, releasing large volumes to produce specific water levels may allow cultivation of profitable vegetables on exposed riverbanks. Although fisheries will be impacted by impoundments and high-magnitude water level fluctuations, the dam operation may support fishing and aquaculture, if, for example, pools are maintained during the dry season. Fisheries are expected to peak in production 1-2 years after impoundment, and decline thereafter due to an excess of trapped nutrients in the lake (Laugen 2011). 
In the recession agriculture model sceario, the reservoir water level will be drawn down to expose riverbank gardens during the growing season. The gardens at the preresettlement villages have been selected because farmers prefer to return there rather than farm in new locations due to concerns about garden fertility (Reis et al. 2012). Not all farmers will be able to return to old gardens due to fuel costs for the boat journey and labor costs. There may be new sites to cultivate closer to Keosenkham, but preliminary field assessments have indicated that most shoreline land near Keosenkham is too steep and that fishermen from outside of the village already camp on the few sites that are potentially suitable for gardening. Further geospatial analysis that is outside the scope of this study may identify other suitable sites for gardening.

In addition to geographical considerations, the timing and duration of the crop seasons must be considered. Riverbank gardens can be cultivated in the dry season (DecMay). Some crops (e.g. chili and long bean) can be harvested past May, into the wet season. The second gardening season begins in April and can last through August (Douangsavanh 2011; Reis et al. 2012). The crop calendars of the vegetables traditionally grown in the area were compared to the typical exposure of riverbank gardens in the preresettlement villages to find the arability of gardens during the crop cycles (Fig. 2.4). The crop calendar was also compared to the minimum monthly elevation of the water level to demonstrate that crops can be grown on the reservoir drawdown area, although in some gardens certain crops (e.g. chili, eggplant) will be constrained by the minimum water level in the reservoir. 


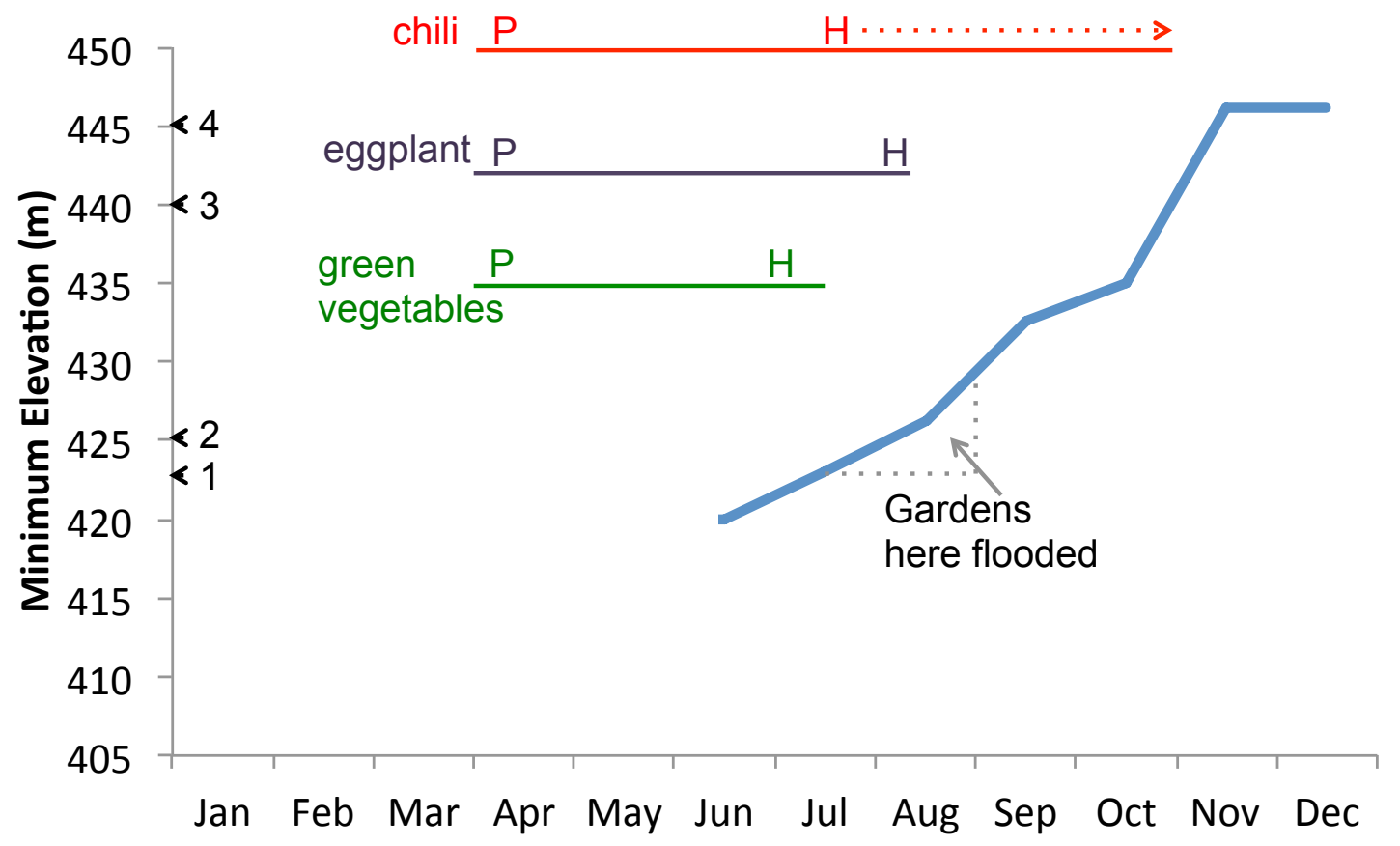

Fig. 2.4. Diagram of crops that could be grown on the shores of the reservoir. The blue line represents the minimum legal water level in the NG Reservoir (starting in June). The numbers along the $y$-axis represent the lowest elevation of the gardens at each of the four former villages $(1=$ Phonkeo, $2=$ Saensi, $3=$ Thambing, $4=$ Sopchat $) . \mathrm{P}=$ planting; $\mathrm{H}=$ harvesting. Timelines of commonly grown crops are shown to demonstrate that crops with a longer growing season, such as chili, would need to be grown at higher elevations than those with a shorter growing season, such as green leafy vegetables.

To integrate recession agriculture into the reservoir operations, several rules were developed and tested. The recession agriculture rule A1 keeps the water level at or below $425 \mathrm{~m}$ during the growing season of April to August. The measure called A2 draws down the water levels to $425 \mathrm{~m}$, from March to August to create a longer growing season. The rules are overridden after July $20^{\text {th }}$, when the water level is required by the Thai power purchaser to be higher than $425 \mathrm{~m}$.

As typical of hydropower plants, the THXP reservoir will be operated on a peaking schedule (Allen 2012). The hourly model accounts for a peaking schedule that would release hydropower during peak electrical use and conserve storage during nights 
and weekends, the hours of lowest electrical usage. The lower releases during nights and weekends allow the water level of the THXP reservoir, which has very little storage (41.8 $\mathrm{Mm}^{3}$ at $400 \mathrm{~m}$ ), to refill during the day.

To evaluate the performance of the measure for shoreline gardens, I compared a daily model with a constant power demand corresponding to the optimal releases from the downstream THXP and an hourly model with a peaking hydropower schedule. I also tested whether using a daily model, with a constant demand that corresponds to the average peaking schedule demand, could approximate the hourly operation. I examined the gardening measures A1 and A2 with respect to the impacts on water level in NG Reservoir and hydropower at the downstream dam THXP, and on the risk of flooding the gardens. I also considered whether the gardening benefits of altered dam operation are concentrated at certain elevations.

Constructed wetlands have been proposed to promote diversified habitat for birds and fish, and to increase fish productivity to allow for sustainable harvesting (Meynell 2012). Adjacent the NG Reservoir, small earth dams may be constructed at five small stream inlets to the reservoir. The locations and size of the wetlands were drafted by the power company based on three criteria i) the inlets have small catchment sizes, and thus small flows, preventing large flows from overtopping of the earthen dam, ii) the earthen dams are located in the official conservation zone or iii) the earthen dams are close to the resettlement communities. The two wetlands planned to be close to Keosenkham may also be used as sources for irrigation of small vegetable gardens.

The type of habitat created can be identified through a water balance model to determine the degree of inundation. For example, year-round submerged areas separate 
from the reservoir would be ponds while seasonally submerged areas might be marshy wetlands. I simulated the wetlands as a single small reservoir to evaluate their impact on downstream flows and to assess how the reservoir operation would impact the wetlands' water balance. I performed calculations to identify how often the water level in the NG reservoir would reach the elevation of the wetlands (potentially allowing fish passage), to calculate the annual and monthly water balances of the wetlands, and to assess the feasibility of water withdrawals from the wetlands for irrigation.

\subsection{Results}

\subsubsection{Recession Agriculture}

The recession agriculture rules A1 and A2 drew down the water level in the NG Reservoir starting in April (A1) or in March (A2) (Fig. 2.5). In the daily model with a constant demand of $205 \mathrm{~m}^{3} \mathrm{~s}^{-1}$, the garden measure A1 and A2 reduced the water level in the NG Reservoir by an average of 0.6 and $1.6 \mathrm{~m}$ and lowered overall hydropower generation by $3 \%$ and $8 \%$, respectively. Figure 2.6 shows the impact of this reduced storage on the power production during the driest months. The recession agriculture measures $\mathrm{A} 1$ and $\mathrm{A} 2$ create reductions in power production across a broad range of power production levels in May. A2 also creates reductions across the spectrum of power production in April. Neither measure has a significant impact on power production during the third driest month of June. There is not a tradeoff between exposure length and risk of flooding, measured by the number of times that the lowest gardens are submerged, so no figure of garden flooding risk is shown. Very little or no water is released from NG Dam during the wet season because of the high flows at Kham Keut. 
The median baseline simulation of the NG Reservoir in Figure 2.5 shows that in all four of the pre-resettlement villages, some of the gardens along the reservoir shoreline will be submerged in at least half of the years. Some years have slightly higher water levels during the dry season in the spring (Fig. 2.5). This would be because the storage on the previous October $31^{\text {st }}$ would have been lower, resulting in lower releases as coded by rule 2. When the water level drops below the minimum legal elevation due to releases made in a single day, no more releases are made until the level rises above the minimum. By the end of August the legal minimum reservoir elevation is $433 \mathrm{~m}$, so even with the recession agriculture measure the lower elevation gardens in the old villages of Phonkeo and Sensi will be flooded. Farmers can plant greens and other vegetables that can be harvested sooner at these lower elevation gardens. Riverbank gardens further upstream (in Thambing and Sopchat) will have a longer exposure period, enabling eggplants and chili to be harvested later in the year. The growing season of some crops, such as chili, are longer than the exposure period of any of the villages' lowest elevation gardens, although these crops could be grown in upland gardens at these sites. 


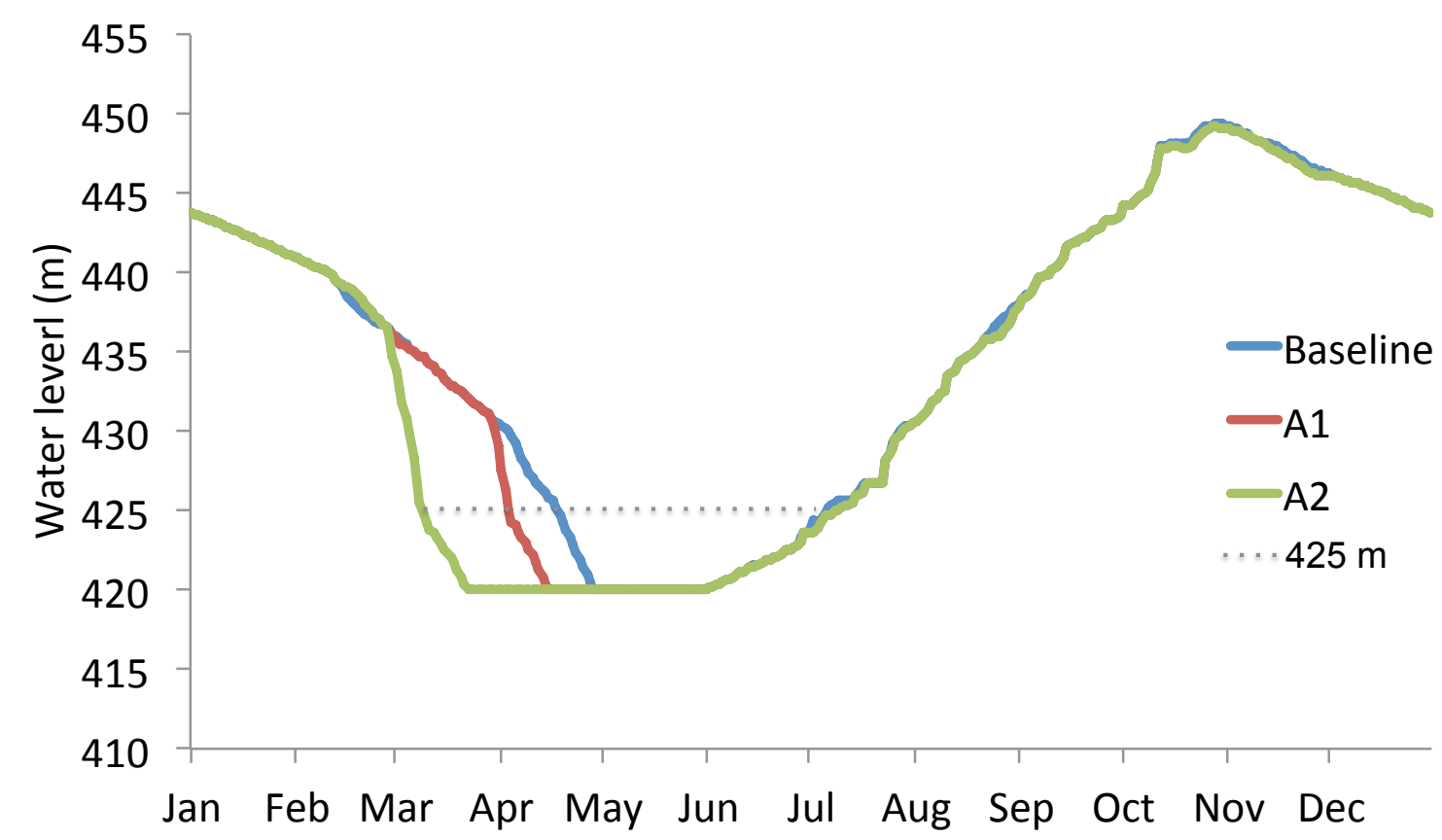

Fig. 2.5. The median elevation of the water level of the NG Reservoir in the Baseline and recession agriculture models $\mathrm{A} 1$ and $\mathrm{A} 2$. 

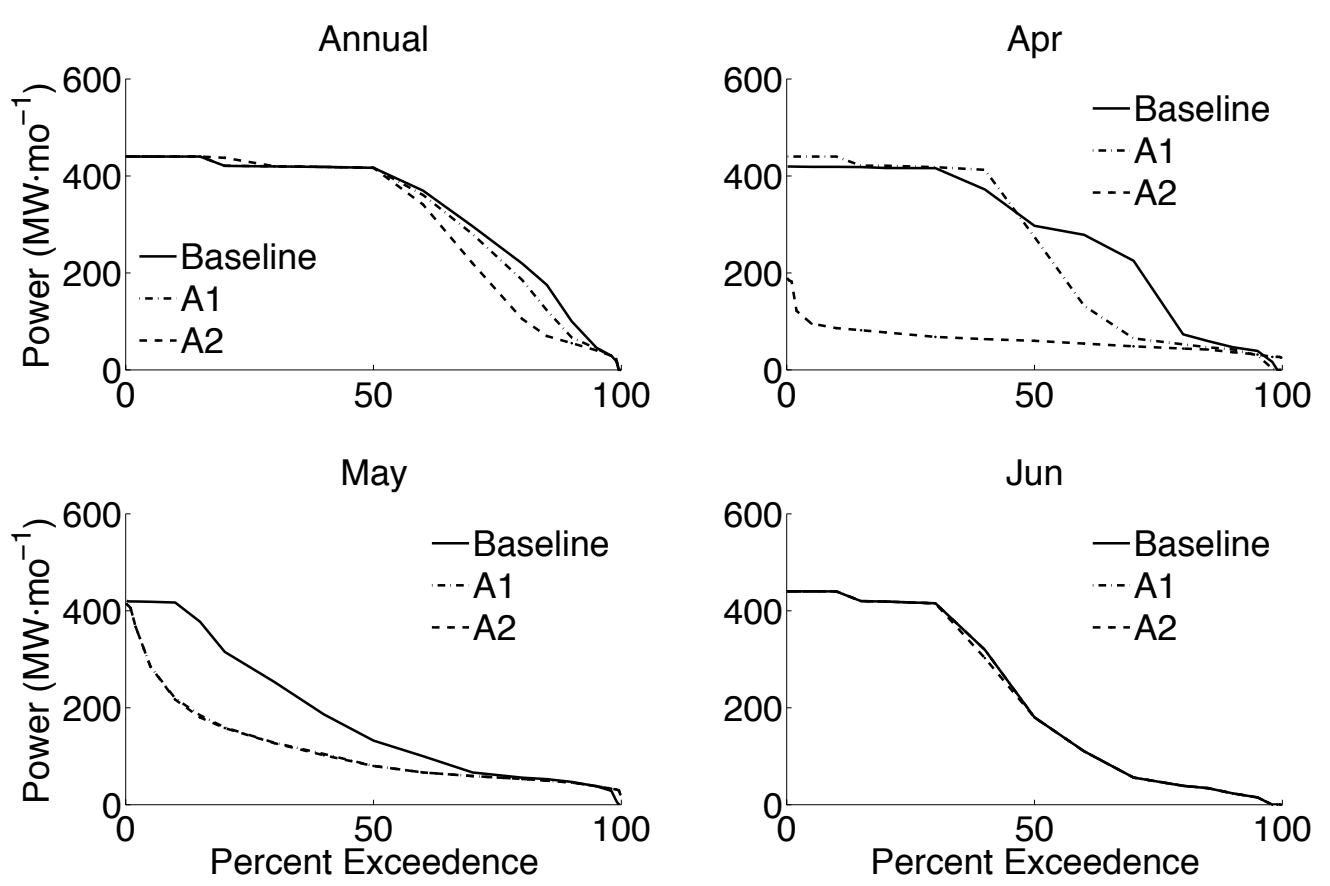

Fig. 2.6. The percent exceedence curves for the baseline and measures A1 and A2 for the annual and dry months April-June.

An hourly model was simulated to identify the hours and days of the week most likely to be impacted by the garden measure. The garden measure A2, starting in March, was used for the hourly model because the daily A2 model had a greater impact on hydropower production than the daily A1 model. In the hourly baseline, the water level is able to stay near the full supply level of the THXP most days in the year. While the hourly baseline can meet the peaking schedule demand 90\% of the hours (Figs. 2.7 and 2.8), the hourly garden measure falls short of the peaking schedule demand more than $25 \%$ of the time. The weekend demand is not fully met for $10 \%$ of days. The production is nearly zero for the minimum of days simulated for both baseline and garden scenarios. The shortages are not very great, however; the total reduction in power for the hourly 
garden measure is just $8.1 \%$, compared to the baseline hourly model. The months of shortage from the hourly demand for the garden measure are April- June.

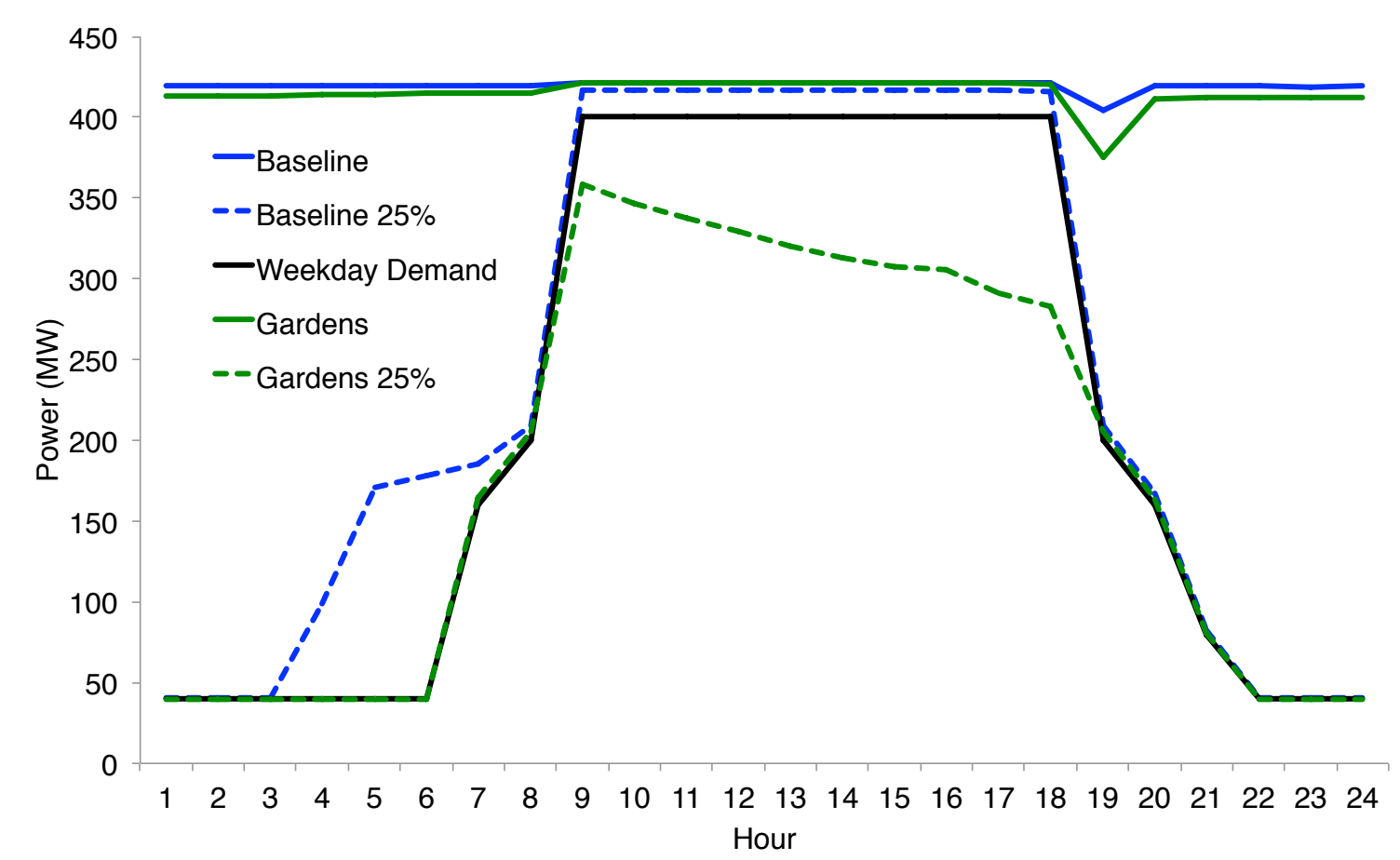

Fig. 2.7. The median and lower power production quartiles of the hourly baseline meet the weekday demand. The lower quartile garden measure A2 falls short of this goal. 


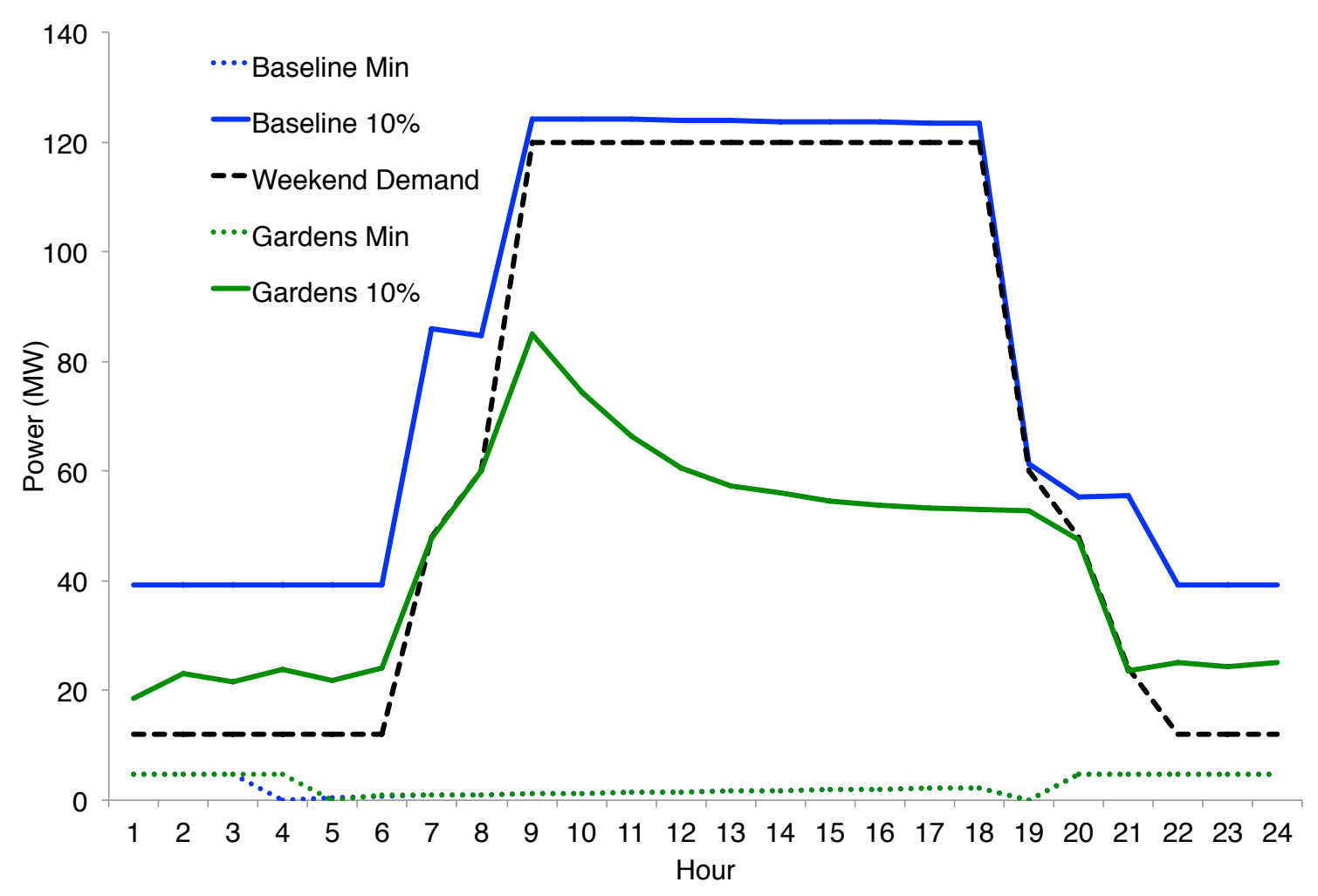

Fig. 2.8. The minimum and $10^{\text {th }}$ percentile power generation (MW) for the baseline and gardens model are shown in reference to the weekend demand (black dashed line).

The daily model that simulates an average daily demand equivalent to the peak demand, $86 \mathrm{~m}^{3} \mathrm{~s}^{-1}$, was evaluated to see whether it could be used as a proxy for the hourly peaking model during the months most impacted by the garden measures. However, the daily model does not show the elevation of the THXP rebounding during off-peak hours, thus diminishing the power generation. As such, the power capacity in the THXP, as predicted by the daily model, appears to be more limited than in the equivalent hourly peaking model described above.

Although flood control was not integrated into the dam operation rules, the simulations show a possibility of flooding downstream of the NG dam. Large outflows occur more frequently when the gardening measures are used (Fig. 2.9). 


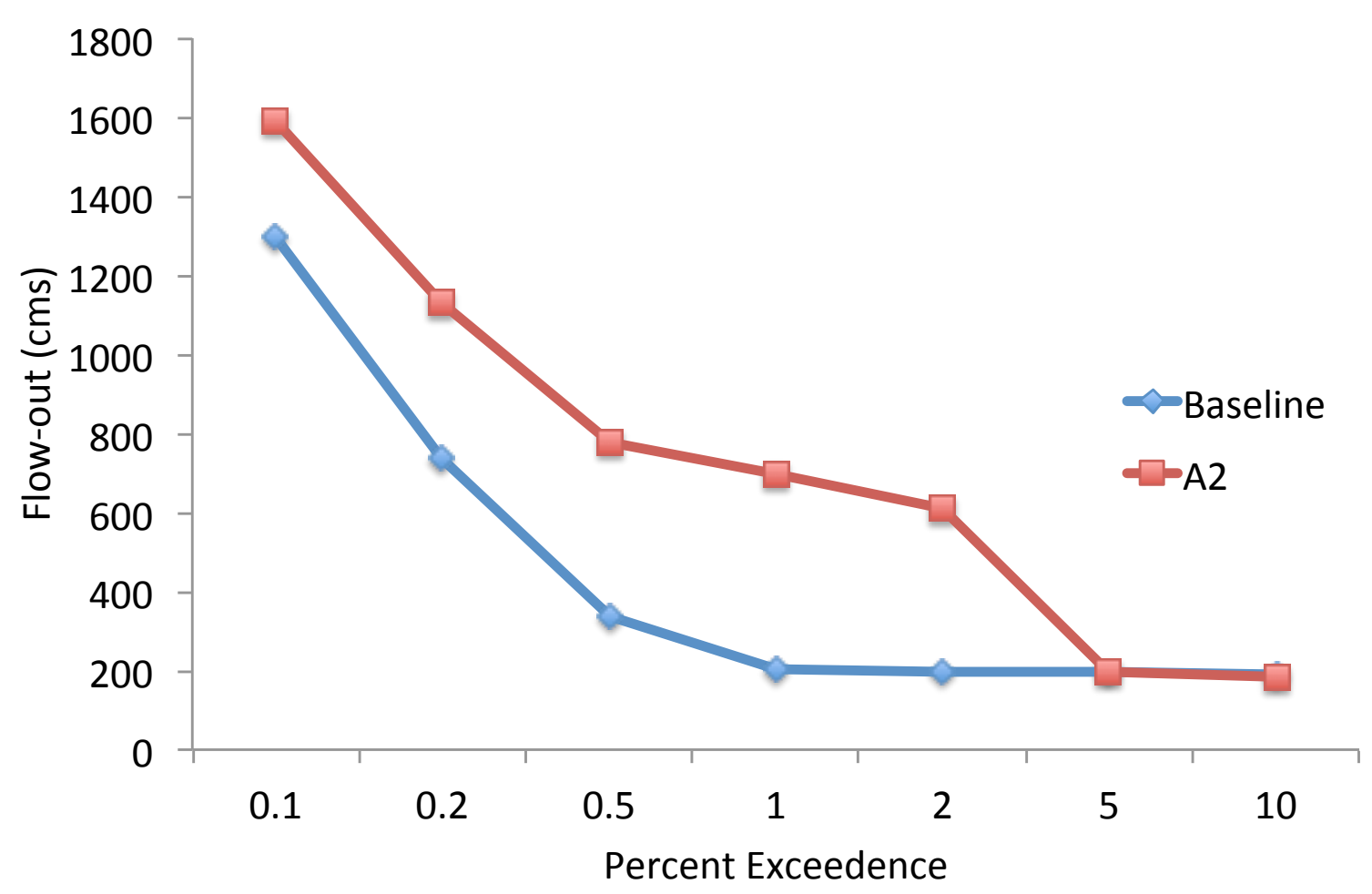

Fig. 2.9. Flows out of the NG Reservoir outlets for the baseline and $A 2$ model.

\subsubsection{Wetlands simulation and calculations}

The ponds or marsh wetlands were simulated as a single reservoir immediately upstream of the NG reservoir. The wetlands are very shallow compared to the NG reservoir. The ratios of the wetlands' sum storage and area to the NG reservoir's are respectively $0.001 \%$ and $0.03 \%$. The cumulative catchment area of the wetlands is just $0.6 \%$ of the total NG catchment area. Thus the inflows to the wetlands and NG Reservoir were simulated as respectively $0.6 \%$ and $99.4 \%$ of the total inflow. The simulations were performed on a daily rather than an hourly time step to speed the modeling run time. The constructed wetlands do not generate any significant differences between the simulated water level, outflows, or power production in the NG and THXP reservoirs. 
A series of calculations were performed to evaluate the potential of the constructed wetlands for fishing. As in the NG model, infiltration or groundwater exchange was not accounted for due to lack of information, and instead it was assumed that the net groundwater exchange may be negative or positive. Each year, annual precipitation is higher than annual evaporation, implying that the rainfall refills the storage lost due to evaporation. The inflow values from the river are much larger than the precipitation or the potential evapotranspiration values. The mass balance of water volumes, shown in Table 2.2, was calculated with the $10^{\text {th }}$ percentile (dry), median, and $90^{\text {th }}$ percentile (wet) inflows for each month. The average monthly excess water could be considered the amount available for withdrawal for irrigation or watering livestock, in locations that could support livestock.

Table 2.2. The net inflow $\left(\mathrm{Mm}^{3}\right)$ to Pond 4 for median, dry (10\%), and wet $(90 \%)$ months.

\begin{tabular}{rrrrrrrrrrrrr}
\hline & Jan & Feb & Mar & Apr & May & Jun & Jul & Aug & Sep & Oct & Nov & Dec \\
\hline Median & 1.6 & 1.3 & 1.2 & 1.0 & 1.5 & 2.9 & 5.4 & 8.9 & 7.8 & 8.9 & 3.3 & 2.0 \\
Dry & 1.1 & 0.8 & 0.8 & 0.7 & 0.9 & 1.5 & 3.6 & 4.8 & 4.7 & 3.7 & 2.1 & 1.5 \\
Wet & 2.3 & 1.6 & 1.5 & 1.3 & 2.2 & 5.1 & 8.2 & 12.3 & 18.4 & 18.9 & 7.3 & 2.7 \\
\hline
\end{tabular}

Because the net monthly inflow values are always positive, the regions will stay inundated throughout the year. Hence the wetlands will be a pond in the deeper areas where vegetation is completely submerged, so that eventually only aquatic vegetation will survive, and a marshy wetland on the perimeter where the water is shallow. Although the ponds will stay full throughout the year, another question is whether they would be contiguous with the NG reservoir or whether they would be separate small ponds. Table 2.3 shows the full supply level of each wetland (Elevation), the maximum and average depths, and the percentage of years that each wetland would remain separate from the NG 
Reservoir for the entire year. The averaged depth is the storage divided by the area. The wetlands would be separate ponds throughout some years, potentially allowing the ponds to serve as controlled fisheries for the community (Table 2.3).

Table 2.3. The pond identity number given by THPC, elevation, max and averaged depth, and the percentage of years that the pond remains separate from the NG Reservoir for the entire year.

\begin{tabular}{ccccc}
\hline Number & Elevation (m) & Max Depth (m) & $\begin{array}{c}\text { Avg. Depth } \\
(\mathrm{m})\end{array}$ & $\begin{array}{c}\text { Annual } \\
\text { Separation } \\
\text { Percentage }\end{array}$ \\
\hline 1 & 443 & 1.5 & 0.57 & 7.5 \\
2 & 447 & 1.5 & 0.63 & 31.4 \\
3 & 443.5 & 1.5 & 0.93 & 9 \\
4 & 447 & 1.3 & 0.69 & 31.4 \\
5 & 450.5 & 0.8 & 0.76 & 43.5 \\
\hline
\end{tabular}

\subsection{Discussion and conclusions}

I set out to find the water resources implications of altering the operation of the NG hydropower dam located in central Lao PDR in order to accommodate shoreline gardening and fishing. I found that the gardening operation measures did reduce hydropower production, although in the hourly peaking model the reduction in productivity was limited and did not meet the demand $25 \%$ of the time. The steep geometry of the NG basin limits the potential for recession agriculture, as a small drop in water level correlates to a large decrease in storage and lost hydropower generation. The price of electricity may help decision makers evaluate the true cost of the loss in hydropower. If prices increase as the dry season progresses, then hydroelectric losses due to the gardening scenario may increase the economic losses, or conversely if the electricity price is lower during this time, the hydropower losses may be acceptable.

I considered whether certain elevations were more important than others for riverbank gardening, so that the gardening operation rule could specify this threshold as a 
target, but did not find such critical elevations associated with large areas of land. Rather, the elevation and area of the reservoir increase uniformly.

One potential concern with the gardening operation measure is that large releases are made to quickly draw down the water level to expose the gardens. While there was no maximum release control criteria specified by the power company, the gardening measure releases that are routinely in excess of $200 \mathrm{~m}^{3} \mathrm{~s}^{-1}$ could possibly cause flooding. Because the large flows will occur more frequently, researchers should determine what flow rate would exceed the channel capacity and cause flooding. Limiting the maximum outflow could prevent damage downstream, which would conserve storage and would likely have an additional benefit of generating more hydropower.

For our goal to promote fish for livelihoods, I followed the assumption of the power company and other researchers that wetlands will enhance fisheries. The neighboring Nam Theun 2 Power Company has already constructed 30 wetlands in the vicinity of their reservoir (Meynell 2012). Currently little is known about the NG fisheries, however, and characteristics of fish populations are very difficult to predict following an impoundment in new lacustrine environments (Warren 2011).

The water level in the wetland ponds oscillated widely on a daily basis in simulations because the wetlands were too small to simulate effectively. Still, as expected, the addition of the ponds had no impact on the downstream dam operation. The calculations provide clues that these inundated areas may be marshes for the lower elevation wetlands (no. 1 and 3) and discontinuous ponds at the higher elevations (nos. 2, 4, 5). Further, the ponds closest to the community, nos. 4 and 5, would thus be filled year-round, serving as a support for the livelihoods of fisherman in Keosenkham. 
One area of potential synergy is the possibility to manage the wetlands and the gardens together, so that the gardens could be planted next to the wetland ponds either on the shorelines or just above by using a simple irrigation system. This would allow dry season cultivation and provide an additional benefit from the wetlands of enhanced food security (McCartney et al. 2010). The water from the ponds may also be useful as a source of water for livestock, depending on the location of the animals and availability of the water. My analysis has shown there is an excess of water without needing to reduce the level of water in the wetlands. When the elevation of NG exceeds that of the wetlands, withdrawals from the wetlands increase water flow into the wetlands, allowing for increased water withdrawals. Further ground reconnaissance and GIS analysis can be undertaken to locate and evaluate potentially suitable garden space adjacent to the ponds.

\subsection{Works Cited}

Allen, R. (2012). "Personal Communication." Company Manager, Vientiane, Lao PDR.

Cruz, R.V., H. Harasawa, M. Lal, S. Wu, Y. Anokhin, B. Punsalmaa, Y. Honda, M. Jafari, C. L. and N. H. N. (2007). "Asia." Climate Change 2007: Impacts, Adaptation and Vulnerability. Contribution of Working Group II to the Fourth Assessment Report of the Intergovernmental Panel on Climate Change, P. J. van der L. and C. E. H. M.L. Parry, O.F. Canziani, J.P. Palutikof, ed., Cambridge University Press, Cambridge, UK, 469-506.

Douangsavanh, S. (2011). "Calendar of Crop Plantation.” (DOA), Department of Agriculture (MAF), Ministry of Agriculture and Forestry, Lao PDR.

Hughes, D. A., and Smakhtin, V. (1996). "Daily flow time series patching or extension: a spatial interpolation approach based on flow duration curves." Hydrological Sciences Journal, 41(6), 851-871.

Kay, A. L., and Davies, H. N. (2008). "Calculating potential evaporation from climate model data: A source of uncertainty for hydrological climate change impacts." Journal of Hydrology, 358(3-4), 221-239. 
Keskinen, M., Chinvanno, S., Kummu, M., Nuorteva, P., Snidvongs, A., Varis, O., and Västilä, K. (2010). "Climate change and water resources in the Lower Mekong River Basin: putting adaptation into the context." Journal of Water and Climate Change, 1(2), 103.

Klipsche, J. D., and Hurst, M. B. (2007). HEC-ResSim: Reservoir System Simulation User's Manual, v.3.0, CPD 82. HEC. Davis.

Laugen, J. J. (2011). “Fisheries Management Plan Draft Final_17.” THPC. Vientiane, Lao PDR.

McCartney, M., Rebelo, L.-M., Sellamuttu, S. S., and Silva, S. de. (2010). Wetlands, Agriculture and Poverty Reduction (IWMI Research Report 137). IWMI. Colombo, Sri Lanka, 39.

Meynell, P.-J. (2012). Creating wetlands within reservoirs: Concept note for CPWF $M K 3$. Challenge Program on Water and Food (CPWF). Vientiane, Lao PDR.

Nemec, J., and Schaake, J. (1982). "Sensitivity of water resource systems to climate variation.” Hydrological Sciences Journal, 27(3), 327-343.

Norplan. (2008). Theun Hinboun Expansion Project: Final EIA/EMMP. Environment, THPC, Vientiane, Lao PDR.

Rani, D., and Moreira, M. M. (2010). "Simulation-Optimization Modeling: A Survey and Potential Application in Reservoir Systems Operation.” Water Resources Management, 24(6), 1107-1138.

Reis, J., Hoanh, C. T., Kam, S. P., Keophoxay, A., and Douangsavanh, S. (2012).

"Personal Interview." Keosenkham Resettlement Village.

Warren, T. (2011). “Personal Interview.” Vientiane, Lao PDR.

Wit, M. de, and Stankiewicz, J. (2006). "Changes in Surface Water Supply Across Africa with Predicted Climate Change." Science, 311, 1917-1921. 


\section{Chapter 3: Optimizing and evaluating water- and land-based}

\section{livelihoods}

\section{Introduction}

When deciding among multiple livelihood options, land-use planners often use computational models. Computer-based models can support qualitative decisions, as they can be used to integrate more information, predict long-term effects, and explore alternative scenarios (Van Paassen et al. 2007). Land-use policy-makers and modelers have sought more integration with other natural resources models, such as those accounting for water, economics, and social systems (van Ittersum et al. 2004). When designing a model for multiple systems, the many advantages of computationally powerful and integrative models, however, can lead to unwanted complexity. Thus, the sophistication of the models must be weighed against the value of simplicity. The most useful and effective models are easy to learn and compute quickly. Efficient models are particularly important for developing countries where institutions may be limited in the energy and human resources they can devote to managing their natural resources. Further, when multiple agencies are involved in using a model, the costs of using the software, including time spent learning the model, training costs, and purchasing software licenses, can multiply.

This research builds on multiple projects that are known as the Land Use Planning Analysis System (LUPAS). Each researcher using the LUPAS framework has created an independent model for a particular case study, including sites in India, Malaysia, the 
Philippines, and Vietnam. For example, Mandac and Luat (1998) created a LUPAS model to evaluate farm systems and technologies in an effort to intensify agricultural production in Vietnam to levels of China. Based on their evaluation with LUPAS, they recommended crop-fish-fruit tree farming systems. Van Passan et al. (2007) emphasized the use of their LUPAS model as a technology to model sustainable land uses in order to answer the questions of stakeholders. Their model demonstrated meeting multiple objectives, in a transparent way, to foster trust among stakeholders. The problems it addressed were food security, nature conservation, and social objectives, such as equity. As a tool in the decision-making process, LUPAS can show policymakers and stakeholders how each option under consideration may perform.

The objective of this project is to evaluate relevant land and water use options for livelihoods, including possible pilot projects. While other studies have focused mainly on allocation of land area to land use types, this project optimizes the labor allocations (which are constrained by land uses and reservoir operation) for livelihoods in a reservoir resettlement community; this is an innovative application of the LUPAS model framework. The case study is set in Laos, which has a low population density (26.7 inhabitants per $\mathrm{km}^{2}$ ) compared with other surrounding countries (Cambodia: 81.8, Thailand: 132.1, Vietnam: 272.0, respectively). Laos is sparsely populated in part because of its hilly and mountainous topography, which may contribute to its low mechanization level in farming. The case study considers Keosenkham, a resettlement village for communities displaced by the Theun Hinboun Expansion Project (THXP), a hydropower dam and reservoir. One thousand farmers and fishers live in Keosenkham village. In addition to labor allocations, the optimization model evaluates the use of 
shoreline gardens, also known as recession agriculture, which are dependent on the water level in the reservoir. Sub-objectives are to determine income strategies over time, based on projected changes in natural resources, to compare food security versus income goals, and to evaluate the rewards from a pilot program for irrigated gardens. The optimizations are performed at the household level and at the community level, in which households collaboratively share labor and resources. The hypothesis is that the livelihoods optimization model will allocate resources in an economically productive and sustainable way that may allow the resettlement community to succeed and improve their livelihoods when living near the new hydropower reservoir.

\subsection{Methods}

\subsubsection{Method Overview}

This model optimizes the ratio of land- and water-based livelihoods practiced in the resettlement Keosenkham village in central Laos (Fig. 1.1). Keosenkham, created during the construction of the Nam Gnouang (NG) Reservoir, is comprised of the four sub-villages: Phonkeo, Saensi, Sopchat, and Thambing (Fig. 3.1). Among other constraints, land-use zones limit the land area that can be used for upland crops. The THPC created land use zones to allow exclusive rights of use to residents of Keosenkham, prevent new areas from being deforested, and protect and limit access to the reservoir. The model is used to evaluate a pilot study, raising dry-season vegetables, that has been proposed by IWMI. The garden plots would potentially draw water for irrigation from constructed wetlands, which simulation has shown to supply small amounts of water for irrigation even during dry years (Chapter 2). This model considers only land- and water- based activities and excludes non-agricultural or non-fishery 
livelihood activities such as logging, weaving, or other outside work. Although such wage-based livelihoods are practiced, these options are not included because the scope of this project is to optimize rural livelihoods that intersect with the NG reservoir and its operation - the intersection being either through fishing, farming along its shorelines, or farming new plots in lieu of those submerged. In short, the scope of this study is to consider the best use of the limited upland and shoreline gardens allocated to the residents of Keosenkham. The livelihood model described here is conceptually similar to prior LUPAS models but was developed independently. No LUPAS model has ever been used in the context of a hydropower system, nor has one ever allocated resources for fisheries or riverbank gardens. 


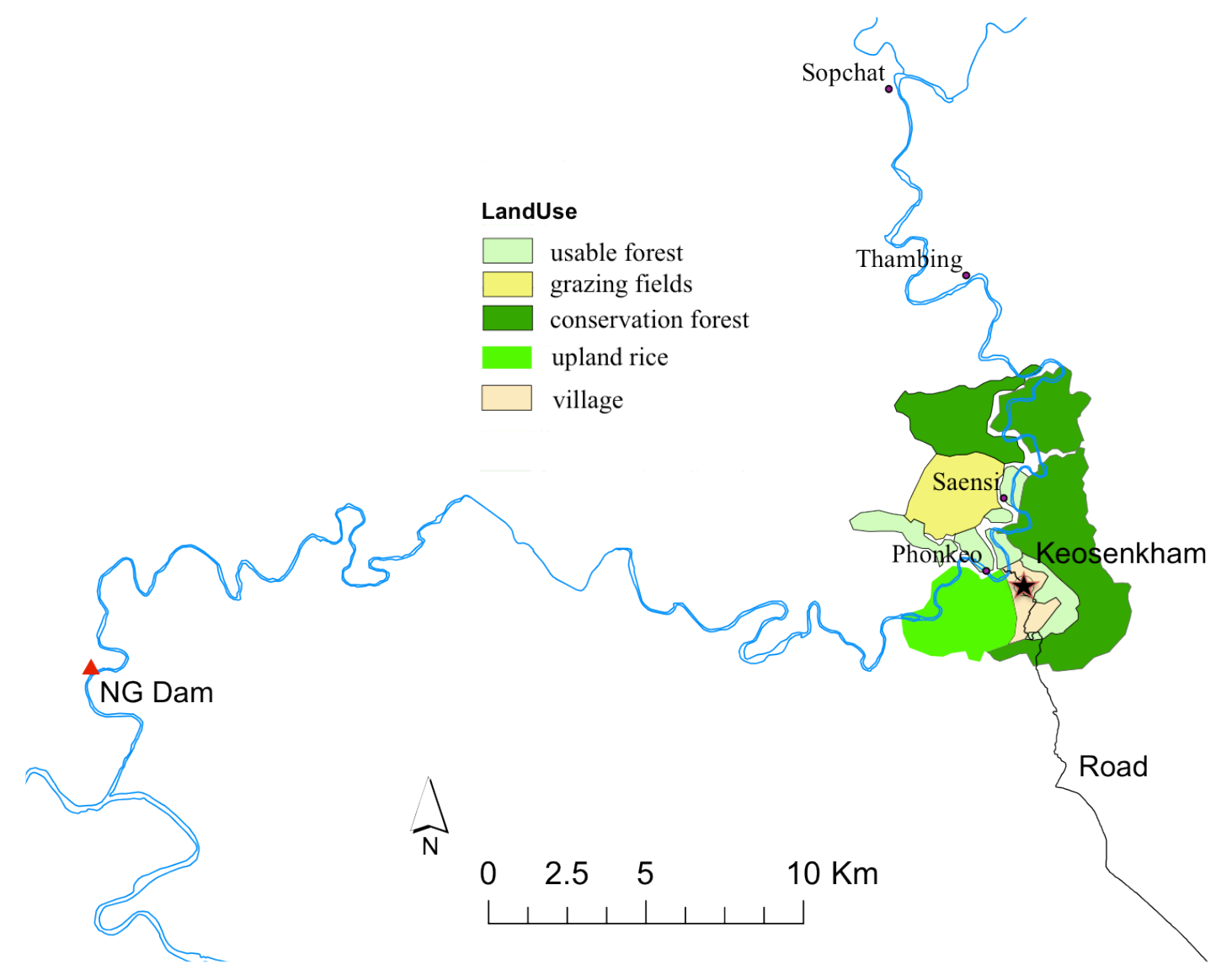

Fig. 3.1. The resettlement village Keosenkham (starred), the location of the former subvillages, and the land use zones allocated by THPC.

The net gain found in this optimization model can be compared to the companyset income target of \$1,813 USD per household in Keosenkham (THPC and NORPLAN 2008). This income target was calculated based on the price of necessary supplies (e.g. food, medical costs, and school fees). The company has agreed to continue to invest in livelihood programs for Keosenkham until the income target is met by at least $80 \%$ of sample households for two consecutive years.

This model is a resource allocation model that uses linear programming and an optimization plug-in for a spreadsheet model, e.g. Solver (Frontline 2012), to identify the most profitable and beneficial proportion of livelihood activities. The model optimizes 
labor allocation, thus the decision variables in this problem have units of labor per activity. Labor is measured in man-days, where one man-day is equal to two people working 12 hours per day. This definition of a man-day is appropriate for our application where labor is allocated to households in each sub-village, and each household is assumed to each have two adult full-time workers. Prices and costs were originally in Lao Kip (LAK) (Joffre 2011; Reis et al. 2012) and were converted to USD, assuming that 1 $\mathrm{USD}=8,000$ LAK as an average exchange rate from 2010 to 2013. The following section 3.1.1 describes each livelihood activity for the five-year baseline case, which is modified for the experiments described in section 3.1.3.

\subsubsection{Livelihoods}

Upland Rice and Vegetable Cultivation

Labor requirements for upland rice and vegetable cultivation are calculated on an annual basis, assuming the seasonal distributions shown in Table 3.1. For example, rice farmers need to work more days to prepare the land during February than they do while the rice grows in March, so the monthly labor fraction $(\gamma)$ in February and March is $18 \%$ and $0 \%$, respectively, representing the percentage of available labor required during each month. The decision variable labor for each activity $i\left(l_{i}\right)$ (i.e. annual man-days for each activity), was distributed over each sub-village $(v)$ and month $(m)$, constrained by the maximum monthly man-days of labor (26) for the population of subvillage $v\left(p_{v}\right)$ :

$l_{i, v, m}=\sum_{i} \gamma_{i, m} \times l_{i, v} \leq 26 \times p_{v}$ 
Table 3.1. The percent distribution of labor $(\gamma)$ for upland rice and shoreline vegetable cultivation. Sub-villages and their population are also shown.

\begin{tabular}{|c|c|c|c|c|c|c|c|c|c|c|c|c|}
\hline & Jan & Feb & Mar & Apr & May & Jun & Jul & Aug & Sep & Oct & Nov & Dec \\
\hline Rice & 16 & 18 & 0 & 0 & 8 & 25 & 8 & 0 & 0 & 0 & 8 & 16 \\
\hline Vegetables & 0 & 0 & 0 & 13 & 7 & 13 & 33 & 33 & 0 & 0 & 0 & 0 \\
\hline \multicolumn{2}{|c|}{ Sub-village $(v)$} & \multicolumn{2}{|c|}{ Phonkeo } & \multicolumn{3}{|c|}{ Saensi } & \multicolumn{3}{|c|}{ Sopchat } & \multicolumn{3}{|c|}{ Thambing } \\
\hline \multicolumn{2}{|c|}{ Population $\left(p_{v}\right)$} & \multicolumn{2}{|c|}{46} & \multicolumn{3}{|c|}{39} & \multicolumn{2}{|c|}{58} & & \multicolumn{2}{|c|}{37} & \\
\hline
\end{tabular}

Land area $(a)$ for upland rice and vegetable gardens, computed via local standard relationships of labor and area, is constrained to the maximum area (ha) available as determined by a geospatial analysis (Kam 2013). The NG reservoir is operated within a range of water level from 420 to $455 \mathrm{~m}$, and for the baseline case in this chapter, vegetable garden plots above $425 \mathrm{~m}$ in elevation are considered cultivable from April to mid-August (as diagrammed in Fig. 2.5). Kam's analysis (2013) also classified land area into zones using the unitless "cost-distances" method (ESRI 2013), a measure of accessibility with respect to slope and distance from the villages, as shown in Fig. 3.2. Several cost-distance analyses were performed. For the land area of upland crops, this study uses Kam's Case D, which considers travel by road or by boat, for the sub-villages Phonkeo, Saensi, and Thambing, and Kam's Case E, which considers travel only by road, for the sub-village Sopchat, because Sopchat does not travel by boat for upland rice. The land area for shoreline gardening (Fig. 3.3), defined as lands adjacent to the reservoir on slopes of less than $12.5 \%$, was also tabulated for cost-distances. 


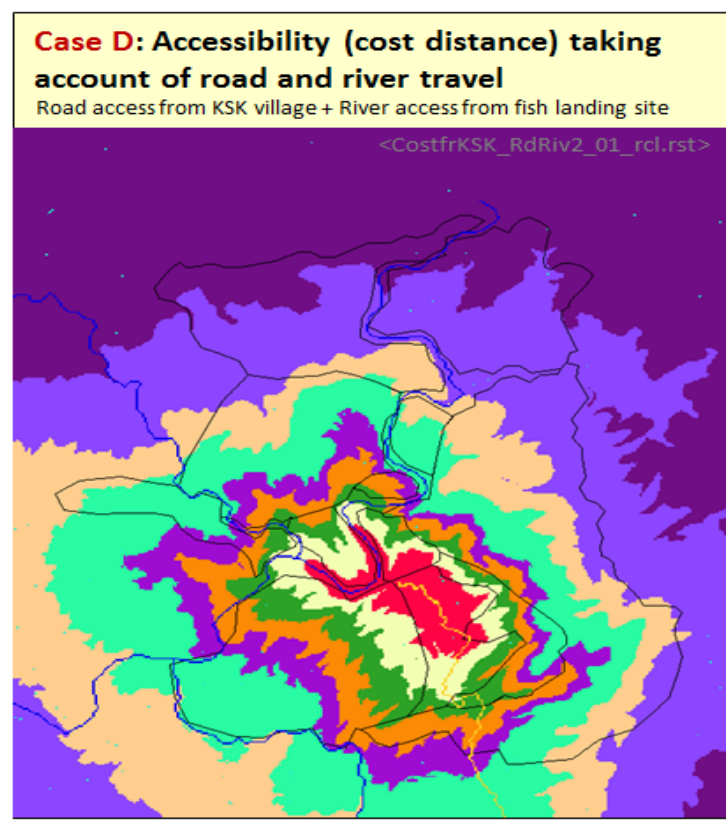

Case E: Accessibility (cost distance) from KSK, without river travel

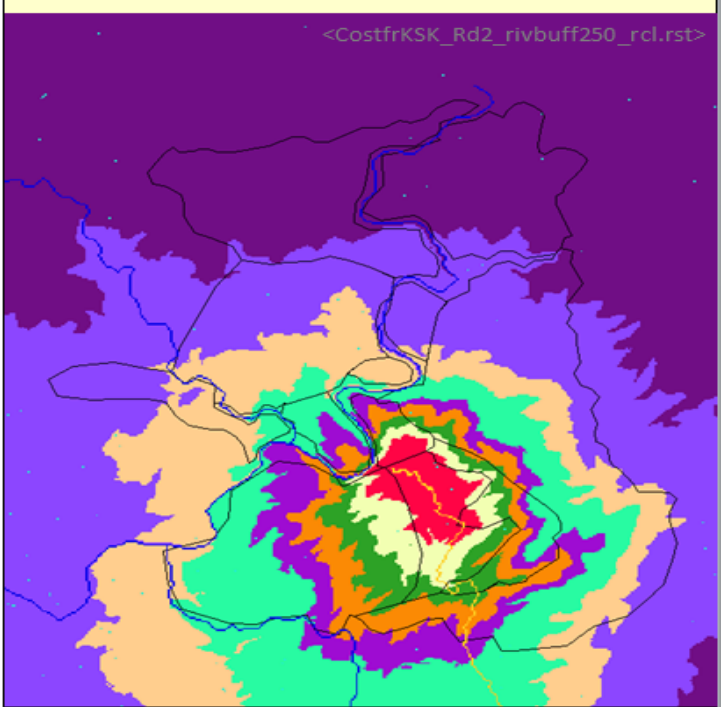

Fig. 3.2. The cost distance zones identified through spatial analysis (analysis and figures by Kam 2013), superimposed over the land use zones shown in Fig. 3.1. The red zone is closest to the village, and the purple zones are furthest away. Left plot: Case D, accounting for travel on the road (shown in Fig. 3.1) or on the NG Reservoir, as applied for the sub-villages Phonkeo, Saensi, and Thambing. Right plot: Case E, accounting for travel only by the road, as applied for the sub-village Sopchat.

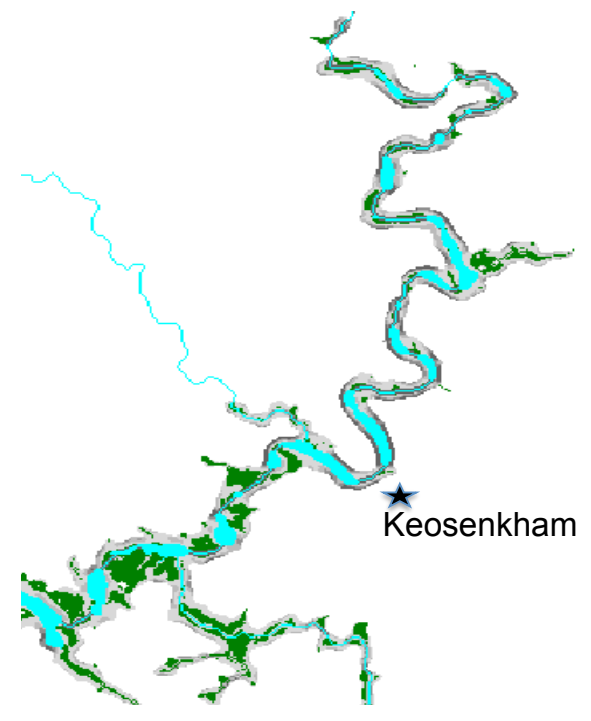

Fig. 3.3. The shoreline gardening areas shown in dark green (cost-distances not shown) (Kam 2013). 
For this dissertation, the values assigned to the cost-distance zones are travel times. Travel times were determined by asking residents to approximate the time to travel from their homes to the location of the cost-distance zones (Reis et al. 2012). Using these zones and travel times, the model requires greater labor for less accessible locations (those with high cost-distance values). The model allows for farming rice on steeper slopes $(>25 \%)$ than is recommended to prevent erosion, while associating higher costs with such practices. Land can only be used within the assigned zones for Keosenkham residents (Fig. 3.1). Some areas close to the village, such as the western bank of the river, which is slated for conservation, cannot be used at all. The land available for upland rice and vegetable gardening are shown in Table 3.2.

Table 3.2. The available land area (ha) for upland rice for Phonkeo, Saensi, and Thambing (Case D) and Sopchat (Case E). The available land area (ha) for shoreline gardening.

\begin{tabular}{lllllllll}
\hline & Zone & 1 & 2 & 3 & 4 & 5 & 6 & 7 \\
\hline Case D & Shallow & 4.7 & 27.2 & 31.2 & 20.5 & 12.6 & 37.9 & 1.8 \\
Case D & Steep & 14.7 & 74.3 & 94.1 & 94.9 & 81.6 & 149.1 & 2.2 \\
\hline Case E & Shallow & 4.7 & 18.2 & 19.3 & 12.8 & 30.2 & 45.4 & 5.5 \\
Case E & Steep & 12.6 & 55.4 & 66.8 & 75.2 & 99.3 & 180.0 & 21.5 \\
\hline \multicolumn{2}{l}{ Garden Area } & 2.7 & 10.9 & 19.4 & 6.9 & 8.5 & 90.0 & 61.7 \\
\hline
\end{tabular}

To link land area and labor, a proportional value between required area $(R A)$ and labor required per month $(R L)$ is assumed for the activities $(i)$ upland rice and shoreline gardening. The area $(a)$ used by each sub-village $(v)$ is found by multiplying the maximum labor for a particular optimization run $(l)$ by the ratio of land area $(R A)$ to its required labor $(R L)$. The area $(a)$ must be smaller than the total area available $(A)$. For instance, if farmers spent a maximum of 20 man-days in month $m$ to farm 2 ha, then the ratio of $A$ to $L$ would be 0.1 ha $\cdot$ man-day ${ }^{-1}$.

$a_{i, v}=l_{i, v, m} \times \frac{R A_{i, m}}{R L_{i}, m} \leq A_{i, v}$ 


\section{Raising Livestock}

Livestock are assumed to require attention evenly distributed year-round. Because the maximum area available for livestock grazing is unknown, the labor allocated is limited to the baseline amount of 56 man-days per year. The livestock are kept upriver, so villagers must take boats to care for the animals. Because of the distance to access the reservoir, labor for Sopchat and Thambing is assumed to require 20 minutes per man-day beyond the standard amount of labor.

Fishing

Because the productivity of the fishery is linked to the season, such that more fish can be harvested during the dry season, the fishing decision variables $\left(l_{f, v, m}\right)$ in each subvillage $(v)$ and revenues $\left(R_{f, m}\right)$ are monthly $(m)$ as opposed to the yearly time step of the other livelihood activities. Thus the revenue from fishing is calculated as:

$r_{f, v}=\sum_{m=1}^{12} l_{f, v, m} \times \frac{R_{f, m}}{L_{f, m}}$

To mimic natural decline of return with increasing time spent fishing in the reservoir each month, fishing revenue is computed as a piecewise linear model. Initially yield is high, but after a certain number of days each month, the return is lower. The profitability declines after 7 days and 3 days, respectively, during the dry and wet months. The baseline revenue coefficients for the most profitable days of fishing are shown in Table 3.3. The coefficients for the less profitable days of fishing (after 7 or 3 days for the dry and wet seasons, respectively) are two-thirds of the numbers in Table 3.3.

Table 3.3. The coefficients for fishing revenue (USD).

\begin{tabular}{lllllllllllll}
\hline Month & Jan & Feb & Mar & Apr & May & Jun & Jul & Aug & Sep & Oct & Nov & Dec \\
Coefficients & 8.7 & 8.9 & 8.2 & 8.9 & 6.8 & 7.6 & 7.0 & 8.0 & 7.0 & 6.3 & 7.6 & 8.0 \\
\hline
\end{tabular}


Fish yield is expected to double over the coming 2-3 years due to high nutrient content in the impounded lake (Laugen 2011). However, after about 5 years, fish yield is expected to decline less than half of first-year post-impoundment productivity, due to oxygen depletion from excess nutrients, a eutrophication process as observed at the nearby NT2 reservoir (Laugen 2011). The fraction of fishing revenue assumed for the five years, shown in Table 3.4, are multiplied by the revenue coefficients in Table 3.3. The baseline thus optimizes labor over five years based on the time-varying expected fish yield.

Table 3.4. The fraction of the fishing revenue assumed over five years.

\begin{tabular}{llllll}
\hline Year & 1 & 2 & 3 & 4 & 5 \\
Fraction & 1 & 2 & 1.5 & 1 & 0.5 \\
\hline
\end{tabular}

Fish catches beyond $5 \mathrm{~kg}$ fish per man-day require a monthly permit costing $\$ 12.50$. Commercial fishing is limited by the constraints below (3.4-3.6), considering the natural decline of fishing return with labor. Equation 3.6 constrains the labor for noncommercial fishing households $\left(l_{h}\right)$ to a catch of $5 \mathrm{~kg}$ by relating the cost of fishing, assumed to be $\$ 1.25$ (the cost of fuel) per unit catch $(\mathrm{kg})$, to the revenue that could be derived from fishing.

$$
\begin{aligned}
& l_{c, v, t 1} \leq 7 p_{c, v} \\
& l_{c, v, t 2} \leq 23 p_{c, v} \\
& l_{h, v} \leq p_{h, v} \times 5 \times \frac{1.25}{c_{m, y}}
\end{aligned}
$$

Where $l_{c, v, t 1}$ and $l_{c, v, t 2}$ are the labor (man-days) of commercial fishers in each subvillage $(v)$ for the two time periods during one month, $p_{c}$ and $p_{h}$ are the populations of commercial fishers and household $(h)$ fishers (those with and without, respectively, a 
commercial license in each village) (Table 3.5), and $c_{m, y}$ is the revenue (USD) per manday from fishing shown in Table 3.5.

Table 3.5. The number of fishers with commercial licenses and without commercial license (household) in each sub-village.

\begin{tabular}{lllll}
\hline Sub-village & Phonkeo & Saensi & Sopchat & Thambing \\
\hline Commercial & 46 & 39 & 20 & 9 \\
Household & 0 & 0 & 38 & 28 \\
\hline
\end{tabular}

\subsubsection{Optimization Model Formulation}

The objective function maximizes the net gain $G$, the difference between the gross revenue $(r)$ and the overhead cost (c) of each livelihood activity (Eq. 3.7).

$$
\operatorname{Max} G=\sum_{i, v}\left(r_{i, v}-c_{i, v}\right)
$$

Where $i$ indicates each potential livelihood activity: $i \in\{$ upland rice farming, vegetable farming, raising livestock animals, fishing, pilot $\}$, and $v$ indicates the sub-villages: $v \in$ \{Phonkeo, Saensi, Sopchat, Thambing\}.

The decision variable is labor $(l)$, with units of two man-days (totaling 24 hours), assuming that each household has two full-time workers. Labor is allocated for each activity $(i)$ in each sub-village $(v)$. The revenues $\left(r_{i}\right)$ and costs $\left(c_{i}\right)$ from these activities are calculated using constant coefficients (Table 3.6), which are the ratio of the standard revenue earned $\left(S R_{i}\right)$ and costs incurred $\left(S C_{i}\right)$, respectively, to standard labor required $\left(S L_{i}\right)$. The standard annual revenue and cost data were determined from household surveys carried out over several months (Joffre 2011). The standard values for labor were selected among a range of estimates given during surveys consisting of household questionnaires with several farmers from each sub-village (Reis et al. 2012; Appendix B). The data used to determine standard costs, revenues, and labor are shown in Appendix C. Shoreline vegetable farmers from Thambing and Sopchat must walk farther to the 
reservoir, and so are assumed to require an extra 20 minutes more per man-day. Farmers from these villages are not all farther from the rice plots, so no extra time was allocated. Fixed costs $\left(c_{F}\right)$ for tools for rice farming and the boat for fishing are added using binary variables $\left(\operatorname{bin}_{i}\right)$ and an associated constraint (3.10) to link the fixed costs to the appropriate decision variable.

$r_{i, v}=l_{i, v} \times \frac{S R_{i}}{S L_{i}}$

$c_{i, v}=l_{i, v} \times \frac{S C_{i}}{S L_{i}}+b i n_{i, v} \times c_{F}$

$l_{i, v} \leq \operatorname{bin}_{i, v} \times 10^{6}$

Constraint 3.10 ensures that if any man-days are allocated to activity $i, b i n_{i}$ must be set equal 1 and the fixed cost will be incurred.

Table 3.6. The coefficient ratios, $\frac{S R_{i}}{S L_{i}}$ and $\frac{S C_{i}}{S L_{i}}$ in Eq. 3.8 and 3.9, for calculating revenue and costs (USD). The cost values, except for upland rice, are slightly higher for Thambing and Sopchat to account for the greater travel costs. The difference is small and does not show up at the scale displayed in this table. The revenue for fishing is given in Eq. 3.3, with the monthly coefficients shown in Table 3.3.

\begin{tabular}{llll}
\hline & Revenue & Costs & Fixed Costs \\
\hline Upland Rice & 7.6 & 0.4 & 3.2 \\
Shoreline gardens & 8.9 & 0.4 & - \\
Livestock & 6.6 & 1.3 & - \\
Fishing & - & 3.0 & 21.5 \\
\hline
\end{tabular}

Equation 3.7 is subject to the constraints of the available land area for upland rice and vegetables (Eq. 3.2), maximum fish yield (3.4, 3.5, and 3.6), and limits on labor and capital.

The maximum feasible labor for the sum of the activities each month is 26 mandays. Any supplemental labor hired with capital is not added to the households' labor each month, but incurs a cost to that household. The hired laborers could either come 
from Keosenkham when they have unallocated time, as is commonly practiced (Reis et al. 2012), or could come from outside of the community.

The amount of labor hired $(l h)$ each year $(y)$ is limited by the cost of labor $(\omega)$, starting at $\$ 3.75$ per man-day with $3 \%$ inflation added each year, and the capital constraint, $30 \%$ of the previous year's net gain $(G)$ :

$\sum l h_{y, v} \times \omega_{y} \leq 0.3 \times G_{y-1, v}$

\subsubsection{Numerical Experiments}

The following five numerical experiments are used to evaluate the impact on the baseline model: Steady Fish Response, Food Security, Irrigation Pilot, High Water, and Community Level. The Steady Fish experiment models the revenue from fishing using the coefficients in Table 3.3 for five consecutive years. The Steady Fish Response experiment serves as a multiyear control to the variable fish response (Table 3.4) that is used for the baseline model, allowing the results of the other four experiments to be considered independently.

The Food Security experiments allocate resources for food security. In community workshops, $42 \%$ of surveyed individuals cited food security as more important than income (Baran et al. 2011). Many of these participants may have resided in the two sub-villages Sopchat and Thambing, which we will call Sopchat/Thambing, which are more risk-adverse than the other two sub-villages Phonkeo and Saensi (Phonkeo/Saensi) (Reis et al. 2012). The Food Security experiments require all livelihoods be practiced to a minimum threshold, either for just Sopchat/Thambing or for all sub-villages. The food security experiment can also be considered a requirement for 
diversification of livelihoods because it enacts a minimum labor allocated to each livelihood:

$S L_{i} \times \varepsilon_{i} \times p_{v} \times \alpha \leq l_{i, v}$

Where $S L_{i}$ is the standard labor for each activity, $\varepsilon_{i}$ is the percent weight for each activity in the community workshops, and $p_{v}$ is the population of the sub-village, $v$ (Table 3.1). The values of $S L_{i}$ and $\varepsilon_{i}$ are shown in Table 3.7. The $\alpha$ is a fixed value of $89 \%$, the ratio of the $42 \%$ of villagers who prioritize food security to $47 \%$, the relative population of the Phonkeo and Saensi to the whole of Keosenkham. This constant $\alpha$ allows each subvillage to require food-security, while assuming that the ratio in each sub-village is equal to the proportion in Keosenkham who prioritized food security.

Table 3.7. The values used in equation 3.12 .

\begin{tabular}{lllll}
\hline Activity & Upland Rice & Vegetables & Livestock & Fishing \\
\hline Labor $\left(S L_{i}\right)$ & 55 & 37 & 55 & 83 \\
Weight $\left(\varepsilon_{i}\right)$ & 0.8 & 0.7 & 0.4 & 0.3 \\
\hline
\end{tabular}

The Irrigation Pilot experiment allows the model to allocate labor for a pilot program for irrigated vegetable gardening to enhance income and food security. The pilot program is a pursuit of a partnership between the dam company, an international research group, and local organizations. Chapter 2 demonstrated that adequate water for small areas of irrigated vegetable crops may be available from five small dams on tributaries feeding the NG reservoir, which are slated for construction to create artificial wetland conservation habitats.

The High Water experiments explore the optimal livelihoods during wet years. The HighWater 75 experiment considers water levels above the $75^{\text {th }}$ percentile, based on reservoir simulations in Chapter 2, which corresponds to inundation elevations of $430 \mathrm{~m}$ 
during the growing season (Apr-Aug). In the HighWater75 experiment, available shoreline gardening area is reduced by $13 \%$. The maximum water level (referred to as MaxWL) during the growing season, of $435 \mathrm{~m}$ was also evaluated. The MaxWL experiment reduces shoreline garden area by $34 \%$, compared to the baseline inundation elevation of $425 \mathrm{~m}$ (areas shown in Table 3.8). Table 3.8 shows the available area by cost-distance zone for each of these experiments. In addition, these available gardens would be exposed later in the growing season, corresponding to a reduced growing season and proportionally lower labor requirement and lower yields.

Table 3.8. Available land area (ha), by cost-distance zone, during the baseline (above $425 \mathrm{~m}$ ), HighWater75 (above $430 \mathrm{~m}$ ), and MaxWL (above $435 \mathrm{~m}$ ).

\begin{tabular}{lrrrrrrrr}
\hline Zone & 1 & 2 & 3 & 4 & 5 & 6 & 7 & Total \\
\hline Baseline & 2.7 & 10.9 & 19.4 & 6.9 & 8.6 & 90.0 & 61.7 & 200.3 \\
High Water & 2.4 & 10.2 & 18.4 & 5.8 & 5.9 & 77.1 & 54.9 & 174.7 \\
MaxWL & 1.9 & 8.9 & 15.6 & 4.2 & 2.6 & 54.8 & 44.6 & 132.7 \\
\hline
\end{tabular}

The Community Level experiment assumes that labor and investments are shared among households. The model framework is generally the same, except that at the community level, some activities are shared among households, and therefore have reduced costs and require less labor. The labor and cost for taking care of livestock are shared, under the assumption that a household will share the task of traveling upriver to feed their livestock with five other households. Similarly, four households share the cost of fuel and labor for bringing the fish from camping sites to fish landing market each day. The fishermen camp overnight for extended stays, and one household can bring the daily catch of three other fishing households to meet traders in Keosenkham. The number of households sharing each task was estimated from the surveys. For the community level 
experiment, the modeling steps and experiments described for the household level model were repeated for the Irrigation Pilot experiment.

\subsection{Results}

\subsubsection{Optimized Baseline}

The first year of the baseline model described above can be verified by comparing the optimized baseline results to the survey data collected 2010-2012. The households surveyed had an average income of $\$ 1,270$ USD. This average is about the same as the income for agricultural activities from previous surveys conducted by the company, of $\$ 1,240$ average over four years $(2005,2008-2010)$ (THPC and NORPLAN 2008; THPC 2011a). The optimized baseline model had an average annual income of $\$ 1,270$ in year 1 . In the first year, the baseline uses 65.6 more man-days days of labor than does the nonoptimized survey data (Fig. 3.4). In the first year of the baseline, the majority of time is spent fishing, followed by rice farming and raising livestock (Fig. 3.4). When the first year of the baseline labor is limited to that of the non-optimized data, the average income would be $\$ 1,220$. This reduction in income was caused by the new reservoir, due to flooded rice paddies and riverbank gardens, increases in the cost of raising livestock (which are pastured far from Keosenkham), and the new fishing licenses. 


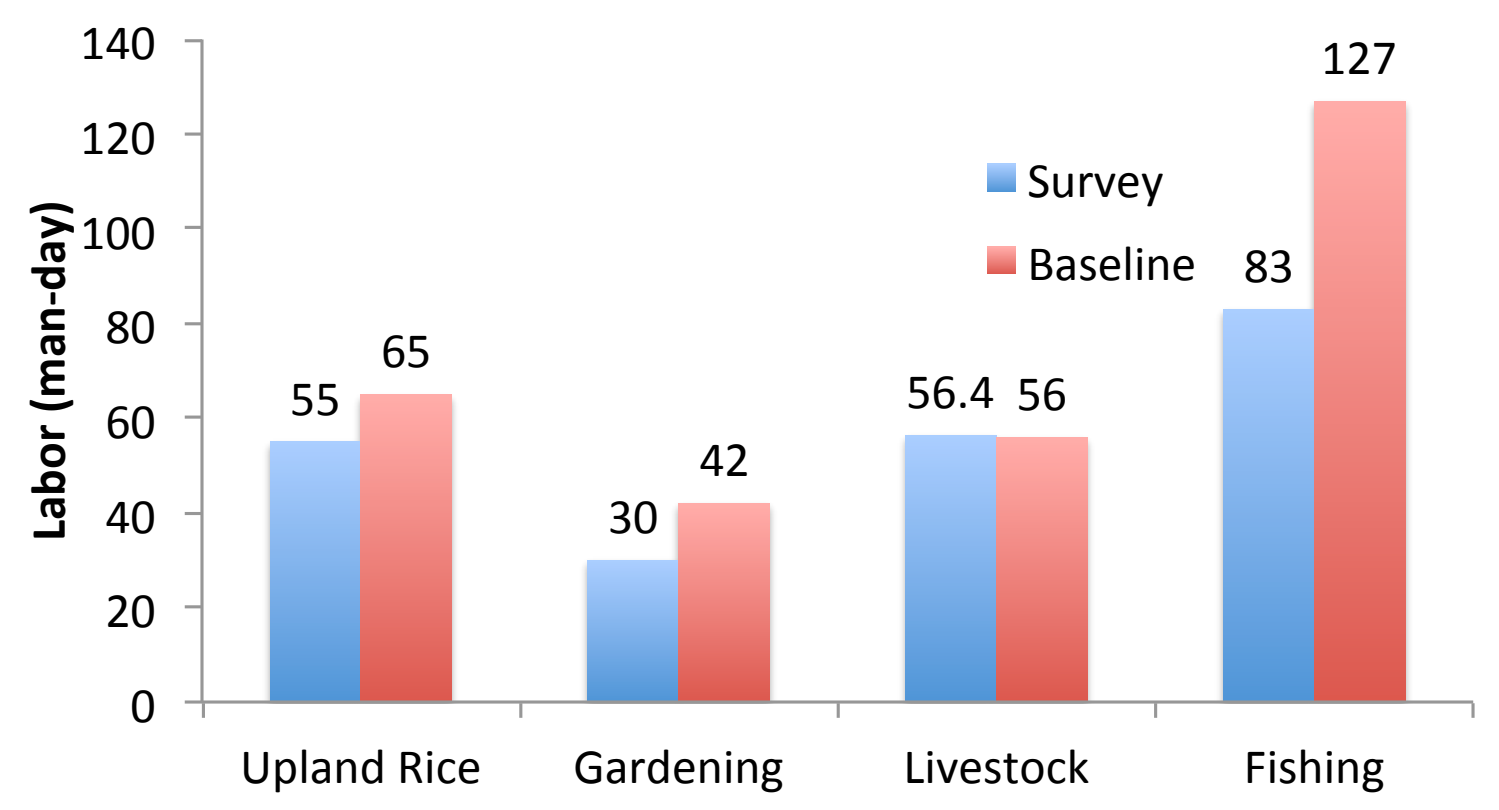

Fig. 3.4. The labor distribution for the survey data compared to the first year of the optimized baseline. The fishing component increased significantly, reflecting the model's use of all available labor.

The allocation of area by the model indicates the degree to which land area is a constraint. In the first year, the moderately graded land areas (slope $<12.5 \%$ ) for upland rice were $65 \%$ used via equation 3.2; the non-used areas were mostly in zones 6 and 7 , located the furthest from Keosenkham. In the first year, the steeper upland rice areas (slope $12.5-25 \%$ ) were $50 \%$ used; the non-used lands were also located in the furthest away zones. The shoreline gardens were $100 \%$ used in year 1, and slightly more were assigned to sub-villages Thambing/Sopchat.

Phonkeo/Saensi, with each household purchasing a commercial fishing license, netted $21 \%$ more income than did Thambing/Sopchat in year 1 . It is interesting to note that if labor were restricted to the historic number of working days, although Phonkeo/Saensi still fished more hours, they would earn less net gain from fishing than 
did Thambing/Sopchat due to the added burden of fishing licenses, which, fishermen have agreed, are necessary to control access to the lake.

Regarding the expected response in labor distribution and income with projected future changes to the composition of the fish in the lake, the baseline multiyear results had varying net gains for each activity for each year (Figure 3.6). The average time spent fishing for all sub-villages increased by $59 \%$ in the second year, reflecting the simulated spike in profitability of fishing. During this second year, labor for vegetable gardening declined by $34 \%$ and labor for livestock decreased by $47 \%$ (Phonkeo/Saensi had zero livestock labor allocated this year); upland rice labor increased by $75 \%$ due to the availability of capital to hire laborers, allowing households to circumvent the maximum labor restriction. The fifth year, as the simulated fish stock declined by half, the labor for fishing decreased by $63 \%$. The average income in year 5 is only slightly smaller than it was in year 1, despite the reduced productivity of the fishery, because capital from the previous year allowed investment in rice production. 


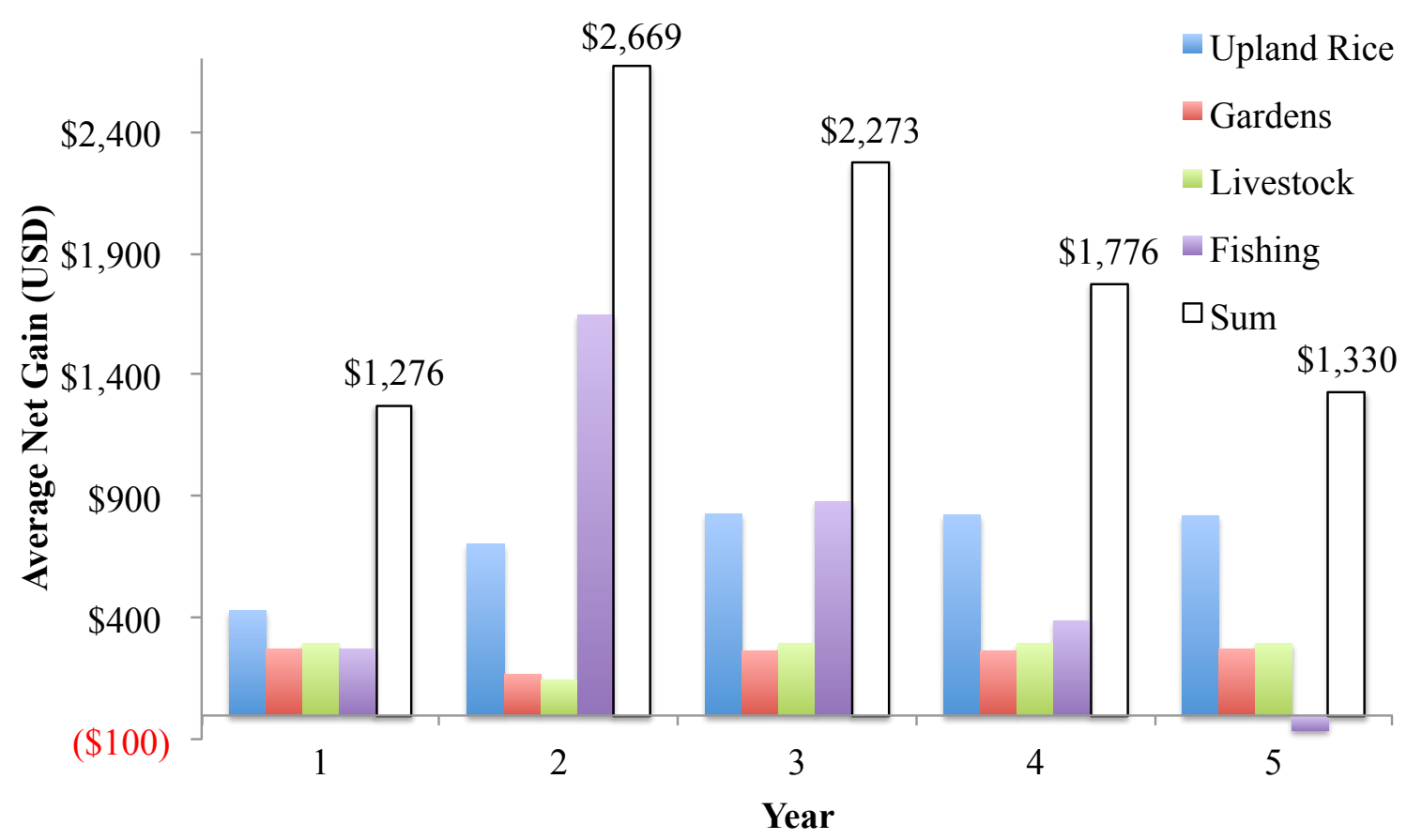

Fig. 3.5. The average net gain for all sub-villages each year, for each activity, and in total for the baseline.

Figure 3.6 shows the distribution among the villages for labor and income. It shows that the villages that have invested in fishing licenses (Phonkeo/Saensi) profit much more than do those with mostly household fishers, Sopchat/Thambing. This discrepancy is exacerbated by the increased cost-distance between Sopchat/Thambing and the lake, which is the gateway to shoreline gardening, livestock, and fishing. Despite the year 5 losses in fishing for Phonkeo/Saensi the fishing licenses are overall a good investment over the entire 5-year period. As a sub-experiment of the baseline, the model was allowed to choose the number of fishing licenses per sub-village with no resource management cap on the total number of licenses. Licenses were allocated to each household in all sub-villages, resulting in a 9\% increase in total average net gain. This is the best possible outcome because the baseline had no mechanism for 'over-fishing' 
besides setting the number of licenses as the 2012 distribution, so this $9 \%$ gain assumes that even if all households had licenses, the catch is not reduced.

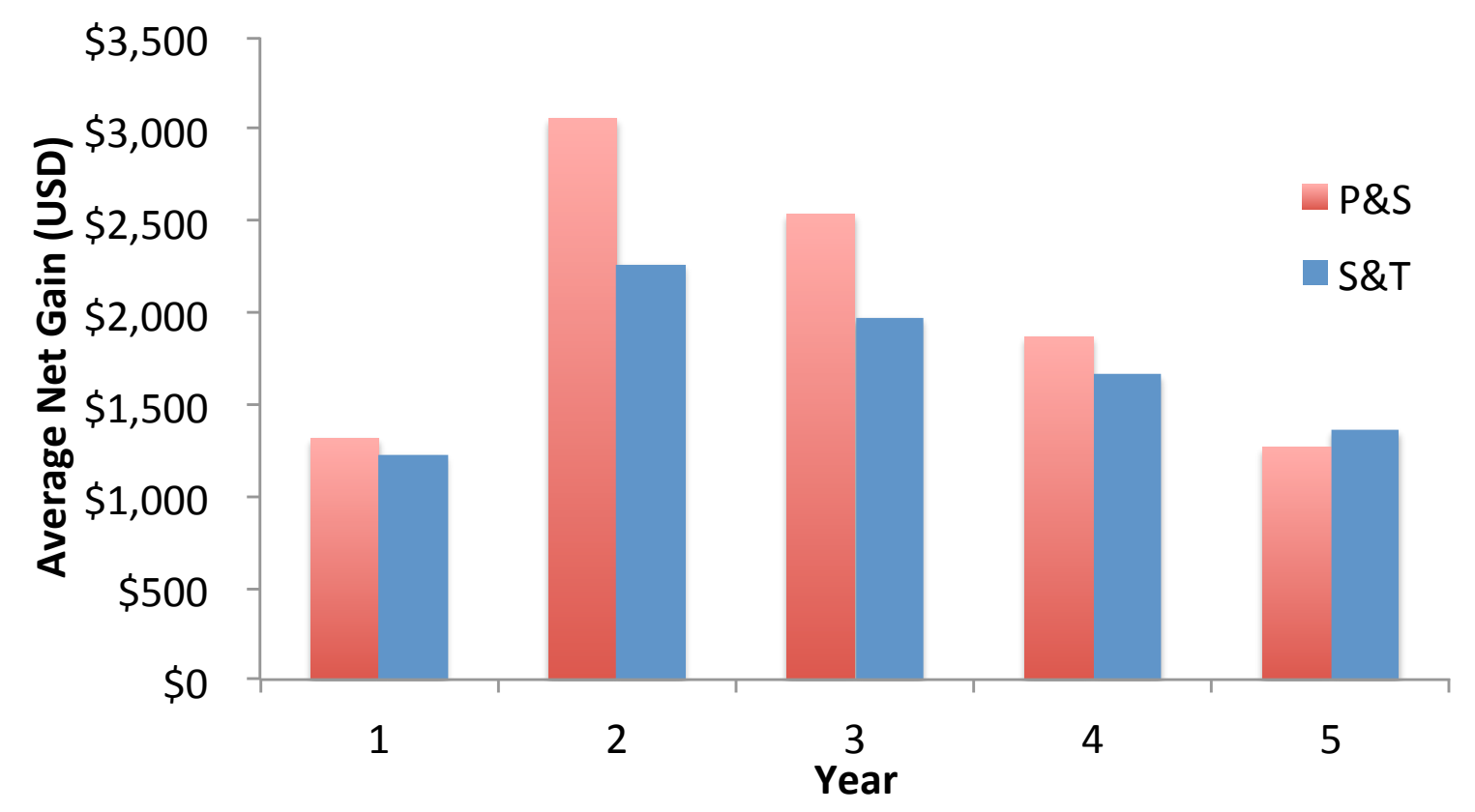

Fig. 3.6. The average net gain for the villages Phonkeo and Sopchat (P\&S) and Sopchat and Thambing (S\&T).

\subsubsection{Results of Experiments}

Figure 3.7 shows the average net gain for each activity for the Steady Fish Response optimization over five consecutive years. Figure 3.7 can be compared to Figure 3.5 to highlight the volatile fish yield and net gain found in the baseline. During years 25 , all land for upland rice and shoreline gardening was used. During year 2-5, the net gain increased by an average of $\$ 32$ per year per household $\left(\mathrm{R}^{2}=0.96\right)$. Rising incomes allowed households to hire agricultural labor and increase the time spent fishing. For all years, fishing rose by an average of 12 labor units per year per household. 


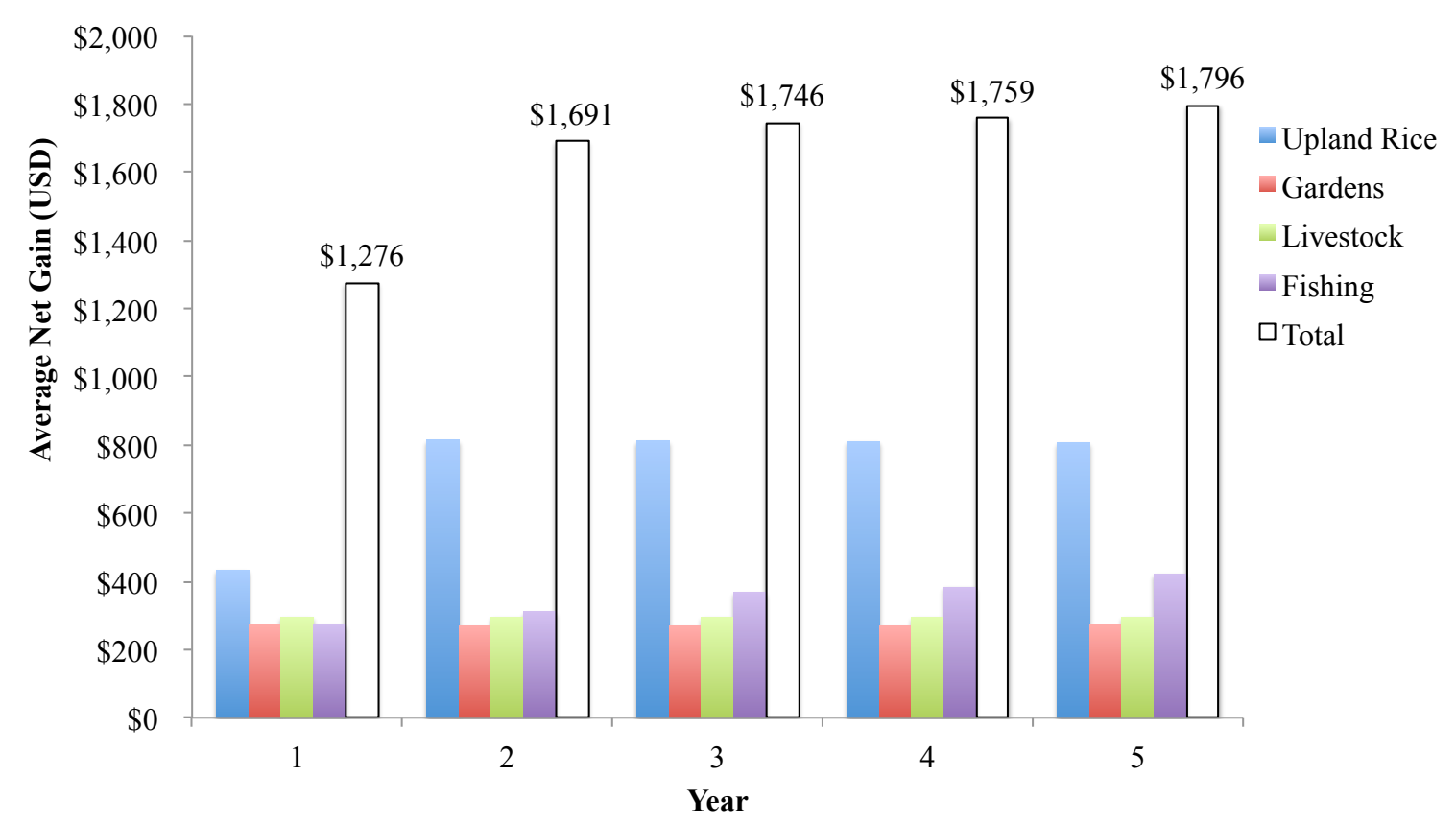

Fig. 3.7. The average net gain for all sub-villages each year, for each activity, and in total for the Steady Fish Response.

The Food Security experiment, which examined the trade-offs between food security and income, found that adding food security constraints for all villages does not yield a loss except of $\$ 26$ during year 2, as a result of reduced allocation of fishing labor. This shows that food security, which can be thought of as diversification in livelihood activities, only reduces the net gain when fishing is very lucrative. The food security constraints positively impacted Phonkeo/Saensi because by investing in gardening and livestock, they avoided some of the losses from a poor fishing year during the fifth year. For Phonkeo/Saensi, however, the added constraints on these activities reduced the number of days fishing, depressing their net gain. Food security is unlikely to apply to Phonkeo/Saensi, however, where most inhabitants are fishermen and willingly purchase rice and other food items. 
The Irrigation Pilot experiment, which determined the impact of the pilot of irrigated dry season vegetable gardening on the distribution of labor among the five activities, found the average income across all villages increased to $\$ 1,700$ in year 1 , a $34 \%$ increase. The sum of net gains across all villages and years increased by $25 \%$. Figure 3.8 shows the change in labor distribution over the 5 years. The reduction of raising livestock, seen during year 3 only, can be attributed to the profitability of dryseason vegetables. The profitability of dry-season vegetable gardening can rival that of fishing, even during the peak of profitability in year 2. Importantly, dry-season farming provides an alternative to fishing for some of the households that do not wish to invest in fishing licenses, and is an activity with a different seasonal labor demand, allowing households to continue to cultivate rice and shoreline gardens. The villages Phonkeo/Saensi and Sopchat/Thambing benefit on average 21\% and 28\%, respectively, compared to no irrigation pilot. The biggest increase to net gain for all sub-villages, $39 \%$, comes in year 5. Applying both the pilot and the food security (for all) experiments does not significantly change the average net gain or the discrepancy between the subvillages, nor does it change the allocation of labor. 


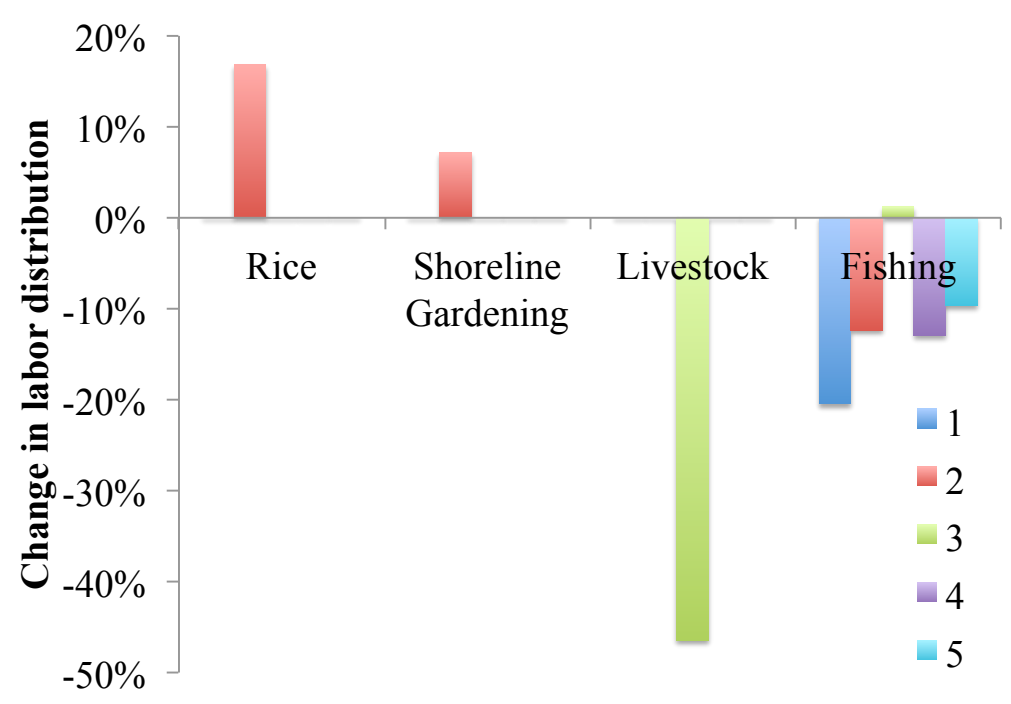

Fig. 3.8. The percent change in the labor distribution from the pilot program of dryseason gardening compared to the baseline without the pilot, over the 5 years optimized.

In the HighWater75 experiment, gardening decreased from the baseline by an average of $12.4 \%$ over four years, excluding year 2 during the fishing boom when it had no change. The average income decreased by just $1 \%$. The model compensates for losses in gardening income by allocating $2 \%$ more labor to fishing, which has similar returns to shoreline gardening. In the HighWater 75 case, $72 \%$ of the gardens were allocated to Sopchat/Thambing, compared to $67 \%$ in a normal year. In the MaxWL scenario, the overall net gain decreased by $3 \%$, and $88 \%$ of the gardens were allocated to Sopchat/Thambing.

For the Community Level experiment, the optimized annual income, averaged over 5 years, increased by $36 \%$ compared to the household 5 -year average, with a $50 \%$ gain in Phonkeo/Saensi and a 22\% gain in Sopchat/Thambing. Phonkeo/Saensi benefited more than Sopchat/Thambing because they practice more fishing, where much of the cost-saving was introduced. Figure 3.9 shows a compilation of the experiments, including Fish Response and Irrigation Pilot, for the household and community levels. The cost 
sharing of the community level enables fishing to remain profitable even during the bust fifth year. The Community Level model with the Irrigation Pilot experiment had an additional increase in income by $30 \%$ compared to just the Irrigation Pilot. Most of the extra labor available in the community model is allocated for fishing (an increase of 53\% fishing labor).

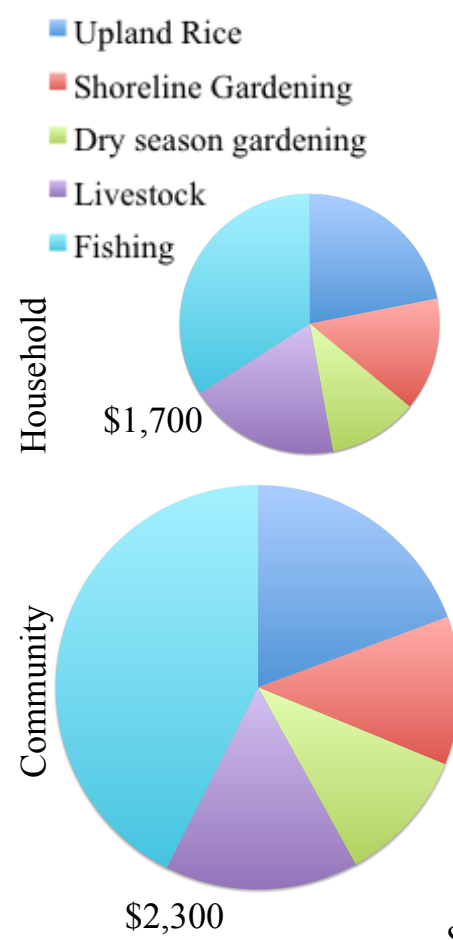

Year 1
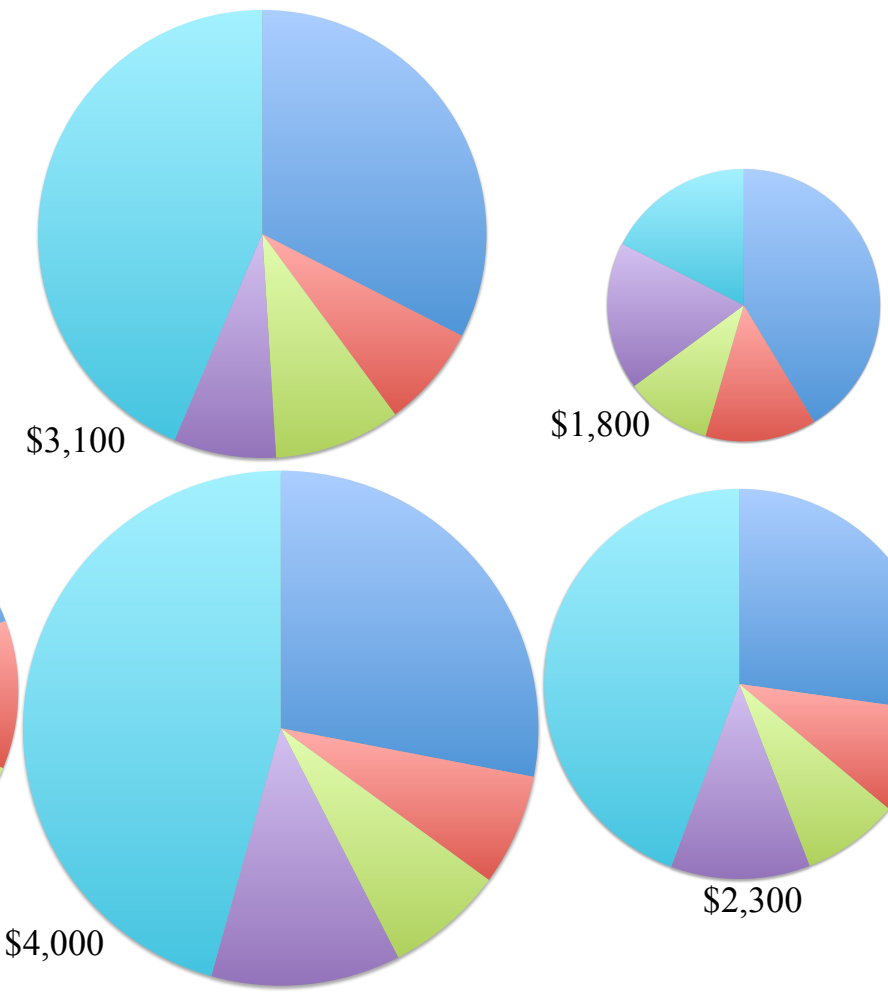

Year 2

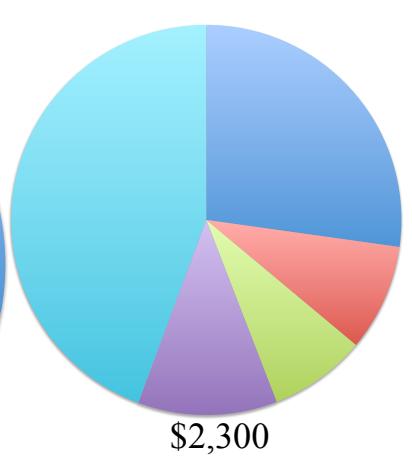

Year 5

Fig. 3.9. The optimized labor distribution for years 1,2 , and 5 , including the dry season vegetable pilot in both options, compared to the community-level results. Average annual net gain is shown in USD.

\subsection{Conclusions and Discussion}

The modeled increase cost of farming in the resettlement village, due to the obstruction of the lake and flooding of fertile land, is offset (in terms of net gain) by the model's optimization routine. In reality it will take a few years for the local people to adapt their activities to the new situation. Agricultural income in the first year may be 
even lower than in previous years, depending on how fast the farmers adapt. New nonfarm opportunities that supplement incomes, for example from the increased access the new road provides, are only options for few households and are not accounted for in this study.

The anticipated rise and fall of fishing yield, as simulated in the baseline, poses challenges for modeling and for fishermen. To profit from the projected second year boom in fish, licenses could be leased to those outside the village that would be renewable only if residents make a minimum catch. One potential pitfall for households relying on fishing is that the fish stocks are also expected to fall to half of their year 1 levels by about the fifth year. As the timing and degree of this decline in the fishery is unpredictable, fishers that invested nearly exclusively in fishing and have not invested in other activities may be vulnerable. While the optimization model is all knowing and diverts resources away from fishing, except licenses, which have been fixed based on their current prevalence, and toward other activities during year 5, individuals will not have such foresight. While the model simulated a possible fishing outcome (Table 3.4), the actual fish yield for a given year will be unknown at the time when villagers must make their investments in livelihood activities. An agent-based model including social persuasions might be able to better simulate farming and fishing choices, although theorizing and implementing livelihoods decisions that are not based on economics would be a challenge.

The species composition will shift from long-range migrant riverine species to lake-adapted fish, and technologies for fishing may be particular to the species. Therefore the fishermen may need to learn new techniques. The fishing organization managed by 
THPC can help with these changes. Their role as brokers who manage access to the lake will also be key to preventing over-fishing and conflict, especially between residents of Keosenkham and non-residents.

The Theun Hinboun Power Company (THPC) set an income target of $\$ 1,813$ for two consecutive years for $80 \%$ of households. In baseline the average household income target is met in years 2 and 3 (Fig. 3.6). However, in years 4-5, due to the declining fertility of the fishing reservoir, even the average household income would not have met the income target. Taking liberties to assume a normal distribution from the mean incomes (Fig. 3.5), with a standard deviation of $\$ 603$, the $20^{\text {th }}$ percentile income for year 3 would be $\$ 1765,{ }^{1}$ which would require the THPC to remain engaged in livelihood programs. Given different fishing outcomes, it is possible that the THPC target could be met at a time when livelihoods have not yet become fully satisfactory and sustainable.

The Steady Fish Response experiment provides a control to the more probably varying fish response simulated in the baseline. Unlike the variable net gains found in the baseline, in the Steady Fish Response experiment, the net gain rises predictably. This experiment points to the unbalancing impact that the unknown future fish yield may have on families, rendering households less effective at planning their investments.

The preference for food security, voiced among mainly Sopchat/Thambing residents during a consulting workshop (Baran et al. 2011) and simulated in the Food Security experiment, revealed that this goal has little cost to these families. Because the model pre-allocated the fishing licenses based on their distribution in 2012, even the baseline optimization biased Sopchat/Thambing to be risk adverse and prefer food

\footnotetext{
${ }^{1}$ Calculation of $20^{\text {th }}$ percentile: $\$ 1773-0.842 * \$ 603=\$ 1765$. If calculated from the mean of 2 consecutive years $(\$ 2471)$, the $20^{\text {th }}$ percentile would be $\$ 1963$, and the THPC could withdraw from livelihood programs.
} 
security to income. Although their income declined in some years, depending on the fishing outcome, these families benefit from the security of a multiple sources of income. This model did not simulate crop failure, a persistent threat for farmers, and due to such unforeseeable events, even a diverse portfolio of agricultural activities would carry some risk. The food security experiment required households to diversify to protect against fish shortages or crop failures, which is important without the foresight of the future value of fishing and farming activities.

The pilot program of dry-season vegetables appears to have high potential for boosting the local economy. Partly this success can be explained by the labor requirements, which do not overlap significantly with rice or shoreline gardening. Constraints on garden area and productivity from potentially rocky soils are yet unknown, and could restrict the application of this activity.

Although the HighWater75 and MaxWL scenarios did not reduce the overall net gain very much (maximum of $3 \%$ ), in these scenarios most of the gardening shifted to the less well-off sub-villages Sopchat/Thambing. The optimization may be unrealistic in changing the allocation of gardening and fishing each year. Without knowledge of the water level throughout the growing season, farmers who invested in shoreline gardening may find their crops flooded during a wet year. As an experiment for future research, the livelihoods model could use a seasonal weather forecast to predict the available gardening area, and simulate this distribution of resources over the coming year, given the changes in the fishery and in shoreline gardening.

The Community Level experiment investigated the outcome of sharing the costs of livestock and fishing duties. If all share, as set in this level of the model, profits could 
dramatically increase. Fishermen already share the costs by camping at fishing sites for weeks and sending a few representatives to sell the combined catch, saving many boat trips and fuel, as simulated by the community model. Community leaders acknowledge, however, that people will share the work of visiting and feeding livestock only among family, due to concerns of theft or cheating (Reis et al. 2012). The gains presented in this model are an indicator of the profitability of managing the farm on the community rather than the farm level, but certain issues of property rights would need structural support to fully realize the benefits of sharing resources.

A consideration for interpreting this model is that while sub-villages were modeled as cohesive units, households may benefit unevenly from the activities optimized. Labor is allocated on the sub-village scale, so variability among households is neglected. Even at the sub-village scale, diversification of labor would not be practiced in some scenarios given only a short-term outlook. For example, Phonkeo/Saensi do not cultivate shoreline gardens in year 2, nor does Saensi cultivate them in years 3-4, yet Phonkeo is able to instantly benefit from the same cost-benefit scale as if they had cultivated the plots continuously. In reality it may be hard to cultivate a new garden bed each year as someone else may have claimed the space; another example is that starting a new livestock operation would take a higher capital cost than is accounted for in the model. A longer-term perspective is needed to survive the variability of the agricultural and fishing economy.

Further research could strengthen the use of the model described in this paper as a planning tool. Accounting for the continuity of investments, discussed in relation to the Fish Response experiment, could ensure the optimization reflects a longer, more realistic 
vision for the community. Another aspect for improvement is that the community level model could include different economic levels of access to resources. While higher costs and labor requirements were allocated to Sopchat/Thambing, the farther villages from the reservoir, certain hindrances are more difficult to model, such as these villages' reduced access to information and communication with the power company (Katus 2012). The model could be used to differentiate between labor among the households and, in doing so, account for gender. The model could also be used to evaluate other pilot programs, including the power company's small livestock program.

\subsection{Works Cited}

Baran, E., Thephavanh, M., Samadee, S., Hoanh, Chu Thai, Keophoxay, A., and Pouthavong, S. (2011). Stakeholder Consultation on Perspectives and Expectations about Nam Gnouang Reservoir Management. World Fish and Water and Food Challenge Program in the Mekong, $37 \mathrm{p}$.

Frontline. (2012). "Microsoft Excel Solver." <www.solver.com/>.

Ittersum, M. K. van, Roetter, R. P., Keulen, H. Van, Ridder, N. de, Hoanh, C T, Laborte, A. G., Aggarwal, P. K., Ismail, A. B., and Tawang, A. (2004). "A systems network (SysNet) approach for interactively evaluating strategic land use options at subnational scale in South and South-east Asia." Land Use Policy, 21, 101-113.

Joffre, O. (2011). Unpublished Preliminary data about the Keosenkham Resettlement Village for the International Water Management Institute.

Kam, S. P. (2013). GIS Analysis for LUPAS Modeling for Keosaenkham, Lao PDR. WorldFish. Penang, Malaysia.

Katus, S. (2012). "Where local power meets hydropower: Conceptualizing resettlement along the Nam Gnouang river in Lao PDR." Master's Thesis for the University of Amsterdam.

Laugen, J. J. (2011). Fisheries Management Plan Draft Final_17. Theun Hinboun Power Company.

Mandac, A. M., and Luat, N. V. (1998). "A socio-economic perspective for Land Use Planning in the Mekong Delta, Vietnam." Exchange of methodologies in land use 
planning. SysNet Research Paper Series No. 1, R. Roetter, C. T. Hoanh, N. V. Luat, M. K. Van Ittersum, and H. H. Van Laar, eds., Los Baños, The Philippines, 119124.

Paassen, A. Van, Roetter, R. P., Keulen, H. Van, and Hoanh, C T. (2007). "Can computer models stimulate learning about sustainable land use? Experience with LUPAS in the humid (sub-) tropics of Asia." Agricultural Systems, 94, 874-887.

Reis, J., Hoanh, Chu Thai, Kam, S. P., Keophoxay, A., and Douangsavanh, S. (2012). "Personal Interview." Keosenkham Resettlement Village.

THPC (Theun Hinboun Power Company). (2011). Social and Environmental Division (SED) Annual Monitoring 2010 Final Report. Company report.

THPC, and NORPLAN. (2008). RAP (Resettlement Action Plan). Company report. 


\section{Chapter 4: Reservoir optimization for hydropower and}

\section{shoreline gardening goals}

\section{Introduction}

Although simulation of water reservoir operation, as described in Chapters 1 and 2 of this dissertation, is useful for evaluating the prospects for a particular goal, it can be cumbersome to evaluate many different options. Optimization can consider a wide range of goals in a single modeling run, and find the best mathematical fit based on the objectives (Labadie 2004). When applied to reservoir systems, a time series of storage or releases is generally optimized (Grygier and Stedinger 1985), and an additional step can find an optimized rule curve from the historical time series (Lund and Ferreira 1996). Rule curves, which are seasonal water level targets, can also be optimized directly (Chang et al. 2005; Chen et al. 2007).

Reservoir optimization is inherently (or implicitly) stochastic as even deterministic models rely on a range of water variations from the historical record (Rani and Moreira 2010). Explicitly stochastic models use data sets generated through probability methods such as Monte Carlo routines, and can have the advantage of evaluating extreme events like floods and droughts that may not otherwise be represented in the historic record.

Optimization models for reservoir operation tend to consider the general system operation at a coarse scale. The classic method of optimization is linear programming (LP), which is attractive mathematically because the cost-benefit equations converge on a single optimal plan. LP models can be extended in a variety of ways including binary, 
integer and mixed integer approaches, interior point algorithms, and network flow programming (Rani and Moreira 2010).

Non-linear programming (NLP) can be useful for accurately representing the nonlinearities of reservoir operation, such as hydropower relationships and leakage patterns. The challenge with non-linear methods is finding the optimal solution. NLP problems tend to use deterministic rather than stochastic modeling to reduce the computational power and time required to process the runs (Kracman et al. 2006).

Many other innovative methods for reservoir modeling have been developed. Dynamic programming (DP) has been very useful to reservoir managers because it efficiently manages the time dimension, with complexity increasing linearly as the number of management periods increase (Bellman 2003). DP can be deterministic or stochastic. Stochastic or Bayesian models have been popular where the inflow progresses with a Markov process (Karamouz and Vasiliadis 1992), although these tend to result in large dimensions, requiring large computational resources. Other optimization methods for reservoir management include genetic algorithms (GAs) (Chang et al. 2005). GAs and other computational intelligence methods, such as fuzzy logic systems and artificial neural networks (ANNs), have the advantage of converging on several answers with few modeling runs using parallel computing, resulting in several discrete options to consider (Broad et al. 2010).

Ready-to-use models for reservoir optimization draw on this extensive literature. The model HEC-ResPRM uses LP to optimize reservoir systems to determine simplified operating policies (Faber and Harou 2007), but it ignores such key aspects of the reservoir operation as rule curves and the structural characteristics of the dam. HEC- 
ResPRM is still in development and has not been released to the public. MODSIM (Labadie 2006) also does not incorporate rule curves, although it uses the more complex optimization methods of successive approximations solution procedure and a proprietary Lagrangian relaxation algorithm.

This study used a gradient-based nonlinear algorithm to optimize dam releases, subject to penalty functions. In this study, the model was coded in MATLAB, rather than using an existing model with a graphic user interface, to allow for adaptability and transparency (MATLAB 2012). The penalties were designed for meeting the energy target and water level goals to expose shoreline garden plots for seasonal recession agriculture. This optimization model links the simulation model of the Nam Gnouang (NG) Reservoir, described in Chapter 2, with the optimization model of farm-based livelihoods, described in Chapter 3. In linking models developed for water resources and farm livelihoods, this research provides a methodology for IWRM. The optimization model is used to investigate the tradeoffs between operating the reservoir for energy production or for livelihood goals.

\subsection{Methods}

To achieve effective IWRM, the tools for water and livelihood management were linked. In this step, feedback was identified from the results of Chapter 2, the NG Reservoir simulation, and from Chapter 3, the optimal livelihood resource allocation. To illustrate the relationship between these chapters, this study focuses on one of the most profitable livelihood activities, recession agriculture. Recession or shoreline agriculture is the practice of growing vegetables on reservoir shorelines that may be submerged and exposed over the course of a year. To be productive, gardens must be exposed long 
enough for crops to mature. In the case of the NG Reservoir, shoreline gardening requires an operation measure designed to drawdown the water level during the growing season. In Chapter 2, using simulation of reservoir operational logic, alternative plans for shoreline gardening were developed. The agricultural operational measure specified that the reservoir water level drop below the elevation of most shoreline gardens (425 m) during the growing season, in order to enhance the livelihoods of farmers. The measure was simulated and evaluated in terms of the cost on downstream hydropower production and other purposes of the NG dam. In Chapter 3, the net gains from shoreline gardening were investigated under a variety of circumstances, using a livelihoods optimization model. Using the livelihoods model, it was found that gardens are most significant to the farmers who value food security over income, and that the shoreline gardening is most important when fishing return is low. This chapter (4) describes an optimization model linking the results from the other two models, the modeled reservoir releases (Chapter 2) and the value of shoreline gardening (Chapter 3), to optimize reservoir operation simultaneously for goals of energy production and shoreline agriculture. The releases are optimized on a monthly time step for nearly 25 years (January 1986 - October 2010), the same length of time as the operational model (Chapter 2). The model derives the water level and energy generation from the optimized releases using equations shown below.

The program MATLAB was used to code the optimization model with interlocking scripts. One script calls MATLAB's algorithm fmincon, a gradient-based nonlinear programming approach, selecting the option for fmincon's interior-point solution method (Byrd et al. 2000). The model described here determines an optimal sequence of monthly releases $R_{t}\left(\mathrm{Mm}^{3} \mathrm{mo}^{-1}\right)$ to minimize the penalty functions for 
violating two primary goals; penalties ( $\mathrm{p}_{\mathrm{te}}$ and $\mathrm{p}_{\mathrm{ta}}$ ) accrue for violating the goal of energy generation and the goal of preservation of the recession agriculture livelihood, respectively. The resulting objective function (Eq. 4.1) is:

$$
\min \sum_{t=1}^{n}\left[\propto_{e} p_{t e}\left(R_{t}\right)+\propto_{a} p_{t a}\left(R_{t}\right)\right]
$$

where $\propto_{a}$ and $\propto_{e}$ are the weights for the agriculture and energy penalties, respectively. The monthly penalties $\left(p_{t a}\right.$ and $\left.p_{t e}\right)$ in equation 4.1 are unitless values that are assigned for each monthly time series value. Solutions are determined for the following five weighting combinations: equal weighting $\left(\propto_{e}=\propto_{a}=1\right)$, called PenEq; double energy penalty $\left(\propto_{e}=2\right.$, $\left.\propto_{a}=1\right)$, called $2 \mathrm{xEn}$; energy penalty only $\left(\propto_{e}=2, \propto_{a}=0\right)$, referred to as OnlyEn; double agriculture penalty $\left(\propto_{e}=1, \propto_{a}=2\right)$ called $2 \mathrm{xAg}$; and the only agriculture penalty $\left(\propto_{e}=0, \propto_{a}=2\right)$, known as OnlyAg.

The energy generation target is a function of the sum of the NG releases $\left(R_{t}\right)$ and the flow volume in the receiving Theun River $\left(Q V_{N T}\right)$, representing the energy generation potential at the downstream station THXP (Fig. 1.1). Flows in the Theun River, as described in Chapter 2, are taken as a time series that does not change with the optimization model. A combined downstream flow $(Q)$ of $200 \mathrm{~m}^{3} \mathrm{~s}^{-1}$ or $518 \mathrm{Mm}^{3} \mathrm{mo}^{-1}$ is the smallest release without penalty, which corresponds to a monthly energy target $\left(E_{t}\right)$ of about $300 \mathrm{GWh} \cdot \mathrm{mo}^{-1}$, where $\mathrm{E}_{\mathrm{t}}$ is defined as:

$$
\begin{aligned}
& Q=R_{t}+Q V_{N T} \\
& E_{t}=\rho g h(Q-2.6) \varepsilon \times 30.4 \times 24
\end{aligned}
$$

and $\rho$ is the density of water $\left(10^{3} \mathrm{~kg} \cdot \mathrm{m}^{3}\right)$, g is the gravitational constant $9.8 \mathrm{~m} \cdot \mathrm{s}^{-2}, h$ is the hydraulic head at the downstream station $(\mathrm{m}), \varepsilon$ is the plant efficiency, assumed to be $95 \%$, and the constants $30.4 \mathrm{~d}$ and $24 \mathrm{~h}$ convert the units from months to hour. For NG, $h$ 
is held constant at $225.3 \mathrm{~m}$, which is the difference between the THXP dam inlet (400 m) and the tailwater elevation $(174.7 \mathrm{~m})$. The elevation at normal full supply level is $400 \mathrm{~m}$, but can actually vary by $7 \mathrm{~m}$, which is up to $3.1 \%$ of the constant head assumed in this study (THPC 2011b). This error is negligible compared to the larger inaccuracies in this study, such as the storage simulated by the transition equation, which has an RMSE of $7 \%$ (Eq. 4.9). As shown in equation 4.3, a constant station use of $2.6 \mathrm{Mm}^{3} \cdot \mathrm{mo}^{-1}$, equivalent to $1 \mathrm{~m}^{3} \mathrm{~s}^{-1}$, assumed for power generation at the station, is subtracted from the releases prior to calculating the energy production. Flows $(Q)$ greater than the turbine capacity of $220 \mathrm{~m}^{3} \mathrm{~s}^{-1}$ also incur penalties.

Penalties for shoreline agriculture $\left(p_{t a}\right)$ are incurred when the water level $(W L)$ in the NG Reservoir exceeds the monthly maximum water level goal $(G)$. The maximum monthly water level goal is $425 \mathrm{~m}$ during the growing season (April-August), and during the rest of the year it is $455 \mathrm{~m}$, the maximum water level in the reservoir. Monthly penalties are assigned based on the Exceedence, Ex (Eq. 4.4). A penalty is also incurred for falling below a monthly $(m)$ minimum WL, minWL, that is confidential and set by the hydropower company. During August, the minimum WL is $426.2 \mathrm{~m}$. Penalties are also assigned based on falling below (TL) the minWL (Eq. 4.5). The total penalty is assigned based on the deficit, $D$ (Eq. 4.6):

$$
\begin{aligned}
& E x_{m}=\operatorname{Max}\left(0, \mathrm{WL}_{m}-\mathrm{G}_{m}\right) \\
& T L_{m}=\operatorname{Max}\left(0, \min \mathrm{WL}_{m}-\mathrm{WL}_{m}\right) \\
& D_{m}=E x_{m}+T L_{m}
\end{aligned}
$$

Because of the competing WL goal for agriculture, there is necessarily a penalty incurred each August, which will be minimized when the WL is between $425 \mathrm{~m}$ and $426.2 \mathrm{~m}$. 
Therefore, when considering the metric for shoreline agriculture performance, only the penalties incurred from April-July are considered. The penalty developed for this study is linearly interpolated from the values shown in Table 4.1.

Table 4.1. Energy produced and corresponding penalties $\left(p_{t e}\right)$ and water level deficit $(D)$ and corresponding penalties $\left(p_{t a}\right)$. Penalties are linearly interpolated for values between those indicated below.

\begin{tabular}{lrrrrrrrr}
\hline Energy & & & & & & & & \\
$\left(\mathrm{GWh} \bullet \mathrm{mo}^{-1}\right)$ & 0 & 300 & 340 & 1000 & & & & \\
Penalty $\left(\mathrm{p}_{\mathrm{te}}\right)$ & 50 & 0 & 0 & 30 & & & \\
\hline$D(\mathrm{~m})$ & 0 & 5 & 10 & 20 & 30 & 35 & 45 & 50 \\
Penalty ( $\left.\mathrm{p}_{\mathrm{ta}}\right)$ & 0 & 5 & 15 & 20 & 25 & 30 & 35 & 50 \\
\hline
\end{tabular}

A variety of constraints must be satisfied to determine feasible solutions to equation 4.1.

Both $R_{G}$ and the reservoir storage, $S_{t}\left(\mathrm{Mm}^{3}\right)$ must remain within the feasible ranges:

$$
0 \leq Q<41,693 ; 0 \leq S<2550
$$

In addition, the optimization model requires a transition equation to predict changes in reservoir storage over time. A generic equation for reservoir storage is shown in Eq. 4.8, with respect to inflow $(Q)$, rainfall $(P)$, evaporation $(E T)$, leakage and seepage $(L)$, and releases:

$$
\mathrm{S}_{\mathrm{t}+1}=\mathrm{S}_{\mathrm{t}}+\mathrm{Q}_{\mathrm{t}}+\mathrm{P}_{\mathrm{t}}-\mathrm{ET}_{\mathrm{t}}-\mathrm{L}_{\mathrm{t}}-\mathrm{R}_{\mathrm{t}}
$$

Leakage and seepage, which are typically difficult to measure, are unknown for the NG reservoir, especially because of karst geology near the dam outlet. A simplified equation can be obtained by using linear regression to relate the storage to the inflow and releases. For the NG Reservoir, a simplified transition equation can be represented in a constraint of the following form:

$$
\begin{aligned}
& \mathrm{S}_{\mathrm{t}+1}=\mathrm{S}_{\mathrm{t}}+0.96 * \mathrm{Q}_{\mathrm{t}+1}-0.98 * \mathrm{R}_{\mathrm{t}+1} \\
& \mathrm{~S}_{0}=1945
\end{aligned}
$$


The specified initial storage $\left(\mathrm{S}_{\mathrm{o}}\right)$ corresponds to a NG reservoir elevation of $450 \mathrm{~m}$. Regression of the transition equation (Eq. 4.9a) to the storage simulated in Chapter 2 yields a root mean squared error (RMSE) of $177 \mathrm{Mm}^{3}$, which is $7 \%$ of the maximum storage. To equivalently compare the results of the optimization model to the baseline, Eq. 4.9 and the simulated releases from Chapter 2 were used to compute the baseline storage, elevation, and energy. The RMSE of the simulation (Ch. 2) and regression (Eq. 4.9) values for elevation and energy are respectively $5 \%$ and $7 \%$ of the maximum values.

Optimal release sequences are determined for the five penalty weight combinations and compared to the baseline releases, which are considered to be the releases simulated by the reservoir operation model described in Chapter 2. The baseline releases were produced based on operational logic appropriate for how the reservoir is currently operated. The single goal of the current operation regime is to release and store water for optimal energy production at the downstream power station THXP (Fig. 1.1). To compare equivalent entities, the baseline water level and energy were computed from the baseline releases and flows at the Theun River using equations 4.2, 4.3, and 4.9. The baseline releases were used as the initial guess for the optimization. In addition, the modeled releases based on agricultural operational rules A1 and A2 from Chapter 2 were tested as initial release values, to see whether they produce better results for recession agriculture than the baseline initialization.

\subsection{Results}

The water level and reservoir releases for baseline case in Chapter 2 and optimized values for PenEq, with equally weighted penalties, are shown in Figure 4.1. On average, the optimization increased the energy generated downstream at the reservoir 
release tunnels by $3.2 \%$ relative to the base case. The baseline and optimized median annual water levels are shown in Figure 4.2. The optimal water level stays below $425 \mathrm{~m}$ during the growing season $15 \%$ longer than does the baseline water level, and yet is 2.4 $m$ higher than the baseline water level in November and December (after the end of the wet season). The maximum differences between the baseline and PenEq-optimized water levels occur during the growing season, with June and July PenEq median water levels respectively $5.3 \mathrm{~m}$ and $5.2 \mathrm{~m}$ lower than the baseline. For the baseline releases, the energy and agriculture penalties are respectively 2,766 and 1,196 (unitless). The penalties for PenEq are respectively 2,153 and 567 , which is a net $31 \%$ decrease in total penalties. Most of the agriculture penalties occur in July and in August, because the target level for gardening was not met. PenEq's gains in arable shoreline are more significant than its improvement in energy because the baseline simulation (Ch. 2) only targeted hydropower generation, and so in the PenEq optimization, there is more room for improvement for the gardening goal.
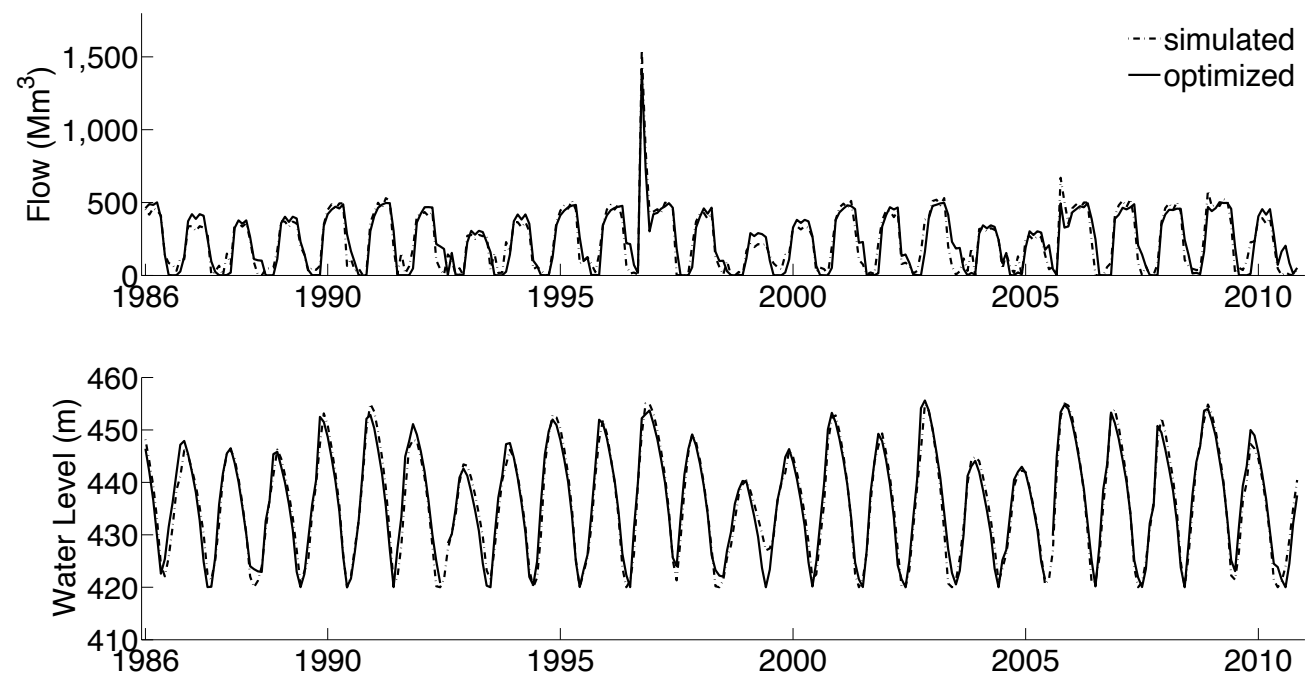

Fig. 4.1. The baseline and PenEq-optimized values for release $\left(\mathrm{Mm}^{3}\right)$ and water level (m) in the Nam Gnouang Reservoir. 


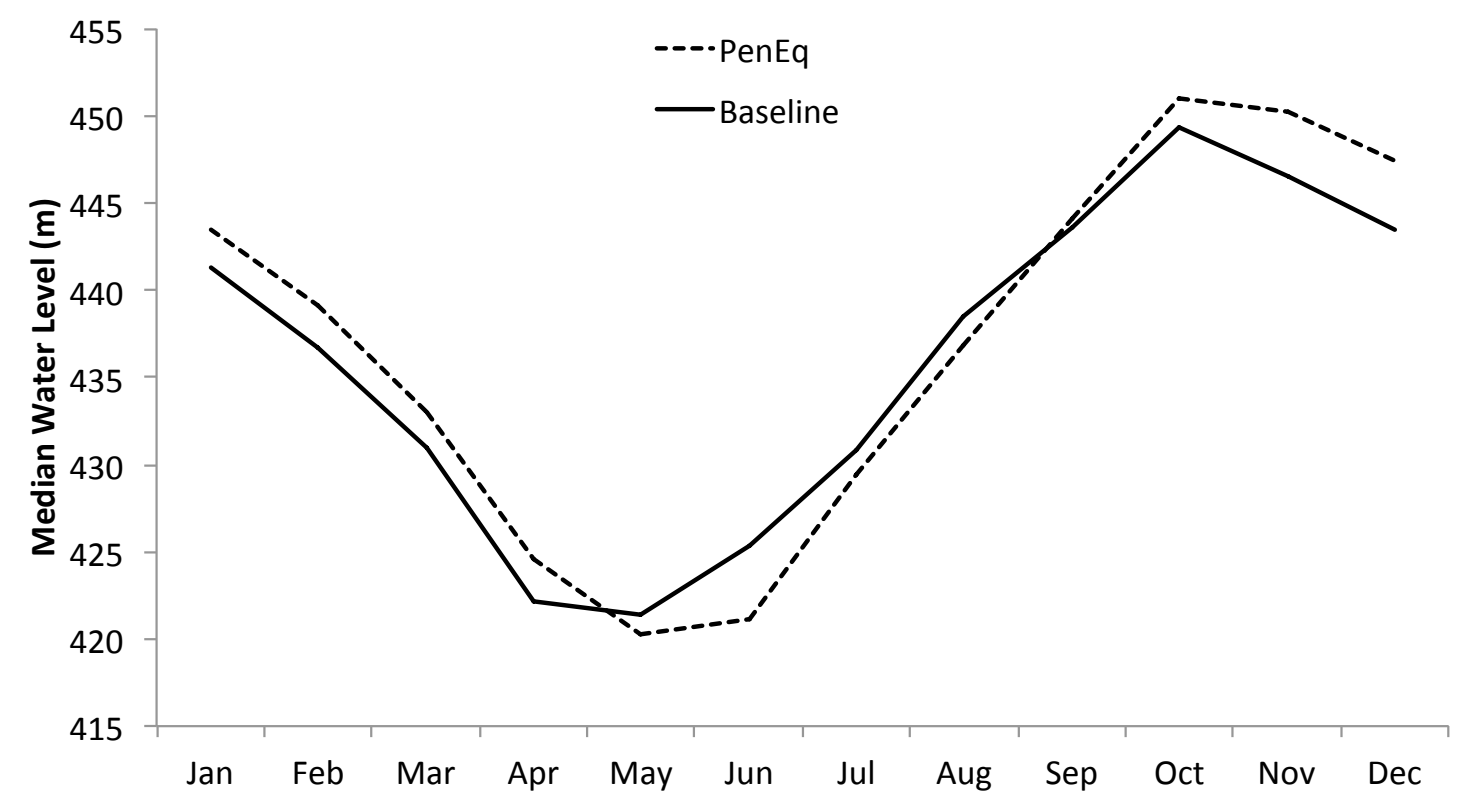

Fig. 4.2. The PenEq-optimized and baseline median water level (m) in the Nam Gnouang Reservoir.

Figure 4.3 plots the mean energy, median water level, and percent of months exposed during the growing season for the baseline, 2xAg, and OnlyAg, with all axes scaled relative to the baseline. The energy optimized for $2 \mathrm{xAg}$ increased by $2.1 \%$ compared to the baseline, while using exclusively the agriculture penalty, OnlyAg, the energy decreased by $9.4 \%$. With the shoreline agriculture prioritized for the $2 \mathrm{xAg}$ optimization, the penalties for energy and agriculture were 2,307 and 459, respectively, a net $21 \%$ decrease compared to the baseline. Figure 4.4 compares the frequency distribution of the water level for the baseline, 2xAg, and OnlyAg. With the OnlyAg optimization, the water level dropped significantly, by a mean of $3.1 \mathrm{~m}$, compared to the baseline. 


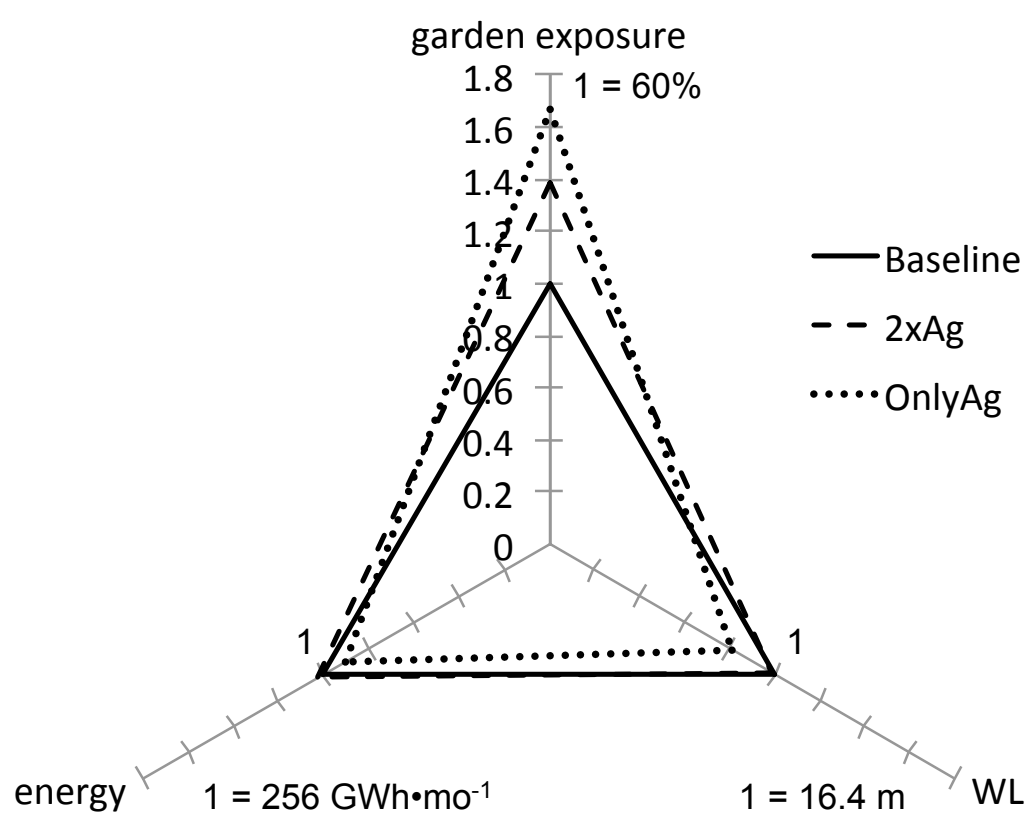

Fig. 4.3. The average energy, median water level above the minimum operating reservoir water level (WL- $420 \mathrm{~m}$ ), and percent garden exposure during the growing season for the baseline, 2xAg and OnlyAg models are shown as a fraction of the baseline metrics. The values of the baseline metrics are shown for reference, as a scale for the axes.
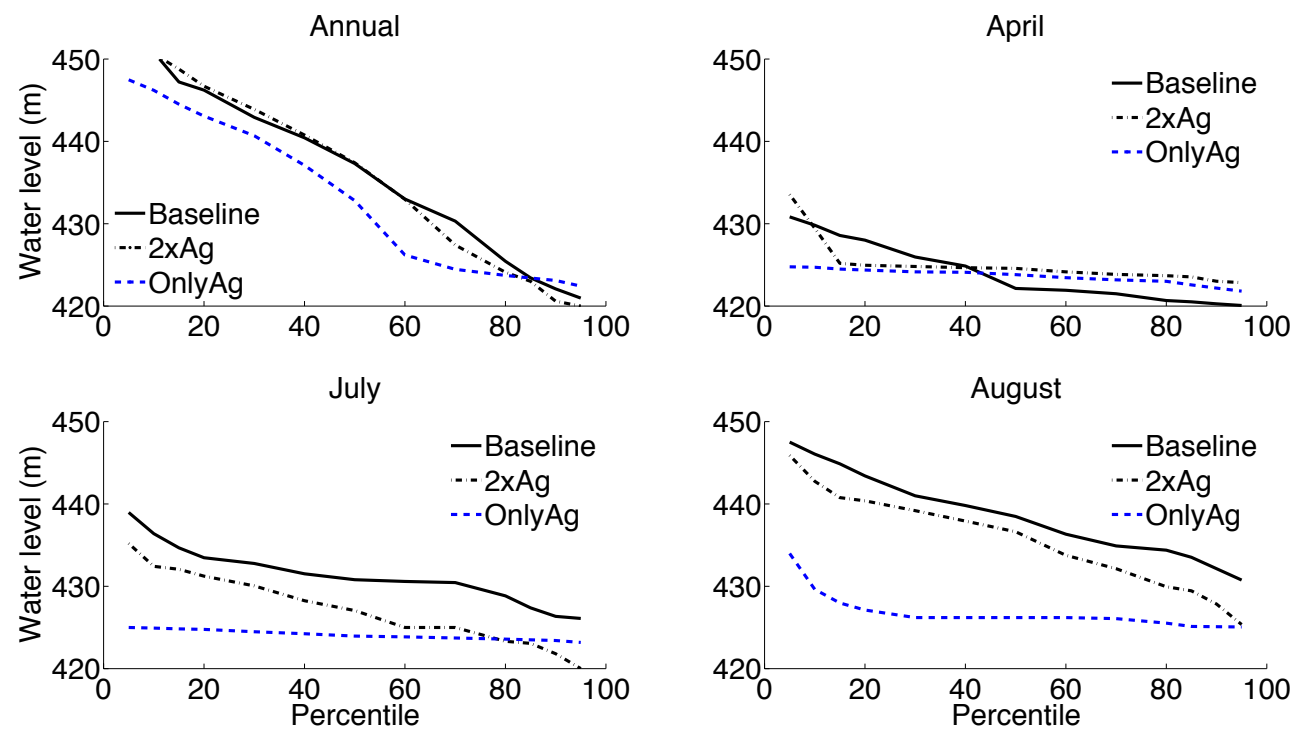

Fig. 4.4. The percent distribution of the water level for the baseline, $2 x A g$, and OnlyAg. 
With the energy penalty doubled ( $2 x E n)$, the average energy increased by $3.8 \%$ compared to the baseline; with only the energy penalty (OnlyEn), the increase is nearly the same, $3.9 \%$. Figure 4.5 shows the energy percent distribution annually, May and June, the months that gained the most energy, and November, the month that lost the most energy for the Baseline, 2xEn, and OnlyEn cases. For OnlyEn, the water level stays below $425 \mathrm{~m}$, the maximum target level for agriculture, just $26 \%$ of growing season months, effectively eliminating recession agriculture.
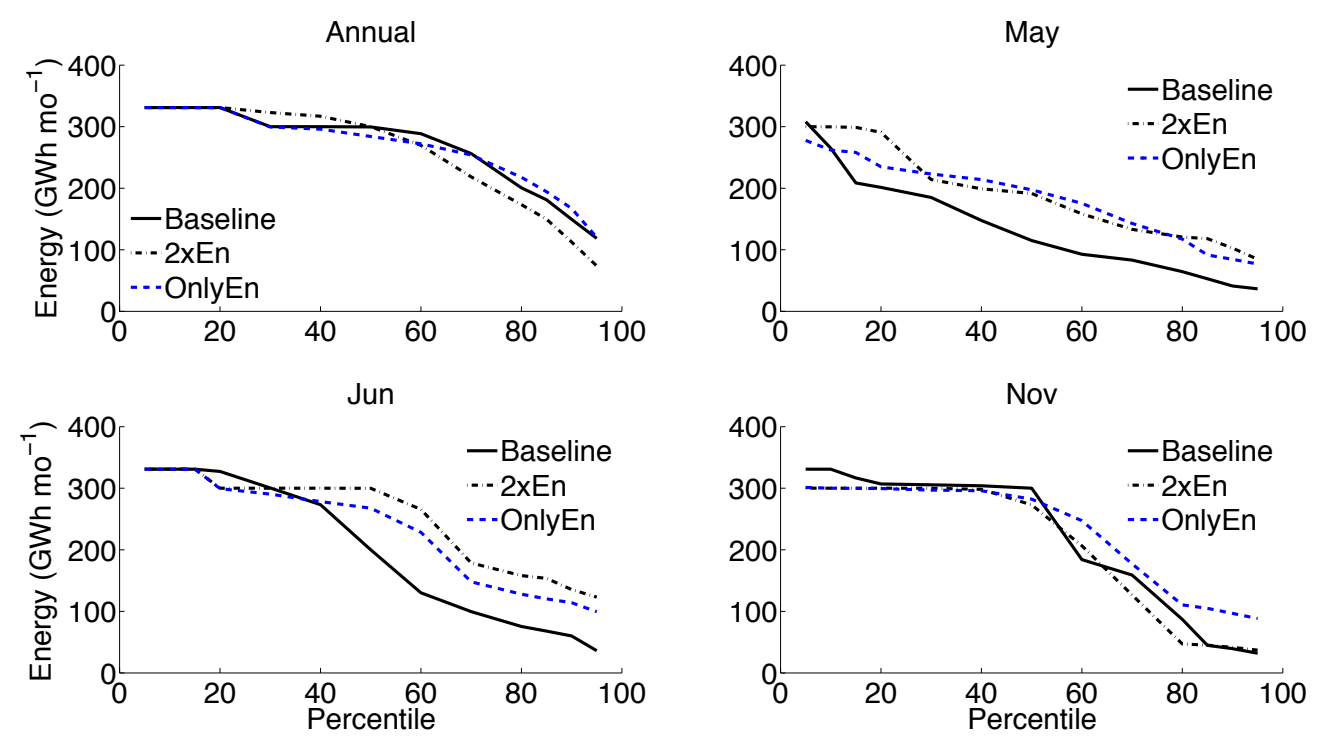

Fig. 4.5. The percent distribution of the energy for the baseline, 2xEn, and OnlyEn.

Figure 4.6 shows the results as an approximate Pareto Frontier for the optimization in terms of energy generated $\left(\mathrm{GWh} \cdot \mathrm{mo}^{-1}\right)$ and percent exposure of gardens. As shown, three of five optimization models (2xEn, PenEq, and 2xAg) performed better than the baseline for both metrics. $2 \mathrm{xAg}$ performed better for both metrics than the simulated measures for agriculture A1 and A2 (Chapter 2). 


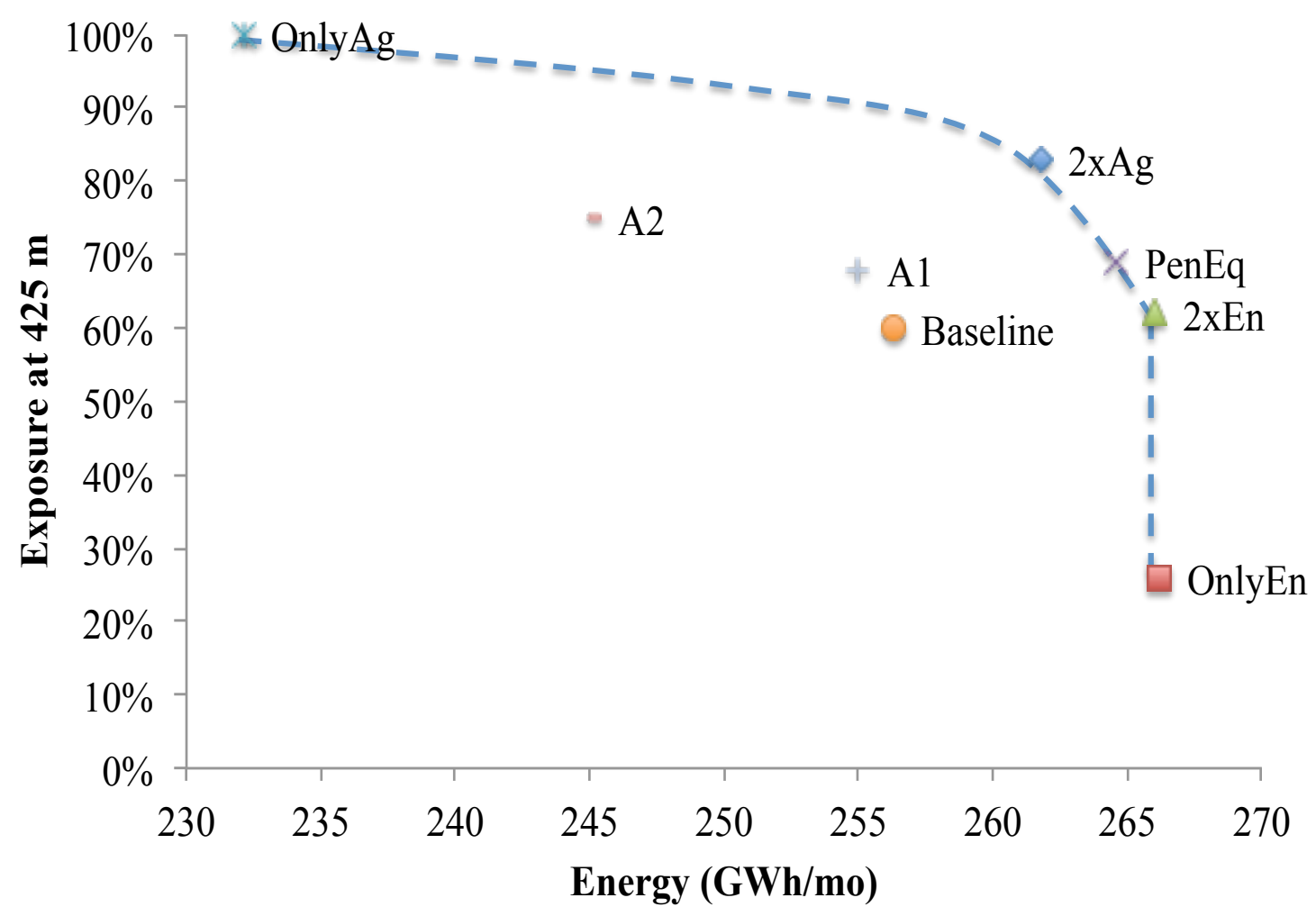

Fig. 4.6. Results for all simulations and optimizations in terms of percent garden exposure during the growing season (Apr-Jul) and mean energy generation $\left(\mathrm{GWh} \bullet \mathrm{mo}^{-1}\right)$. The Pareto Optimal Frontier is sketched.

The optimization was also initialized with releases simulated from the agricultural measures A1 and A2, as described in Chapter 2. When doing so, the OnlyAg optimization exposed gardens a lesser and equal proportion of growing season months for A1 and A2, respectively, compared with OnlyAg initialized with the baseline releases (Fig. 4.7). While initializing with the baseline and A2 yielded $100 \%$ exposure, initializing with A1 hardly improved the exposure duration, pointing to the dependency of the optimization on the initialization. 


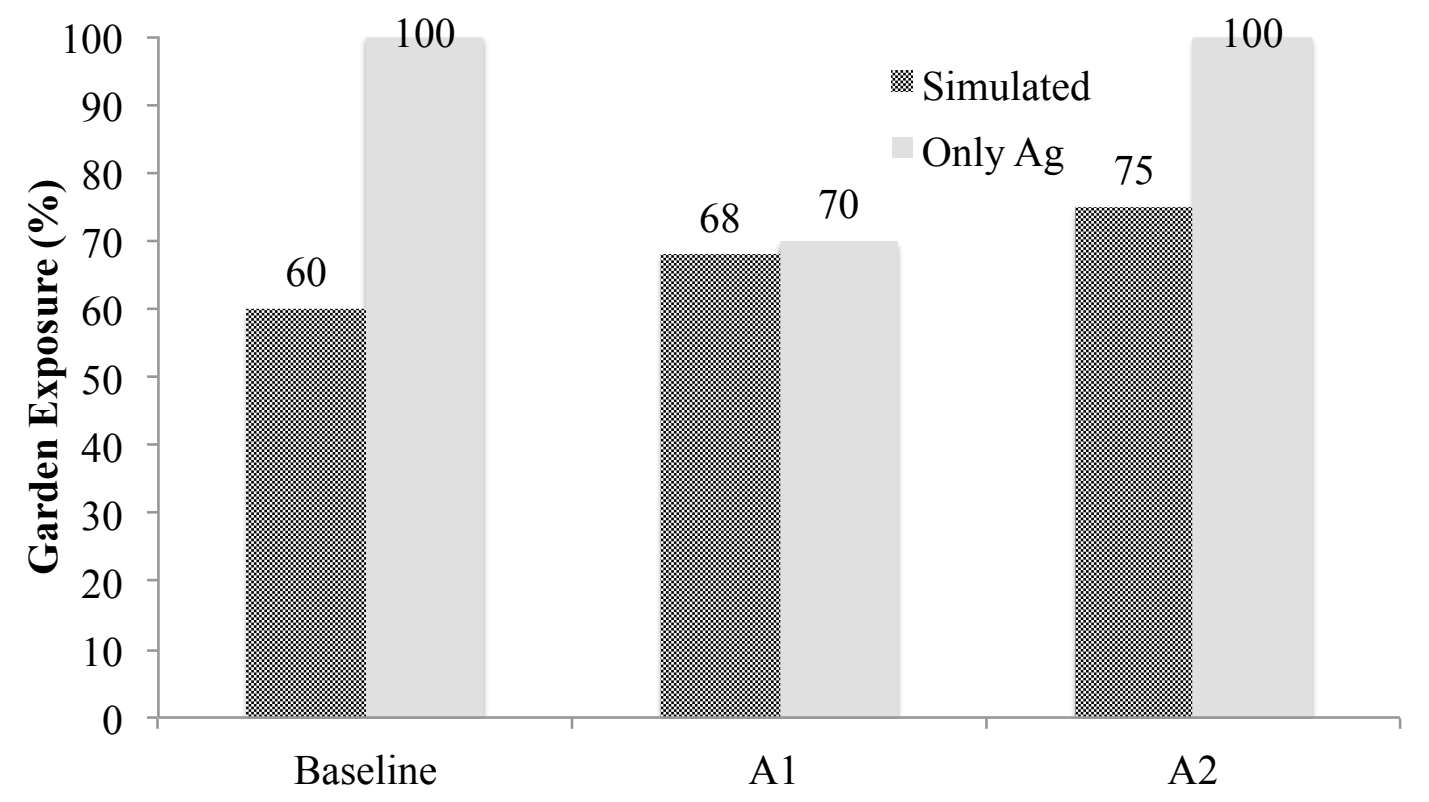

Fig. 4.7. The percent garden exposure during the growing season for simulation models and for optimized OnlyAg models, given initializations with the Baseline, A1, and A2 reservoir releases modeled in Chapter 2.

\subsection{Discussion}

The optimization model described here optimizes dam releases in order to analyze reservoir operation goals and the tradeoffs between energy generation and recession agriculture. The optimization is dependent on the simulation model for developing a correlation between the inflow, release, and storage. In addition, the optimization requires realistic initial release values, because it is a gradient-based search tool that may find only local minima. While the optimization model is not a substitute for simulation, the optimization can be used to improve upon the releases of the existing operation regime. Further, the optimal releases can be used to develop rule curves, which in turn can be tested through simulation. Notably, this optimization relies on perfect foresight; hence, simulation is required to develop operable procedures that can adapt as conditions change. 
Optimization with the OnlyAg weightings exposed the gardens better when simulated with A1 or A2 measures, which were designed to draw down the reservoir level during the growing season. This promising result suggests that the optimization may allow dam managers to improve their operation, if improving livelihoods through shoreline gardening is a priority. When initializing the releases with the simulated results from A1 (but not A2), the optimization exposed gardens a fewer percentage of months during the growing season, and produced 9.7\% more energy, compared to OnlyAg that was initialized with the baseline releases. The increase in energy may be due to the uneven outflow simulated in the agricultural measures, which spikes at the start of the growing season to draw down the water level. Again, this result suggests that the optimization model may help plant managers develop better operation policies to allow a more even release and prevent storage losses.

As shown in Figure 4.6, the approximate Pareto Optimal Frontier for energy generation and recession agriculture is clearly beyond the simulation runs (baseline, A1, and A2). As can be seen, the optimization lessened the reduction in energy due to instituting an operation measure to preserve shoreline gardening. Still, Figure 4.6 demonstrates that the tradeoffs between energy generation and shoreline agriculture are inversely proportional. The energy tradeoffs to meet the recession agricultural goal (e.g. OnlyAg) may be too large for dam managers to justify, as the dam must meet energy demands to fulfill its original purpose. The measure tested here applies a penalty for submerging any of the gardens. Less stringent penalty functions could be tested, to evaluate the possibilities for some gardens to remain exposed while flooding others. 
This study demonstrated an optimization tool as a means of integrating multiple goals into reservoir operation, to allow the reservoir to benefit a broader group, and to offset the costs imposed on local residents who may be least able to recover from its impacts. Future studies could link the penalties to actual economic costs. Integrating economic costs is a complex task since the value of fish species and livelihoods cannot be equated with monetary value. This model could also be developed into a portable optimization tool for handy community decision-making and for quickly evaluating multiple variables.

\subsection{Works Cited}

Bellman, R. (2003). Dynamic Programming. Princeton University Press, Princeton, NJ.

Broad, D. R., Maier, H. R., and Dandy, G. C. (2010). "Optimal Operation of Complex Water Distribution Systems Using Metamodels." Journal of Water Resources Planning and Management, 136(4), 433.

Byrd, R. H., Gilbert, J. C., and Nocedal, J. (2000). "A Trust Region Method Based on Interior Point Techniques for Nonlinear Programming." Mathematical Programming, 89(1), 149-185.

Chang, F. J., Chen, Li, and Chang, L. C. (2005). "Optimizing the reservoir operating rule curves by genetic algorithms." Hydrological Processes, 19(11), 2277-2289.

Chen, L, McPhee, J., and Yeh, W. (2007). "A diversified multiobjective GA for optimizing reservoir rule curves." Advances in Water Resources, 30(5), 1082-1093.

Faber, B. A., and Harou, J. J. (2007). "Multi-objective Optimization of Reservoir Systems using HEC-ResPRM." ASCE World Environmental and Water Resources Congress 2007: Restoring Our Natural Habitat, 1-14.

Ittersum, M. K. van, Roetter, R. P., Keulen, H. Van, Ridder, N. de, Hoanh, C. T., Laborte, A. G., Aggarwal, P. K., Ismail, A. B., and Tawang, A. (2004). "A systems network (SysNet) approach for interactively evaluating strategic land use options at sub-national scale in South and South-east Asia." Land Use Policy, 21, 101-113. 
Kracman, D. R., Mckinney, D. C., Watkins, D. W. J., and Lasdon, L. S. (2006). "Stochastic Optimization of the Highland Lakes System." Journal of Water Resources Planning and Management, 132(2), 62-70.

Labadie, J. W. (2003). Generalized dynamic programming package: CSUDP. Documentation and User Guide Version 2.44.91.

Labadie, J. W. (2004). "Optimal Operation of Multireservoir Systems : State-of-the-Art Review." Journal of Water Resources Planning and Management, 130(2), 93-112.

Lund, J. R., and Ferreira, I. (1996). "Operating Rule Optimization for Missouri River Reservoir System." Journal of Water Resources Planning and Management, 122(4), $287-295$.

MATLAB. (2012). "Version 8.0 R2012b." The Mathworks Inc., Natick, Massachusetts.

Mays, L. (2010). Water Resources Engineering, 2nd Ed. John Wiley \& Sons, Inc.

Rani, D., and Moreira, M. M. (2010). "Simulation-Optimization Modeling: A Survey and Potential Application in Reservoir Systems Operation." Water Resources Management, 24(6), 1107-1138.

Simonovic, S. (2000). “One View of the Future.” Water International, 25(1), 76-88.

THPC (Theun Hinboun Power Company). (2011). Theun Hinboun Expansion Project: Technical Feasibility Study \& Tender Documents. Document shared from THPC president for the purspose of this research. 


\section{Chapter 5: Conclusions and Discussion}

\section{Summary}

This dissertation presents the novel integration of water resources and livelihoods, and presents engineering tools to enable integration sought by policy makers. This work is important as it explored the technical interfaces of reservoir operation and farm-based livelihoods, and discovered potential benefit-sharing mechanisms and limiting factors to integration. It is timely to find connections between water reservoirs and livelihoods, because of the rapid growth in the dam sector on the global scale and the need to develop more resilient water resources infrastructure. The case study of this dissertation, the Nam Gnouang (NG) Reservoir in Laos, is pertinent due to burgeoning development in the Mekong Basin, and the problems faced by marginalized farmers in the wake of large dams in Asia. The tools presented here are transferrable, and with data could be adapted for simulating and optimizing other hydropower and food producing systems.

Chapter 2 of this dissertation explored the possibilities of operating the NG dam for livelihoods through simulation. To accommodate farmers who grow vegetables on the shorelines of the NG Reservoir, this study coded an operation measure to lower the reservoir water level below the elevation of the garden plots during the growing season. This study also considered the interactions between dam operation and constructed wetlands anticipated on tributary channels into the reservoir, and the hydrology of these micro dams to consider any benefit the infrastructure may have on livelihoods. The simulation study found that the operation measure for recession agriculture reduced the hydropower generation during the growing season, a critical time for power generation because the climate is dry, which reduces hydraulic head and storage. This study found 
that, as expected, the constructed wetlands would not impact the reservoir operation, and that the wetlands may provide a benefit to fishermen in the NG resettlement community as the wetlands closest to the village would be full ponds year-round, potentially enhancing fishing livelihoods. Additionally, the hydrological study found that even during dry years there would be storage adequate in the ponds closest to the village for irrigation of small vegetable gardens.

Chapter 3 analyzed farming and fishing livelihoods in the vicinity of the NG Reservoir to identify productive and sustainable allocation of existing livelihoods and to determine the economic potential of irrigated vegetable farming as a pilot program. This study modeled the farm livelihoods of the community and optimized resource allocation according to the priorities, resources, and limitations of the case study. The optimization found that limiting shoreline farming had little impact on the overall net gain of the community. Villagers who prioritize food security, including growing their own vegetables, will need to accept lower net gains than those who choose to maximize income. This study also investigated the sustainability of the livelihoods allocation in the context of the lacustrine fishery, which is predicted to be highly variable. The optimal allocation specialized heavily in fishing and neglected gardening and other activities, suggesting that special planning and attention to diversification away from fishing is needed to ensure sustainable livelihoods. The pilot program of the irrigated gardens complemented the other livelihood activities in terms of seasonal timing and introduced flexibility in livelihoods, which increased the net gain considerably. Further, irrigated gardening has the potential to reduce the need for the shoreline agriculture, which Chapter 2 showed might compromise hydropower. A computational experiment 
demonstrated that sharing resources is the most important factor for increasing the overall net gain.

Chapter 4 of this dissertation developed an optimization model that simultaneously considers the energy generation, which is of chief importance to plant managers, and shoreline agriculture, which is vital for food security in the absence of irrigated gardens. Using the interior-point algorithm for nonlinear optimization, the model finds releases from the dam in order to minimize penalties when missing energy generation targets and flooding shoreline garden plots. Using equally weighted penalties for energy and agriculture, the mean energy generation and the exposure time period both increased, relative to the baseline simulation. This demonstrated that even if recession agriculture were to become a goal of reservoir operation, the energy generation could still increase. Even with this optimization, however, some gardens would be submerged for part of the growing season. When energy is ignored, all gardens are exposed during the growing season, but the cost to energy production was higher than would be acceptable to hydropower plant managers.

When considering the three models and the goals explored in this dissertation, a few conclusions stand out in reference to the study hypotheses. This dissertation hypothesized (1) that the livelihoods fishing and recession agriculture could be supported by dam operation, and further, that re-operating the dam for recession agriculture would not detract from energy generation. The first lesson from the dissertation was that for the NG Reservoir, operating the reservoir for energy generation and recession agriculture is feasible, as demonstrated by the simulation and the optimization models, as described in Chapters 2 and 4, respectively. Furthermore, this simulation study (Chapter 2) found that, 
contrary to the second part of hypothesis 1 , the recession agriculture measure did reduce energy generation during the dry growing season. However, by using the optimization model (Chapter 4), both energy production and recession agriculture protection could be improved. When considering only the shoreline agriculture, both the simulation model (Chapter 2) and the optimization model (Chapter 4) demonstrated that the energy generation is reduced considerably. The overall result of hypothesis 1 was that the reservoir can be operated for recession agriculture, but only for the higher elevation gardens or only for part of the growing season for all shoreline gardens. Hypothesis 2, that the optimization model for livelihoods (Chapter 3) could allocate resources in an economically productive and sustainable way, was found to be correct, and the results, as discussed above and shown in Chapter 3, demonstrated how resources could be maximized for different objectives. By linking the simulation of the reservoir (Chapter 2), the optimization of livelihoods that intersect with the reservoir (Chapter 3), and linking the key results from these two studies in an optimization model (Chapter 4), this dissertation demonstrates hypothesis 3 , that developing these tools provides an effective methodology for IWRM. This last finding is significant because this dissertation is the first known study to include livelihoods in water resources management. While the value of doing so has been noted and proposed, the methods and tools to link goals for traditional water resources and agricultural and fishing livelihoods had not previously been demonstrated. In particular, the optimization tool in Chapter 4 added value to the simulation study in Chapter 2, by proving that adding a livelihoods objective to dam operation would not necessarily reduce energy generation, given improved release policies. 


\subsection{Outreach}

The tools presented in this dissertation are highly adaptable to other livelihood objectives for the NG dam and other contexts for improving reservoir operation for livelihoods. The simulation model was performed in ResSim, a freely-available software, which is widely used abroad. Several training sessions for ResSim have been given in Laos, the case study for this dissertation, and interest in this software is high. As a tangible demonstration of the interest, a series of workshops in ResSim were planned to a detailed level, but were canceled due to delays in administrative processes. The livelihoods model was adapted into a game that was demonstrated with leaders from the resettlement village Keosenkham. As described in Appendix D, the farmers and fishers of the village used this game activity as a platform to discuss the allocation of their time and resources for several hours and took notes about the results. This demonstrated that the livelihoods optimization model could be simplified for a collaborative planning process that farmers and fishers found interesting and useful. The optimization model described in Chapter 4 was coded in MATLAB so it could be adapted for use in Excel, which most water resources professionals even in low-income countries can access.

\subsection{Future Work}

This dissertation could be extended in a variety of other ways. Future work could extract improved release policies from the optimization results; these release policies could be implemented by dam operators and used as the basis for future simulation studies and dam operators. A study in Laos is already investigating the potential to leverage the planned wetlands for irrigated gardening, through community surveys, workshops, and ground geographical reconnaissance. Recession agriculture in reservoirs could be investigated on multiple reservoir sites of varying steepness and dam heights, to 
identify key factors for success and generalize the recommendations for operation measures. Future work integrating livelihoods with water reservoir operation could consider activities that were not practiced in the community, such as integrated shrimp and rice farming on the reservoir shorelines, which may be of use in a reservoir with a shallower grade in a lower elevation and tropical climate, for example in Vietnam. Another useful extension of the optimization in this dissertation would be economic study of resource allocation that quantifies in equivalent units the values of livelihoods, nature, and hydropower. In addition, the resource allocation model in Chapter 3 could be extended to consider uncertainty, especially regarding access to food security for the vulnerable resettlement population. Other approaches to modify the harmful impacts of dams should be developed. To improve the water quality so that the dam impacts fisheries less, for example, biochemical studies could investigate the nascent practice of adding dissolved oxygen via hydrogen peroxide to the impounded water. 


\section{Appendix A: Time series used in Chapter 2}

Monthly

THPP 1961-93; Jan98- Jul11

Daily (* represents frequent gaps in the time series)

\begin{tabular}{ll} 
Station & Available \\
\hline Kham Keut & 1985-86; 90, 92-93 \\
Ban Signo & 1986-2006 \\
Ban Sopphon* & Jun01-Sep02; Apr03-Jun07 \\
THPP & Aug02-Dec10 \\
CS04* & Apr07-Oct11 \\
CS05 & Apr07-Nov11 \\
CS03 & Aug07-Jun10 \\
\hline
\end{tabular}

\section{Appendix B. Survey of livelihoods data in Keosengkham}

July 2012

1. Travel time for Cost-Distance Zones (used with maps of zones)

\begin{tabular}{llll} 
Zone & Walk & Moto & \\
\hline 1 & & \\
\hline 2 & & \\
\hline 3 & & \\
\hline 4 & & \\
\hline 5 & & \\
\hline 6 & & \\
\hline 8 & & \\
\hline
\end{tabular}

2. Costs, revenues, and land area constraints for livelihood activities.

\begin{tabular}{lccc}
\hline & Cost $\left(10^{3} \mathrm{LAK} \cdot \mathrm{kg}^{-1}\right)$ & Revenue $\left(10^{3} \mathrm{LAK} \cdot \mathrm{kg}^{-1}\right)$ & Land limit (ha) \\
\hline Upland Rice, etc. $^{f}$ & $\mathrm{LAK} \cdot \mathrm{y}^{-1}$ & & \\
$\begin{array}{l}\text { Riverbank } \\
\text { Vegetables }\end{array}$ & & & \\
$\begin{array}{l}\text { Livestock } \\
\text { Tree products }\end{array}$ & /animal & /animal & \\
Fishing & $\mathrm{LAK} \cdot \mathrm{d}^{-1}$ & dry $/$ wet & N/A \\
\hline
\end{tabular}


$f$ May include other hillside crops (corn, watermelon, garlic)

$B$ Includes eggplant, green vegetables, and chili.

$\dagger$ Includes fruit, NFTPs (e.g. cardamom), and timber, as listed in RAP (THPC and NORPLAN 2008).

\section{Upland Rice}

-Do you have enough land to cultivate upland rice? How much?

-In your opinion, what is the limiting factor in rice production? (land, labor, costs of seeds, time)

Profit model per household (hh): $\quad$ Profit $=-\frac{h a}{h h} \times-\frac{\text { yield }(\mathrm{kg})}{h a} \times-\frac{K I P}{k g}$

Cost model:

$$
\text { Costs }=-\frac{h a}{h h} \times — \text { inputs }(K I P)
$$

\section{Livestock}

-Where are you livestock like cattle and water buffalo? How do you get there? Is it working well?

-Do you have enough space for your chicken and pigs?

-What are the limitations for scaling up?

-Would you consider participating in a pilot program to raise high-quality livestock to sell in Thailand or Vietnam?

\section{Gardens}

-How are the garden plots near your house? What are the limitations?

-Have you already started riverbank gardening like as before resettling in KSK?

If not, would you if they were not flooded?

If so, would you look for new areas for your gardens? If so, how would you choose suitable spots?

-Do you water your garden? If so, how? How far can you carry the water?

-How near should your garden be to the water's edge so that it is not too difficult to bring water to your plants?

-If not intending to continue with riverbank gardening, why not?

Possible pilot activities

-Could you grow fruit trees to dry and sell the dry fruit?

\section{Fishing}

Please review the following information:

Income $=$ Average monthly income $(\mathrm{AMI})(1,000 \mathrm{Kip} / \mathrm{mo} \bullet \mathrm{hh}) \mathrm{x}$ labor

\begin{tabular}{rrrrrrrrrrrrr}
\hline & Jan & Feb & Mar & Apr & May & Jun & Jul & Aug & Sep & Oct & Nov & Dec \\
\hline AMI & 60 & 53 & 44 & 47 & 48 & 61 & 61 & 79 & 68 & 59 & 70 & 65 \\
\hline
\end{tabular}




\section{Appendix C: Standard labor, revenues, and costs used in}

\section{Chapter 3}

\section{Standard Labor}

Standard labor found from semi-structured interview (see appendix B for survey sheet) in July 2012 by Reis et al.

Table C.1. Standard labor (2 man-days) for upland crops (mostly rice), shoreline gardening, animal livestock, irrigated vegetable gardening, and fishing.

\begin{tabular}{lrrrrrrrrrrrrr}
\hline & Jan & Feb & Mar & Apr & May & Jun & Jul & Aug & Sep & Oct & Nov & Dec & Total \\
\hline Upland & 9.0 & 10.0 & 0.0 & 0.0 & 4.5 & 13.5 & 4.5 & 0.0 & 0.0 & 0.0 & 4.5 & 9.0 & 55.0 \\
& & & & & & & & & & & & & \\
Shoreline & 0 & 0 & 0 & 4 & 2 & 4 & 10 & 10 & 0 & 0 & 0 & 0 & 30 \\
Livestock & 4.7 & 4.7 & 4.7 & 4.7 & 4.7 & 4.7 & 4.7 & 4.7 & 4.7 & 4.7 & 4.7 & 4.7 & 56.4 \\
& & & & & & & & & & & & & \\
Irrigated & 2.7 & 5.3 & 20.0 & 0.0 & 0.0 & 0.0 & 0.0 & 0.0 & 2.0 & 0.0 & 0.0 & 1.3 & 31.3 \\
Fishing & 8.6 & 8.4 & 9.6 & 9.6 & 9.3 & 6.5 & 5.0 & 4.2 & 4.3 & 4.5 & 5.6 & 7.6 & 83.2 \\
\hline
\end{tabular}

$\underline{\text { Fish Costs and Revenues }}$

Monthly standard revenue per labor $=$ Fish catch $(\mathrm{kg} / \mathrm{mo}) *$ avg selling price $(\mathrm{LAK} / \mathrm{kg})$ * $\%$ catch sold / standard labor (2 man-days)

Table C.2. Catch $(\mathrm{kg})$, average selling price $\left(10^{4} \mathrm{LAK} / \mathrm{kg}\right)$, percent of catch sold, average household income ( $\left.10^{4} \mathrm{LAK}\right)$, and standard labor (two man-days).

\begin{tabular}{lrrrrrrrrrrrr}
\hline & \multicolumn{1}{c}{ Jan } & Feb & Mar & Apr & May & Jun & Jul & Aug & Sep & Oct & Nov & Dec \\
\hline Catch & 81 & 79 & 80 & 84 & 74 & 64 & 54 & 56 & 49 & 47 & 62 & 79 \\
Price & 1.27 & 1.28 & 1.27 & 1.28 & 1.32 & 1.29 & 1.31 & 1.29 & 1.30 & 1.26 & 1.27 & 1.27 \\
\% sold & 57.8 & 58.7 & 62.4 & 63.6 & 52.2 & 47.9 & 38.9 & 37.1 & 37.6 & 38.4 & 43.4 & 48.2 \\
Income & 53.5 & 47.1 & 44.5 & 45.9 & 46.2 & 40.4 & 30.7 & 33.3 & 29.0 & 26.7 & 39.8 & 52.3 \\
Labor & 8.6 & 8.4 & 9.6 & 9.6 & 9.3 & 6.5 & 5.0 & 4.2 & 4.3 & 4.5 & 5.6 & 7.6 \\
\hline
\end{tabular}

Upland crops and shoreline vegetables

Revenue and cost data from Joffre (2012) internal IWMI document titled "Mk1_Lao_Upstream_analysis_draft 2". Note KIP used interchangeably with LAK. Values shown for shoreline vegetables (Table A.3) and irrigated vegetables (Table A.4). Standard Revenue $=$ Gross Return * \% riverbank $/$ standard labor $=2,131,150$ LAK/ standard labor Standard Cost: Cost $* \%$ riverbank $/$ standard labor $=99,355 \mathrm{LAK} /$ standard labor 
Riverbank area $=$ area $(\mathrm{ha} / \mathrm{hh}) * \%$ riverbank $=1.4375(\mathrm{ha} / \mathrm{hh})$

Table C.3. Area, production, cost and gross return of the most cultivated crops $(n=108)$ (reprinted: Table 12 in Joffre 2012)

\begin{tabular}{|c|c|c|c|c|c|c|}
\hline $\begin{array}{l}\text { Type of } \\
\text { crops }\end{array}$ & $\%$ of $H H$ & Type of land & $\begin{array}{l}\text { Area } \\
\text { (ha)/HH }\end{array}$ & $\begin{array}{l}\text { Production } \\
(\mathrm{kg} / \mathrm{HH})\end{array}$ & $\begin{array}{l}\text { Cost } \\
\text { ('000 } \\
\text { kip/HH) }\end{array}$ & $\begin{array}{l}\text { Gross } \\
\text { Return } \\
\text { ('000kip } \\
\text { /HH) }\end{array}$ \\
\hline Rice & $99 \%$ & $\begin{array}{l}\text { Upland field } \\
\text { Lowland (4\%) }\end{array}$ & 1.5 & 2,045 & 186 & 3,337 \\
\hline Chili & $42 \%$ & $\begin{array}{l}\text { Riverbank }(75 \%) \\
\text { Garden and homestead } \\
(25 \%)\end{array}$ & 0.77 & 470 & 101 & 2,279 \\
\hline Maize & $31 \%$ & $\begin{array}{l}\text { Riverbank ( } 50 \% \text { );garden } \\
47 \% \text { ) Upland ( } 3 \%)\end{array}$ & 0.8 & $\begin{array}{l}1,900-\text { but large } \\
\text { variation }\end{array}$ & 36 & 402 \\
\hline Cassava & $36 \%$ & $\begin{array}{l}\text { Riverbank (25\%); garden } \\
(70 \%)\end{array}$ & 0.54 & 1,366 & 18 & 296 \\
\hline Vegetables & $13 \%$ & $\begin{array}{l}\text { Riverbank (65\%); } \\
\text { Homestead (21\%); } \\
\text { Garden(14\%) }\end{array}$ & 0.5 & - & 1.7 & 226 \\
\hline
\end{tabular}

Table C.4. Area, production, cost and gross return of the most cultivated crops $(n=53)$ (reprinted: Table 14 in Joffre 2012)

\begin{tabular}{|c|c|c|c|c|c|c|}
\hline $\begin{array}{l}\text { Type of } \\
\text { crops }\end{array}$ & $\%$ of $H H$ & $\begin{array}{l}\text { Type of } \\
\text { land }\end{array}$ & $\begin{array}{l}\text { Area } \\
\text { (ha)/HH }\end{array}$ & $\begin{array}{l}\text { Production } \\
(\mathrm{kg} / \mathrm{HH})\end{array}$ & $\begin{array}{l}\text { Cost } \\
\text { ('000 } \\
\text { kip/HH) }\end{array}$ & $\begin{array}{l}\text { Gross } \\
\text { Return } \\
\text { ('000kip/ } \\
\text { HH) }\end{array}$ \\
\hline & & $\begin{array}{l}\text { Riverbank } \\
(75 \%)\end{array}$ & & & & \\
\hline Chili & $32 \%$ & $\begin{array}{l}\text { Garden and } \\
\text { homestead } \\
(20 \%) \text {-upland } \\
\text { field (5\%) }\end{array}$ & 0.69 & 414 & 30 & 2,181 \\
\hline Tobacco & $27 \%$ & $\begin{array}{l}\text { Riverbank } \\
(100 \%)\end{array}$ & 0.59 & 86 & - & 1,966 \\
\hline Maize & $17 \%$ & $\begin{array}{l}\text { Riverbank } \\
(44 \%) ; \text { garden } \\
33 \%) \text { Upland } \\
(22 \%)\end{array}$ & 0.91 & $\begin{array}{c}603 \text { - but large } \\
\text { variation and crop } \\
\text { loss }\end{array}$ & 52 & 201 \\
\hline Vegetables & $12 \%$ & $\begin{array}{l}\text { Riverbank } \\
(77 \%) ; \\
\text { Homestead } \\
(23 \%) ;\end{array}$ & 0.54 & $\begin{array}{l}119 \text { but large } \\
\text { variation and crop } \\
\text { loss }\end{array}$ & 14 & 399 \\
\hline
\end{tabular}

\section{Livestock}

Revenue given from the data in the table from Joffre. The cost is simply the labor multiplied by the cost of fuel, 10,000 LAK. 
Table C.5. Numbers adapted from internal IWMI spreadsheet titled "Livestock data from MK2 surveying" by Joffre. $\mathrm{Nb}$. = number.

\begin{tabular}{|c|c|c|c|c|c|c|c|}
\hline Animals & $\begin{array}{l}2-\mathrm{Nb} \\
\text { own } 12 \\
\text { month } \\
\text { ago }\end{array}$ & $\begin{array}{l}3-\mathrm{Nb} \\
\text { bought } \\
\text { in past } \\
12 \\
\text { months } \\
\end{array}$ & $\begin{array}{l}5-\mathrm{Nb} \\
\text { Sold } \\
\text { past } \\
\text { month }\end{array}$ & $\begin{array}{l}6-\mathrm{Nb} . \\
\text { born in } \\
\text { the past } \\
12 \\
\text { months }\end{array}$ & $\begin{array}{l}8-\mathrm{Nb} \text { lost, } \\
\text { killed, } \\
\text { given } \\
\text { away past } \\
12 \text { months }\end{array}$ & $\begin{array}{l}9-\mathrm{Nb} \\
\text { Owned } \\
\text { Today }\end{array}$ & $\begin{array}{l}\text { Annual } \\
\text { Income } \\
\text { from } \\
\text { Livestock } \\
\text { (LAK) }\end{array}$ \\
\hline Cattle & 5.71 & 0.14 & 1.07 & 90.43 & 0 & 5.15 & $1,810,850$ \\
\hline $\begin{array}{l}\text { Water } \\
\text { buffalo }\end{array}$ & 1.37 & 0.09 & 0.15 & 10.24 & 0.00 & 1.58 & 143,900 \\
\hline Pigs & 5.41 & 0.25 & 2.44 & 112.63 & 0.98 & 3.55 & 680,450 \\
\hline Goats & 0.27 & 0.00 & 0.01 & 9.98 & 0.20 & 0.57 & 7,000 \\
\hline Chickens & 39.66 & 0.32 & 15.02 & 119.78 & 8.51 & 23.98 & 300,400 \\
\hline Geese & 0.00 & 0.00 & 0.00 & 0.00 & 0.00 & 0.00 & 0 \\
\hline Ducks & 2.69 & 0.17 & 1.24 & 70.67 & 0.48 & 1.37 & 41,180 \\
\hline Sum & & & & & & & $2,983,780$ \\
\hline
\end{tabular}

\section{Appendix D: Report on workshop for farm-livelihoods analysis}

\section{game in Keosenkham, Laos}

\section{Introduction}

The Land Use Planning and Analysis System (LUPAS) component of the MK1 project created a geospatial resource allocation tool based on the results of MK1 surveys and research. During a visit to the resettlement town of Keosenkham in Laos, a participatory livelihoods game was presented, during which teams allocated resources for five consecutive years, based loosely on the LUPAS spreadsheet model (described in Chapter 3). The purpose of holding the game workshop was to i) present the research methods and preliminary results to leaders of Keosenkham, ii) evaluate the extent of our knowledge, and iii) gather more information where needed. 


\section{Game Description Overview}

1. Directions: Participants divide into teams according to their sub-village (Phonkeo, Saensi, Thambing, or Sopchat). Each group allocates resources in household model using candy pieces

a. Each team receives 6 candies

b. Place candy on chart for activities

c. After each round, return for 'investment' is given as more candies (Table

A.1). Total value earned is reported but individual investment return is hidden.

Table D.1. Livelihood activities in game. Returns are multiplied by 0.3 and rounded to the nearest integer, assuming $30 \%$ of gain can be invested following year.

\begin{tabular}{cc}
\hline Activity & Return per candy per year \\
\hline Upland rice & 1.9 \\
Riverbank gardens & 2.1 \\
Livestock & 1.4 \\
Fishing years 1-5 & $1.8,3.5,2.7,1.8,0.9$ \\
Pilot (e.g. dry vegetables) & 4.2 \\
\hline
\end{tabular}

2. Details

a. Five years are played, with changing value of fishing

b. Changes described for years $2-5$

2: Fishing boom

3: Pilot program introduced

4: Wet year, some vegetable gardens flooded

5: Fishing bust

c. Input the allocated resources each round in simplified livelihoods model to calculate return on investments. Each team given new candy according to how much they 'earned'. Announce events or trends from year (e.g. fishing boom).

3. Explain that the activity was based on survey results but is only a game and cannot represent actual returns. Hold discussion, starting with questions:

a) Why did you allocate the resources as such?

b) What were some problems with the game?

c) If you played again, would you make any different decisions?

\section{Description of Methods}

The changes for each year (2nd fishing boom, 3rd pilot, 4th riverbank gardens flooded, 5th fishing bust) were pre-set in the game. Each round, the teams received their candy pieces, discussed amongst the group, and allocated their resources. After recording how the teams allocated the resources, the researchers made an announcement (e.g. Last year there was a fishing boom and you caught many fish). The 'scenarios' for fish were 
chosen based on speculations by THPC staff about how fishing may change over 5 years (Laugen 2011). The pilot project was announced at the start of the 'year', i.e. before the teams allocated the resources. A pilot was selected for the game because THPC already has begun at least one pilot project for small livestock, and IWMI may help to organize a pilot program, which is likely to be irrigated gardening. The announcement flooding of gardens was selected because this livelihood activity is being assessed to determine the rewards and the risks of loss from flooding.

It was assumed that $30 \%$ could be invested the following year based on a similar assumption in the LUPAS model. The rate of $30 \%$ may be too high, if spending needs are greater than $30 \%$. For the purposes of the game, however, it is more interesting to see results from a rewarding resource allocation. In other words, initially participants are given only 6 pieces to start investing, and if the investment rate was just $10 \%$, each team may not receive any additional candies to invest, which wouldn't have been as encouraging or fun.

The game sheet is a map of the Nam Gnouang Reservoir and Keosenkham, with representative locations of each livelihood activity circled (Fig. D.1). Hoanh used a game sheet and thumbtacks to record choices each year of each sub-village (Fig. D.2). Each team recorded their resource allocation and profits (Fig. D.3), and one woman took a cell phone photo of her map (Fig. D.4). Participants were very engaged in the activity. 


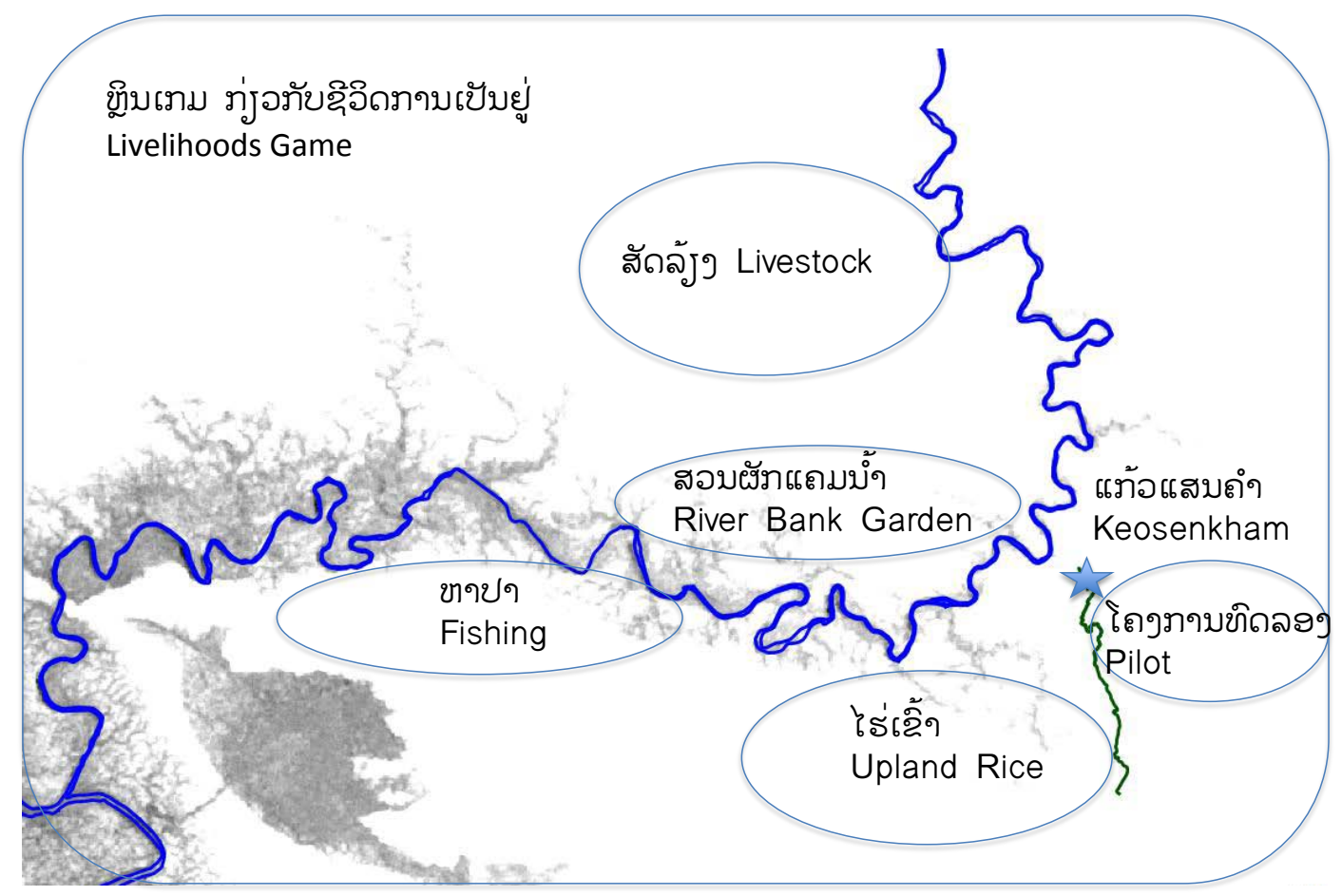

Fig. D.1. Game sheet. placed in circled areas.

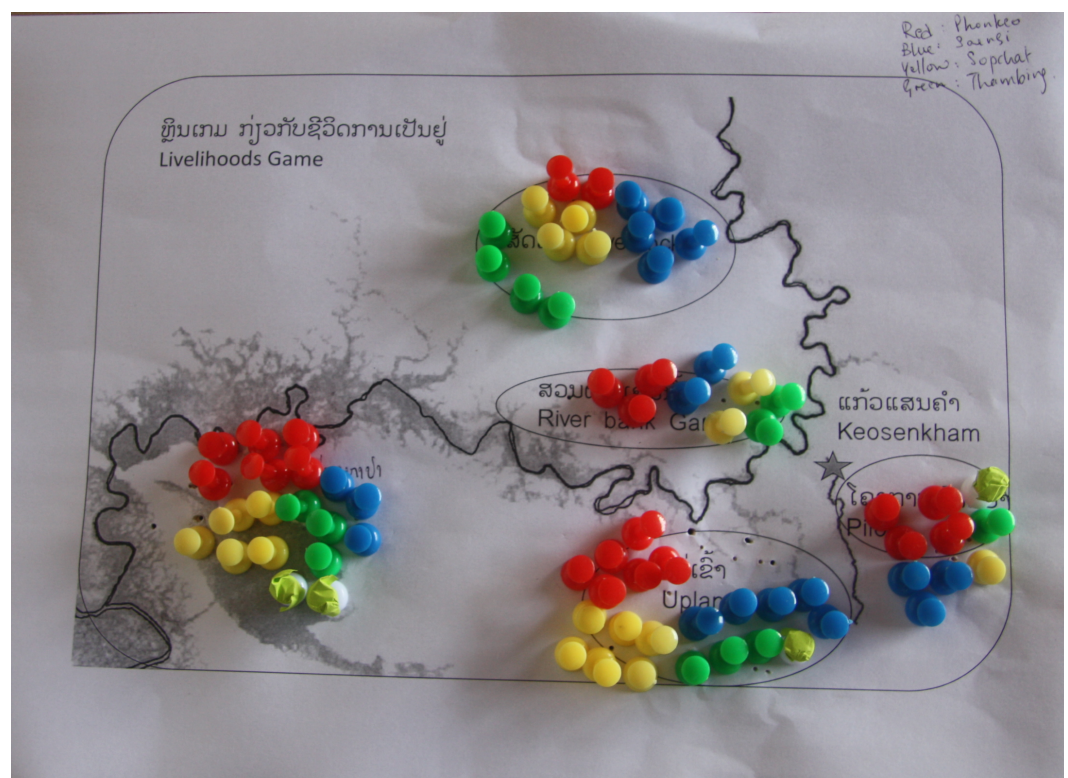

Fig. D.2. Pins represent each sub-village choices of livelihood activities, year 5 (red= Phonkeo, blue $=$ Saensi , green $=$ Thambing, yellow $=$ Sopchat $)$ (photo: C.T. Hoanh). 


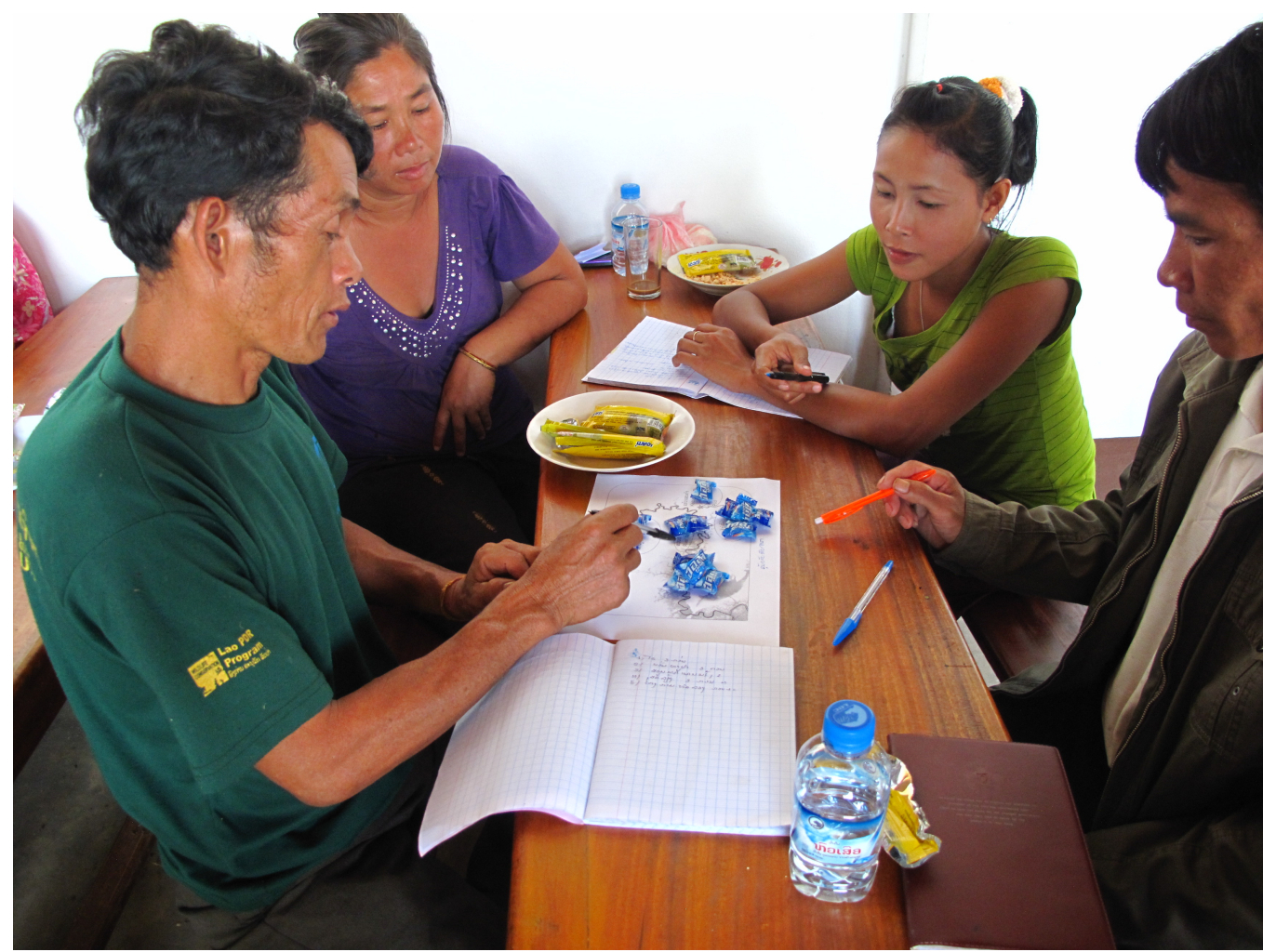

Fig. D.3. Participants from Sopchat playing game (photo: Suan Pheng Kham).

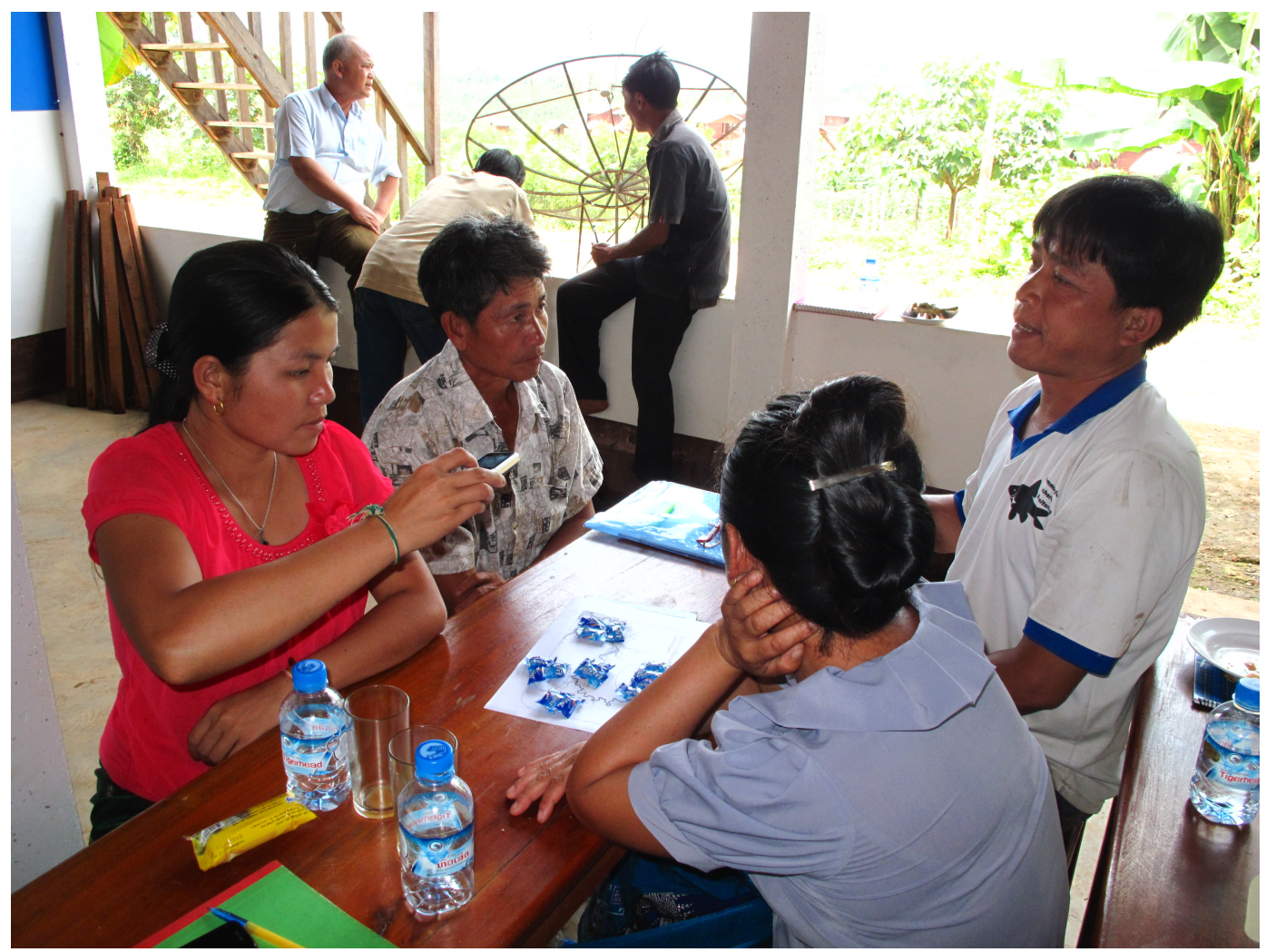

Fig. D.4. Participants from Saensi discuss resource allocation. Woman takes photo with her mobile phone (photo: Suan Pheng Kham). 


\section{Results: Lessons learned during the game}

The game exercise indicated the different preferences in activities among the subvillages. The resource allocation selected by each sub-village is shown in Figure D.5. Phonkeo allocated more resources from the start of the game toward fishing. The other villages gradually added more resources toward fishing in each round. Saensi uniquely allocated more resources toward livestock, perhaps because the location of their former village is close to good grazing land, and is not as far away as Thambing or Sopchat. The differences in allocation of livestock may be in part due to a confusion of the term 'livestock', which in the context of this game meant big, grazing animals (sad leung), but the villagers may have thought meant all animals, including chickens and pigs. While Phonkeo initially allocated only one candy piece for upland rice, by year 5 , they had 7 pieces in rice cultivation, compared to just 4 in Thambing. This is partly because Phonkeo acquired the most pieces during this game (22 versus the lowest of 17 in Thambing), but it is also noteworthy that as the game progressed, Phonkeo invested in rice more than any other activity. 


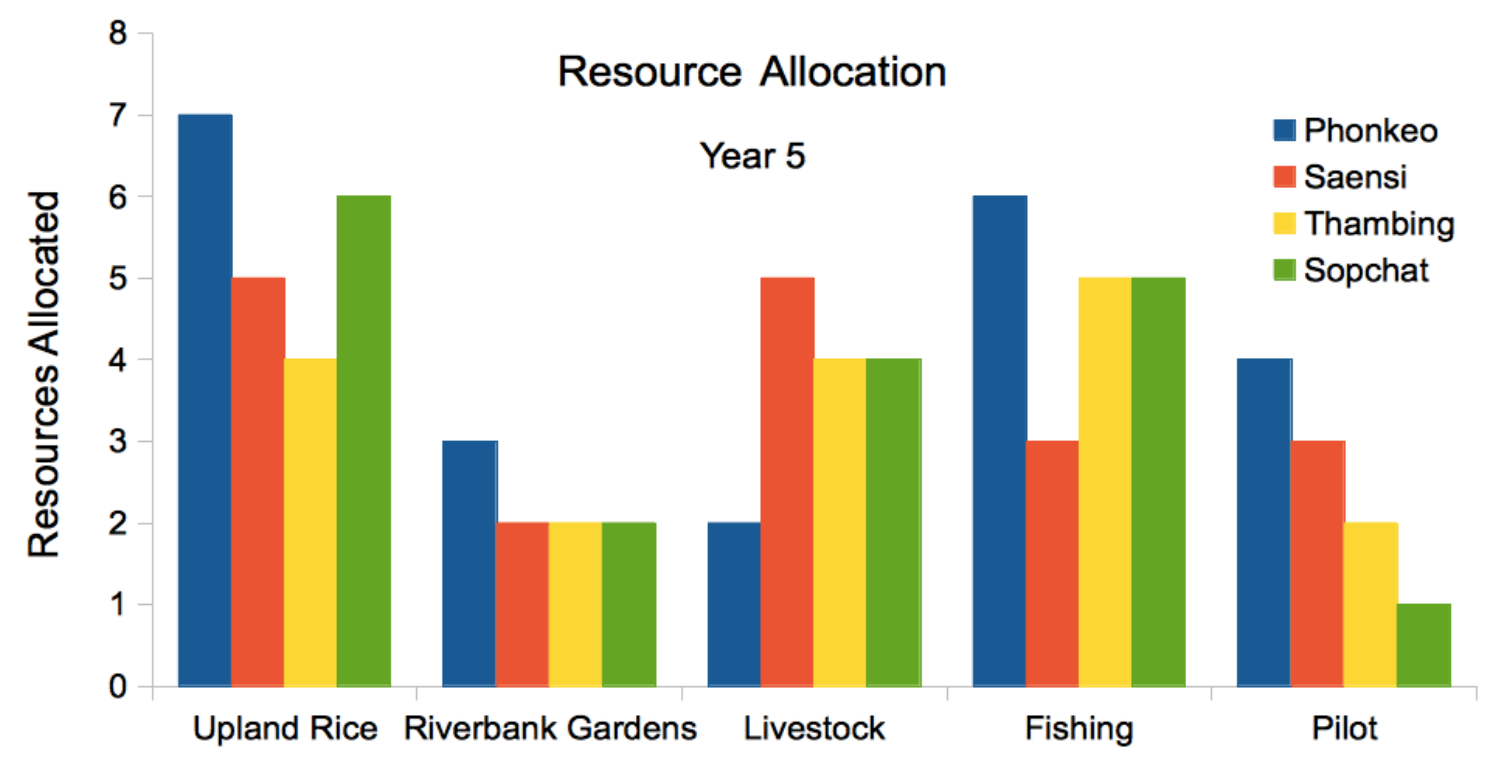

Fig. D.5. The resources allocated by the four sub-villages during the game.

\section{Conclusions and discussion}

The purpose of the game was to see how the different sub-villages allocated their resources. Another objective was to demonstrate the value of diversification, due to the following reasons: i) fish are projected to increase but then decline, ii) gardens may mitigate losses but present a risk, and iii) pilot activity can buffer income during transition period. The last purpose of the demonstration was to spark more conversations aimed at planning livelihoods. In doing so, the game represented a collaborative and quantitative planning tool with the goal of raising incomes and meeting food security.

The results illuminated varying attitudes in the sub-villages toward risk and trust. In general, fishing is seen as a more risky activity because of the unknown returns, particularly during the NG's transition from a river to a lake. Thambing and Sopchat, the sub-villages that were further away from Keosenkham prior to resettlement, showed riskadverse decisions, while Phonkeo and Saensi, those that were located closest to Keosenkham, displayed a high willingness to try new activities. This divergent attitude 
toward risk was most apparent with the allocation of resources toward the pilot activity, which was introduced to the participants rather generally as a pilot that might be vegetable gardening or some other program supported by THPC or IWMI.

After playing the game, participants were informed that in the community version of the game model (described in Chapter 3), which featured pooling money and other resources (through a collective organization), the net gains increased. We shared this information to present the value of cooperation and labor sharing, which may raise wellbeing. One interesting outcome of the discussion about sharing resources was that participants said that although they could save money and time by sharing the responsibilities toward their livestock, which are still upstream, they could not trust people outside of their families to take good care of their animals. The risk of injury from neglect or theft remains too high, although this could be a good opportunity for a structured sharing of responsibly to enable the trust for the safety of their livestock. A private local enterprise could take care of livestock as a secure service to others, especially since according THPC staff, many people in the former villages earned income from taking care of the livestock of their neighbors (Pereira 2012). Cooperation in caring for livestock is different than sharing responsibility among 4-5 fishers in transporting fish back to the fish landing site in Keosenkham to sell to the traders (i.e. one fisher has to return to Keosenkham once every 4-5 days rather than every day) because each fisher can weigh his fishes and know well the price, therefore the problem of trusting does not occur as it does for livestock. By these sharing arrangements, farmers can reduce the cost (for gasoline, in the case of fishers and for tending to livestock) or labor (for both activities). 
Discussion reaffirmed previous findings that food security for some participants was more important than income (Baran et al. 2011). The former upstream villages of Thambing and Sopchat affirmed that although fishing is profitable, they are not interested in becoming full-time fishers. They would rather maintain a mix of livelihood activities than specialize in any one area. Other participants at this workshop, perhaps those who have better knowledge of livelihood opportunities, value a high income over food security. In the list of THXP Core Human Development Indicators (Table 1) (THPC 2011a) there are many items related to food security such as percent of households with food security and percentage of households that planted at least 1 ha of rice in 2010 . This workshop shows that food security is still an objective.

This game exercise provided a structured opportunity for participants to discuss the allocation of their resources. The researchers stated emphatically and repeatedly that although the data in the game was based on surveys, the real outcomes are unpredictable, and hence farmers and fishers should not expect the same results as those in the game. Future researchers could visit the participants to see whether they have integrated any of the game methods or data into their decision-making.

\section{Works Cited}

Baran, E., Thephavanh, M., Samadee, S., Hoanh, C. T., Keophoxay, A., and Pouthavong, S. (2011). Stakeholder Consultation on Perspectives and Expectations about Nam Gnouang Reservoir Management. 37.

Laugen, J. J. (2011). Fisheries Management Plan Draft Final_17.

Pereira, J. (2012). "Personal interview at THPC.” Nam Hinboun, Laos.

THPC. (2011). Social and Environmental Division (SED) Annual Monitoring 2010 Final Report. 